\title{
CONSTRUÇÃO DE UMA BANCADA DE ENSAIO E AVALIAÇÃO DE UM SISTEMA DE MENSURAÇÃO DA PRODUTIVIDADE DE GRÃOS
}

FLÁVIO JOSÉ DE SOUSA PEREIRA

Dissertação Apresentada à Escola Superior de Agricultura "Luiz de Queiroz", Universidade de São Paulo, para obtenção do título de Mestre em Agronomia, Área de concentração: Máquinas Agrícolas.

PIRACICABA

Estado de São Paulo - Brasil

Fevereiro - 2002 


\section{CONSTRUÇÃO DE UMA BANCADA DE ENSAIO E AVALIAÇÃO DE UM SISTEMA DE MENSURAÇÃO DA PRODUTIVIDADE DE GRÃOS}

FLÁVIO JOSÉ DE SOUSA PEREIRA

Engenheiro Agrícola

Orientador: Prof. Dr. JOSÉ PAULO MOLIN

Dissertação Apresentada à Escola Superior de Agricultura "Luiz de Queiroz", Universidade de São Paulo, para obtenção do título de Mestre em Agronomia, Área de concentração: Máquinas Agrícolas.

PIRACICABA

Estado de São Paulo - Brasil

Fevereiro - 2002 


\title{
Dados Internacionais de Catalogação na Publicação (CIP) DIVISÃO DE BIBLIOTECA E DOCUMENTAÇÃO - ESALQ/USP
}

\author{
Pereira, Flávio J osé de Sousa \\ Construção de uma bancada de ensaio e avaliação de um sistema \\ de mensuração da produtividade de grãos/ Flávio J osé de Sousa \\ Pereira. - - Piracic aba, 2002. \\ 109 p. : il. \\ Dissertação (mestrado) - - Escola Superior de Agricultura Luiz de \\ Queiroz, 2002. \\ Bibliografia. \\ 1. Agricultura de precisão 2. Máquinas agrícolas 3. Produtivida de 4. \\ Variabilida de especiall. Título \\ CDD 631.3
}

\section{"Permitida a cópia total ou parcial deste documento, desde que citada a fonte - $\mathrm{O}$ autor"}




\title{
Dedico esta obra
}

\author{
aos meus pais \\ Vicente de Paula Pereira e Celina Aparecida de Sousa Pereira \\ sem os quais não seria possível a realização da obra
}

a Deus

por estar sempre nos proporcionando novos desafios

e a todos os agricultores

que dignificam este nosso imenso Brasil 


\section{Agradeço}

À New Holland Latino America LTDA por ter cedido equipamentos para a realização desta pesquisa, bem como apoio técnico quando necessário.

Ao professor Dr. José Paulo Molin, meu orientador neste trabalho.

Aos professores do Departamento de Máquinas Agrícolas pelas aulas e trocas de informações que muito contribuíram para minha formação profissional. Em especial ao professor Dr. Luiz Antonio Balastreire pelas sugestões e contribuições na realização deste trabalho.

Ao dedicado professor Dr. José Carlos Barbosa, do Departamento de ciência exatas da UNESP de Jaboticabal, pelo auxilio na interpretação das análises estatísticas.

Ao professor Phd. Vicente de Paula Pereira, Titular aposentado da UNESP de Jaboticabal, pela valiosa colaboração em diversas etapas desta obra.

Aos funcionários Chicão, Juquita, Zé Geraldo, Afonso, Dona Lurdes, Fernanda, Sandra e todos os demais do Departamento de Engenharia Rural da ESALQ/USP.

A todos os amigos do curso de mestrado, em especial a Wagner Campanner e Pedro Zambuzzi que muito me ajudaram.

Ao estagiário Luciano Romanelli.

E a todos que de uma maneira ou outra colaboraram para a realização desta obra. 


\section{SUMÁRIO}

Página

LISTA DE FIGURAS …............................................................................ vii

LISTA DE TABELAS ................................................................................

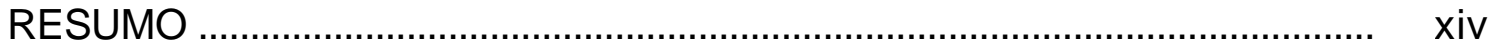

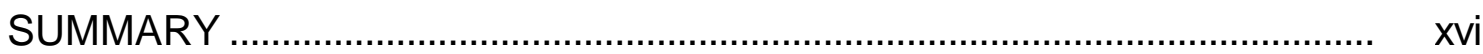

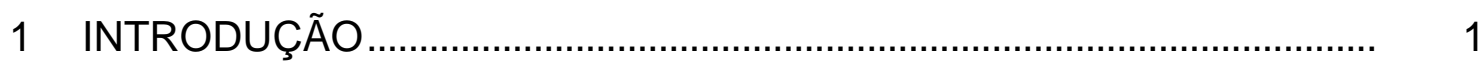

2 REVISÃO DE LITERATURA ……............................................................ 4

2.1 Variabilidade espacial ...................................................................... 4

2.2 Agricultura de precisão ............................................................................ 4

2.3 Monitoramento da produtividade e sensores ......................................... 5

2.4 Conceito de erros ................................................................................. 9

2.5 Acurácia dos monitores de produtividade ............................................. 11

3 MATERIAL E MÉTODOS ...................................................................... 19

3.1 Construção da Bancada de Ensaio......................................................... 19

3.1.1 Tanque alimentador de grãos ........................................................... 20

3.1.2 Estrutura, elevador de taliscas e condutor helicoidal .......................... 23

3.1.3 Tanque de pesagem ..................................................................... 27

3.2 Instrumentos anexados àbancada de ensaio.......................................... 27

3.2.1 Célula de carga ...................................................................................... 27

3.2.2 Coletor de dados ................................................................................. 27

3.2.3 Monitor de produtividade e sensores ……......................................... 28

3.3 Calibração ...................................................................................... 32

3.3.1 Calibração estática da célula de carga ............................................... 32 
3.3.2 Calibração dinâmica da célula de carga ……….................................... 33

3.3.3 Curva de calibração do tanque alimentador .......................................... 33

3.3.4 Configuração e calibração do monitor de produtividade ...................... 34

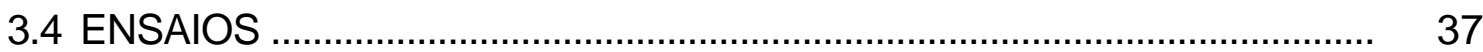

3.4.1 Sensor de velocidade........................................................................ 37

3.4.2 Sensor de fluxo de volume ............................................................... 38

3.4.3 Determinação do grau de umidade dos grãos ..................................... 40

3.4.4 Processamento e análise dos dados .................................................... 40

4 RESULTADOS E DISCUSSÃO …….................................................... 44

4.1 Calibração estática da célula de carga.................................................. 47

4.2 Calibração dinâmica da célula de carga ................................................ 49

4.3 Calibração do tanque de alimentação ………………………................ 52

4.4 Avaliação do sensor de velocidade....................................................... 57

4.5 Monitor de produtividade ....................................................................... 59

4.5.1 Obtenção do intervalo de tempo por dado registrado ......................... 59

4.5.2 Calibração operacional do monitor de produtividade .......................... 63

4.5.2.1 Análise dos fatores de corte de luz ................................................ 64

4.6 Dados do Ensaio Principal ................................................................. 66

4.6.1 Ensaio com taxa de fluxo constante ................................................. 66

4.6.1.1 Efeitos das inclinações transversais do elevador ............................ 74

4.6.1.2 Comparação entre as leituras da balança e do sensor de fluxo de volume para taxas de fluxo constantes em diversas aberturas da comporta................................................................ 80

4.6.2 Ensaio com taxa de fluxo variável.......................................................... 84

4.6.3 Grau de umidade dos grãos de milho ................................................. 91

4.7 Sugestões para trabalhos futuros …………………………………... 92

5 CONCLUSÕES ..................................................................................... 94

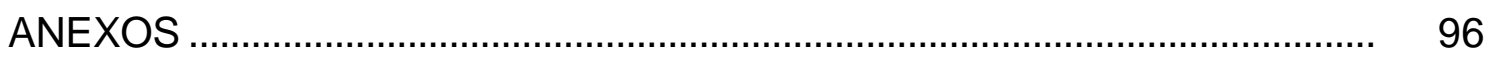

REFERÊNCIAS BIBLIOGRÁFICAS ................................................................ 106 


\section{LISTA DE FIGURAS}

Página

1 Esquema de um sistema de mensuração da produtividade de grãos com elevador triangular (adaptado de Schrock et al., 1995)....... $\quad 7$

2 Constituição da bancada desenvolvida e utilizada nos ensaios.............. 20

3 Tanque de madeira para determinação da seção de área quadrada da comporta. ..................................................................... 21

4 Tanque de alimentação que fica suspenso por guindaste hidráulico

5 Esquema da comporta de seção ajustável acionada pela manivela.

6 Estrutura de sustentação do elevador.

7 Condutor helicoidal e rampas de alimentação (a); detalhe do flange de travamento do eixo de fixação do elevador (b).

8 Esquema da posição do elevador de taliscas adaptado a um suporte de inclinações transversal e longitudinal ajustáveis.

9 Esquema do conjunto que forma o monitor RDS Ceres 2 utilizado nos ensaio, mostrando o posicionamento dos sensores na colhedora.

10 Geometria de posição dos grãos nas taliscas do elevador para a posição em nível (a) e inclinado transversalmente àdireita (b).

11 Posição de instalação dos sensores de fluxo de volume, velocidade, inclinação e grau de umidade na bancada de ensaio.

12 Vista das taliscas dentro do elevador. 
13 Vista da calibração da célula de carga no equipamento de ensaio de tração e compressão Instron.

14 Escala graduada para abertura da comporta de seção ajustável.

15 Elevador inclinado a $10^{\circ}$ na bancada de ensaio, simulando uma colhedora em terreno acidentado de $10^{\circ}$. A linha vermelha indica a posição do elevador na bancada quando da simulação de uma colhedora em nível.

16 Sistema inicial de bancada de ensaio, apresentando os tanques de alimentação e de pesagem em lados distintos da estrutura de sustentação do elevador.

17 Curva de calibração da célula de carga

18 Calibração dinâmica da célula de carga, com adição, de massa de 1,0kg sobre a massa de grãos.

19 Curva de calibração da área de abertura da comporta de seção ajustável do tanque alimentador, em função da escala.

20 Vazão para os grãos utilizados no ensaio, em função da abertura da comporta do tanque alimentador.

21 Massas acumuladas de grãos de milho registradas pela balança com o sistema de alimentação da bancada sendo mantido constante para as aberturas da comporta de seção ajustável no ponto 5 e 7,5 da escala.

22 Vazão de grãos de milho na comporta, registradas pela balança, para abertura da comporta no ponto 5 e 7,5 da escala.

23 Curva de calibração da constante do sensor de velocidade.

24 Defasagem de tempo quando utilizando intervalos de tempo, entre dados gerados no monitor, teórico e calculado, comparados com aqueles da balança, para simulação da colhedora com plataforma de $4 \mathrm{~m}$ e velocidade de deslocamento de $1,67 \mathrm{~m} \cdot \mathrm{s}^{-1}$.

25 Exemplo de um dos gráficos obtidos na realização da calibração do sistema, utilizando-se de 6 fluxos crescentes de grãos. 
26 Valores de percentagem de corte de luz (PC) versus fluxo de grãos de milho estimados pelo monitor e registrados pela balança

27 Taxas constantes de fluxos de grãos para o elevador transversalmente em nível, referentes a uma das repetições do ensaio, para abertura da comporta de seção ajustável nos pontos de regulagem de escala (a) 5,0, (b) 5,5, (c) 6,0, (d) 6,5, (e) 6,75 e (f) 7,0 .

28 Taxas constantes de fluxos de grãos para o elevador transversalmente em nível, referentes a uma das repetições do ensaio, para abertura da comporta de seção ajustável nos pontos de regulagem de escala (a) 7,5, (b) 8,0 e (c) 8,5.

29 Taxas constantes de fluxos de grãos, referentes, a uma das repetições do ensaio, para abertura da comporta de seção ajustável nos pontos de regulagem de escala (a) 6,0, (b) 7,0 e (c) 7,5 para inclinação transversal do elevador $+5^{\circ}$ e (d) 6,0, (e) 7,0 e (f) 7,5 para inclinação transversal do elevador $+10^{\circ}$

30 Dispersão dos erros do fluxo, em percentagem, obtidos pelo monitor em relação ao fluxo obtido com a balança

31 Freqüência dos erros de leitura calculados para o monitor em relação aos dados da balança, a intervalos de $0,5 \%$.

32 Gráfico das taxas de fluxo médias constantes de grãos lidas pelo monitor em relação a aquelas lidas pela balança com os dados do elevador posicionado transversalmente $\mathrm{a}+0^{\circ},+5^{\circ} \mathrm{e}+10^{\circ}$

33 Gráficos de regressão de fluxos de grãos para abertura da comporta de seção ajustável nos pontos de regulagem de escala (a) 6,0 (b) 7,0 e (c) 7,5, com dados do monitor nas 3 inclinações transversais confrontados com os dados da balança 
34 Relação entre as taxas de fluxo lida pela balança e pelo sensor de produtividade, para as diversas aberturas da comporta de seção ajustável, com o elevador transversalmente em nível.

35 Gráficos de regressão entre leituras do monitor e da balança nas diferentes taxas de fluxo aplicadas, referentes à aberturas da comporta no ponto de escala 6,0, 7,0 e 7,5, para as inclinações transversais do elevador de $+5^{\circ}$ (a) $\mathrm{e}+10^{\circ}$ (b)

36 Taxas variáveis de fluxos para o elevador em nível, com aberturas da comporta de seção ajustável referentes aos pontos na escala, 7,5, 6,0, 7,0 (a), 7,5, 6,0, 5,5 (b) e 6,0, 7,0, 7,5 (c), respectivamente.

37 Taxas variáveis de fluxos para o elevador com inclinação de $+5^{\circ}$ à direita, com aberturas da comporta de seção ajustável referentes aos pontos na escala, 7,5, 6,0, 7,0 (a), 7,5, 6,0, 5,5 (b) e 6,0, 7,0, 7,5 (c), respectivamente.

38 Taxas variáveis de fluxos para o elevador com inclinação de $+10^{\circ}$ à direita, com aberturas da comporta de seção ajustável referentes aos pontos na escala, 7,5, 6,0, 7,0 (a), 7,5, 6,0, 5,5 (b) e $6,0,7,0,7,5$ (c), respectivamente 


\section{LISTA DE TABELAS}

Página

1 Áreas estimadas para as diversas aberturas da comporta..................... 23

2 Fatores utilizados nos dois módulos de configuração do monitor........... 35

3 Simulação de taxas de fluxo no elevador a partir de valores limites de produtividades.

4 Taxas de fluxo aplicadas a partir do tanque de alimentação para ensaios do sensor de fluxo de volume com taxas constantes.

5 Dados registrados pelo coletor de dados na calibração da célula de carga.

6 Parâmetros de caracterização da célula de carga.

7 Parâmetros estatísticos obtidos no ensaio de calibração dinâmica da célula de carga.

8 Massa média padrão e desvio padrão para os dados coletados nos últimos 10s no ensaio de calibração dinâmica da célula de carga.

9 Análise da variância dos dados de vazão de massa de grãos de milho em função da variação na seção e na coluna de grãos.

10 Regressão para vazão em função da abertura da comporta de seção ajustável.

11 Erros médios entre leituras de velocidades calculadas e leituras de velocidades mostradas no monitor de produtividade. 58

12 Intervalo de tempo de cada dado gerado pelo monitor ensaiado. 
13 Comparação entre intervalo de tempo por registro teórico e calculado para os dados gerados no monitor de produtividade em algumas situações simuladas dos parâmetros de colheita no monitor.

14 Valores de percentagens de corte de luz (PCt a PC5) utilizados durante os ensaios, registrado pelo monitor de produtividade.

15 Valores de dados médios gerados pelos programas PDmon-1.0 e PDbal-1.0 dos ensaios com fluxos constantes.

16 Análise de variância da influência da inclinação transversal do elevador nas leituras de fluxos de grãos $\left(\mathrm{kg} . \mathrm{s}^{-1}\right)$ realizadas pelos sistemas de balança e sensor com a abertura da comporta de seção ajustável no ponto de escala 6,0

17 Análise de variância da influência da inclinação transversal do elevador ras leituras de fluxos de grãos $\left(\mathrm{kg} . \mathrm{s}^{-1}\right)$ realizadas pelos sistemas de balança e sensor com a abertura da comporta de seção ajustável no ponto de escala 7,0

18 Análise estatística da influência da inclinação transversal do elevador nas leituras de fluxos de grãos $\left(\mathrm{kg}^{\mathrm{s}} \mathrm{s}^{-1}\right)$ realizadas pelos sistemas de balança e sensor com a abertura da comporta de seção ajustável no ponto de escala 7,5

19 Análise estatística do teste de Tukey, para as médias de taxas de fluxo de grãos $\left(\mathrm{kg} \mathrm{s}^{-1}\right)$ nos sistemas de medidas da balança e do monitor de produtividade e em cada inclinação transversal do elevador, para as aberturas da comporta de seção ajustável nos pontos de escala 6,0, 7,0 e 7,5 e seus erros relativos.

20 Resumo da análise estatística para as médias de taxas de fluxo

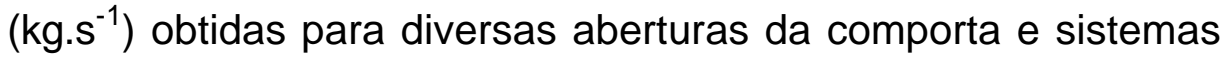
de medida, com o elevador em nível.

21 Erros médios calculados para cada trecho com taxas de fluxo constante dos gráficos de taxas variadas. 
22 Grau de umidade dos grãos de milho utilizados no ensaio determinada pelo método da estufa e aqueles registrados pelo monitor de produtividade e o erro relativo entre ambos. .......................... 92 


\title{
CONSTRUÇÃO DE UMA BANCADA DE ENSAIO E AVALIAÇÃO DE UM SISTEMA DE MENSURAÇÃO DA PRODUTIVIDADE DE GRÃOS
}

\author{
Autor: FLÁVIO JOSÉ DE SOUSA PEREIRA \\ Orientador: Prof. Dr. JOSÉ PAULO MOLIN
}

\section{RESUMO}

Com o avanço da agricultura de precisão, em que a variabilidade da produtividade entre os diversos pontos de uma determinada área é levada em consideração, é necessário aprimorar, cada vez mais, o sistema de coleta de dados, para que os resultados possam ser confiáveis. Dentre outros, faz-se necessário conhecer o desempenho dos sensores localizados nas colhedoras, para que se saiba o nível de acurácia dos dados de campo para a geração dos mapas de produtividade. $O$ objetivo do presente trabalho foi caracterizar 0 desempenho, sob condições controladas, de um equipamento comercial, especialmente o sensor de fluxo de volume e suas interações com os sensores de inclinação, de velocidade de deslocamento da máquina e de grau de umidade dos grãos, destinados àmensuração da produtividade de culturas de grãos em geral. Foi montada uma bancada de ensaio constituída de um tanque alimentador com comporta de abertura variável, que escoa grãos a um condutor helicoidal, que são transportados para um elevador de taliscas de uma colhedora comercial. Os grãos transportados pelo elevador passam através dos 
sensores de fluxo de volume e grau de umidade e, em seguida, são descarregados num tanque superior suspenso por uma célula de carga com capacidade de $2.000 \mathrm{~kg}$ (desprezando a variação da gravidade com relação ao nível do mar) para que os dados de massa sejam comparados com os registrados pelo sensor de fluxo de volume. O monitor de produtividade foi ensaiado na bancada para simulações de fluxos constantes e variados em três diferentes posições transversais do elevador. Os resultados mostraram que a bancada de ensaio mostrou-se eficiente para os tipos de ensaios propostos. Sua estrutura é resistente e a variação da angulação do elevador é de fácil manejo. A geometria da construção do tanque de alimentação mostrou-se eficiente para fornecer vazões uniformes com o tempo, obtendo-se taxas de fluxo constantes dentro dos limites de 2,0 a $8,0 \mathrm{~kg} \cdot \mathrm{s}^{-1}$. O sensor de velocidade apresentou erro médio relativo de $0,31 \%$ e o de grau de umidade, erro médio em módulo de 5,01\% para as condições estudadas. Quanto mais afastado do fluxo médio de calibração, pior é a estimativa do fluxo pelo monitor de produtividade. O erro médio geral dos ensaios com taxas de fluxo constantes foi de $-5,31 \%$, com desvio padrão de 4,14 . O monitor propiciou, em $70 \%$ dos ensaios, erros pontuais menores que $6 \%$ para ensaios com fluxo constante. Suas leituras superestimaram valores menores do que o ponto da taxa de fluxo média de calibração e subestimaram valores para taxas de fluxo maiores que este ponto. As leituras do monitor responderam imediatamente as variações impostas ao fluxo processado pelo elevador de grãos. O clinômetro ou o algoritmo que considera a inclinação é eficiente para compensar as inclinações transversais da máquina, mesmo em condições de taxas de fluxo variadas. $O$ erro médio geral dos ensaios com taxas de fluxo variadas, calculado a partir do erro médio em módulo de cada ensaio foi, 4,84\%. O erro médio global encontrado do monitor de produtividade para as leituras com taxas de fluxo constantes e variadas, foi $5,12 \%$. 


\title{
CONSTRUCTION OF A LABORATORY BENCH AND EVALUATION OF A GRAIN YIELD MONITOR
}

\author{
Author: FLÁVIO JOSÉ DE SOUSA PEREIRA \\ Adviser: Prof. Dr. JOSÉ PAULO MOLIN
}

\section{SUMMARY}

With the progress of the precision agriculture where spatial yield variability is taken into account, it is necessary to improve data collection so the results can be more reliable. It is necessary to understand how yield sensor used on combines works in order to know the accuracy of the field data for generation of the yield maps. This work aims to characterize the performance, under controlled conditions, of a commercial equipment, its yield sensor and interactions with the hillside sensor, forward speed sensor and grain moisture sensor. A test bench with a tank feeder was built with a variable opening floodgate, which drains grains to the foot of the paddle elevator of a commercial combine. The grain flow transported by the elevator pass through the yield and moisture sensor and is unloaded in a superior tank hold by a load cell with capacity of $2.000 \mathrm{~kg}$ (desconsidering the variation of the gravity) so that the mass data is compared with that registered by the monitor. The monitor was tested on simulations of constant and variable flow rates in three different transverse positions of the elevator. The results showed that the test bench was shown 
efficient for the types of proposed tests. Its structure is resistant and the variation of the angle of the elevator is of easy handling. The geometry of the feeding tank was shown efficient to supply uniform flow rates, between 2,0 and $8,0 \mathrm{~kg} \cdot \mathrm{s}^{-1}$. The speed sensor showed relative mean error of $0,31 \%$ and the moisture sensor presented a module mean error of $5,01 \%$. Flow estimation got worst increasing or decreasing the flow rate apart from calibration region. Main mean error of the test with constant flow rates was of $-5,31 \%$, with standard deviation of 4,14 . On $70 \%$ of the test monitor, readings resulted in erros less than $6,00 \%$ with constant flow. Its readings overestimated flow values under the mean flow rate of calibration and underestimated flow above it. The readings of the yield monitor responded to the variations imposed to the flow through by the elevator immediately. The hillside sensor and the algorithm that considers the inclination are efficient for compensating the transverse inclinations of the machine, even in conditions of varied flow rates. The general mean error test with varied flow rates, was $4,84 \%$. The global mean error shown by the yield monitor for the readings with varied and constant flow rates was $5,12 \%$. 


\section{INTRODUÇÃO}

Agricultura pode ser considerada como a ciência ou a arte de cultivar o solo desenvolvendo culturas de interesse para o bem estar humano. Visa a máxima rentabilidade econômica da cultura, a qual depende dos fatores de produção (solo, clima, planta, insumos e equipamentos). O conhecimento das propriedades e características do solo é de suma importância para o sucesso da agricultura.

Pereira \& Freire (1971) descreveram o solo como um corpo anisotrópico, sendo a anisotropia evidenciada na direção vertical, caracterizada pela diferenciação de camadas, denominadas horizontes. Não se tem, tradicionalmente, considerado a existência de variações das propriedades do solo dentro dos horizontes, embora o anisotropismo no solo há muito tempo é conhecido.

Baseada neste conceito a agricultura tem sido desenvolvida, de tal forma que, uma vez reconhecido um determinado tipo de solo, todas as análises são feitas considerando-se que dentro da camada superficial as propriedades são semelhantes para uma dada área.

Com o avanço da tecnologia e a crescente expansão agrícola, tem-se aumentado cada vez mais a área de cultivo, sendo esta considerada homogênea ao longo da sua extensão.

Mais recentemente a pesquisa tem considerado as variações ocorridas dentro de uma unidade de cultivo, buscando minimizar as variâncias através do gerenciamento da cultura. Isto tem sido possível pelo avanço da informática,

possibilitando o estudo da variabilidade espacial das propriedades do solo e da 
construção de mapas de produção com técnicas de georeferenciamento em tempo real. Estas técnicas de gerenciamento da produtividade vêm sendo chamadas de agricultura de precisão (Molin, 1997; Sanaei \& Yule, 1996 e Schueller, 1992).

A grande maioria dos trabalhos que vem sendo executados na área de agricultura de precisão tem por base o levantamento das hipóteses a serem avaliadas a partir dos mapas de produtividade. Estes mapas são, na maioria dos casos, obtidos por levantamento de campo realizado com equipamentos comerciais.

Para a obtenção de um mapa de produtividade é necessário o levantamento de parâmetros do fluxo de massa, do grau de umidade dos grãos e de posicionamento. Esses parâmetros, que permitem a obtenção de um mapa de produtividade, são obtidos com a combinação de sensores como o de velocidade, de grau de umidade do grão, de inclinação (clinômetro), de fluxo de massa e de um sistema de posicionamento (Kormann et al., 1998). Os dados detectados pelos sensores são gerenciados e armazenados por um monitor também instalado na colhedora. A obtenção de informações pontuais dentro da área de cultivo precisa ser feita em tempo real, exigindo um sistema de georeferenciamento, usualmente utilizando o Sistema de Posicionamento Global (GPS) (Balastreire et al., 1997). Este sistema apresenta atualmente acurácia satisfatória, com erros da ordem de menos de 1 metro.

Os sensores de grau de umidade usualmente instalados na saída do elevador de grãos funcionam por condutividade elétrica do grão, estimando o teor de instantânea pela diferença de potencial. Para se conseguir medir o fluxo de volume em tempo real, várias metodologias tem sido empregadas, por meio da força de impacto, pesagem instantânea dos grãos, raio gama ou sensores de volume que medem o fluxo através do corte de facho de luz infravermelho de leitura entre um transmissor e um receptor.

Estes sensores possuem erro de leitura que precisam ser identificados. Uma forma de identificá-los é por meio de ensaios de bancada sob condições 
controladas da taxa de fluxo de grãos passando pelos sensores e do posicionamento do elevador da colhedora, onde fica instalado o sensor que mede o fluxo de massa.

Este trabalho objetivou a construção de uma bancada de ensaio para avaliação de sistemas de mensuração da produtividade de grãos e o estudo do desempenho operacional, sob condições controladas, de um equipamento comercial de determinação da produtividade de grãos para fins de mapeamento, para a cultura do milho. 


\section{REVISÃO DE LITERATURA}

\subsection{VARIABILIDADE ESPACIAL}

No meio agrícola é reconhecido que culturas e solos não são uniformes

dentro de uma determinada unidade de cultivo, variando espacialmente (Nielsen \& Bouma, 1984 e Cassman \& Plant, 1992).

Segundo McBratney \& Pringle (1997), a variabilidade espacial pode acontecer em várias escalas, entre regiões, entre áreas de cultura, ou dentro de áreas de cultura. Schueller (1997) descreveu que os fazendeiros sempre responderam a tal variabilidade em pequenas áreas desenvolvendo ações apropriadas, mas em grandes áreas, com alto nível de mecanização na produção de culturas, tais ações são menos freqüentes do que deveriam ser. Existem diversos termos para referir-se ao estudo e tratamento dessa variabilidade de campo. Dentre eles podem ser citados agricultura de precisão, produção de cultura espacialmente variada, agricultura ponto a ponto, e outros.

\subsection{AGRicultura de PRECIsÃo}

O objetivo da agricultura de precisão é combinar a aplicação de recurso e práticas agronômicas com atributos do solo e exigências da cultura já que eles variam espacialmente no campo (McBratney \& Whelan, 1995). LowenbergDeboer \& Swinton (1995) a definiram como sendo uma tecnologia aplicada à agricultura a qual permite o monitoramento e controle eletrônico aplicado à coleta de dados, processamento de informações e suporte de decisão para alocações temporal e espacial de insumos na produção agrícola. 
Searcy (2000) caracteriza a agricultura de precisão como uma filosofia de administração. Descreve que a agricultura de precisão é um conjunto de técnicas que tentam reduzir as ineficiências na produção agrícola e aumentar o retorno econômico do produtor. Cita ainda que ela só tem sentido se o produtor se empenhar para melhorar a eficiência da produção agrícola.

A disponibilidade de sensores para a obtenção de dados de variabilidade espacial, diretamente por contato, bem como para o sensoriamento remoto, vem crescendo e sugere uma nova realidade para a agricultura dos próximos anos. A tomada de decisão para a recomendação de dosagens de insumos ou a administração dessa dosagem em tempo real será possível por ambos os métodos (Molin, 1997).

A agricultura de precisão, como relatada por Balastreire et al. (1997), fundamenta-se na existência da variabilidade espacial dos fatores produtivos e, portanto, da própria quantidade produzida pela cultura. A representação gráfica da variabilidade espacial é uma das ferramentas mais importantes para sua análise.

Para o levantamento localizado das produtividades de uma determinada área devem ser utilizados sistemas de medição da produtividade, de posicionamento e de aquisição de dados, simultaneamente com a colheita (Balastreire et al., 1997 e Kormann et al., 1998).

\subsection{MONITORAMENTO DA PRODUTIVIDADE E SENSORES}

Por décadas, pesquisadores vêm estudando métodos de medição do fluxo de grãos através de sensores. Um dos primeiros trabalhos sobre fluxo foi feito por Barkov ${ }^{1}$, citado por Baerdemaeker et al. (1985), que descreveu uma técnica de medida descontínua para taxa de fluxo volumétrico de sólidos. Em um tubo vertical duas sondas de posição foram separadamente montadas a

\footnotetext{
1 BARKOV, N.N., Eletronic instruments for measuring the productivity of a ball mill. Instr. Constr. (USSR) 1962. № 6: 32-33.
} 
uma distância finita. No início, uma válvula fechava o fundo do tubo e um cronômetro era disparado no momento em que os materiais atingiam o sensor inferior. $O$ cronômetro era parado quando os materiais atingiam o sensor superior e era registrado o intervalo de tempo no qual o tubo enchia. A válvula de fundo abria, automaticamente, quando o peso do material no tubo excedia um certo limite e o ciclo de medida podia começar novamente.

Outra técnica utilizada em experimentos na medida do fluxo, utilizando um radar de efeito "Doppler" de microondas, foi desenvolvida por Sabir et al. (1976). A técnica é baseada em medidas lineares de velocidade e densidade do campo de fluxo com uma onda contínua produzida pelo radar. Os autores concluíram que o sistema proporciona meio econômico de monitorar velocidades e densidades e, conseqüentemente, taxa de escoamento de massa de partícula sólida no campo de fluxo. Acurácia, resposta rápida e nenhuma obstrução no fluxo de campo, linearidade numa vasta amplitude de velocidade e densidade, dentre outros, são as vantagens apresentadas por este sistema.

Um sistema utilizado para a medição da produtividade, baseado no conceito de fluxo de massa, foi desenvolvido e descrito por Reitz \& Kutzbach (1994). Neste trabalho, sensores luminosos (emissores e receptores) foram instalados no interior do elevador de grãos de uma colhedora de cereais. Sendo o tempo de interrupção do sinal luminoso, o qual é bloqueado pela massa de grãos sobre as taliscas do elevador, proporcional à quantidade, em volume, de grãos colhidos pela colhedora. Com a determinação da densidade dos grãos a massa de grãos é calculada e utilizada para estimativa da produtividade.

Schrock et al. (1995) desenvolveram um elevador de conceito triangular para medida de fluxo de massa (Figura 1). Este consiste na colocação de uma terceira roda denteada na corrente do elevador de taliscas da colhedora. Esta terceira roda denteada foi colocada em nível com a roda denteada superior já existente, distanciada de aproximadamente um metro, formando um trecho nivelado de corrente com taliscas. Este trecho horizontal foi construído como uma "seção ativa" a qual possibilitava que os grãos fossem pesados à medida 
que passassem por este trecho. O mesmo era pivotado na posição de entrada dos grão e apoiado por uma célula de carga em sua outra extremidade.

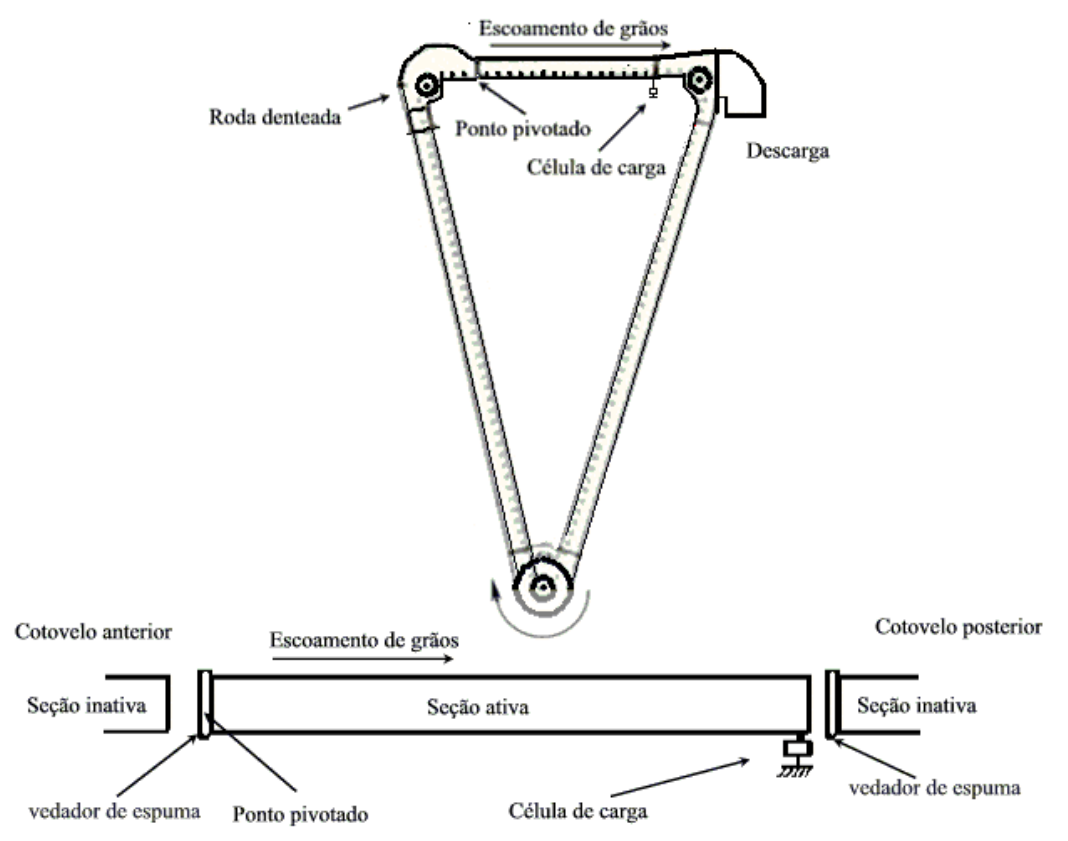

Figura 1 - Esquema de um sistema de mensuração da produtividade de grãos com elevador triangular (adaptado de Schrock et al., 1995).

Pelo fato da célula de carga estar registrando dados com diversos componentes móveis (material de ensaio, correntes, taliscas), seus sinais apresentam ruídos intensos de tal forma que foram necessárias adaptações de sistemas de filtragem dos ruídos para que os dados registrados pudessem correlacionar, de maneira adequada, com a massa fluindo. Após estas filtragens, as medidas obtidas com este tipo de elevador atingiram erros com valor médio absoluto da ordem de $3 \%$ durante os ensaios.

Em um experimento realizado por Balastreire et al. (1997) foi desenvolvido um sistema automático de pesagem da massa de grão para a quantificação da produtividade. Os resultados obtidos na elaboração da curva de calibração constatam que o sistema é linear para o intervalo de peso em que foi utilizado, de 0 até $4905 \mathrm{~N}$. Devido ao fato do sistema ser capaz de medir a 
quantidade de grãos produzidos diretamente através do peso, o sistema não sofre interferência da densidade do material colhido.

A maior concentração das pesquisas sobre mapas de produtividade tem sido com culturas de cereais onde o fluxo de grãos é registrado dentro da colhedora (Godwin \& Wheeler, 1997).

Os monitores de produtividade existentes necessitam ser calibrados para a melhor aquisição de dados. Segundo Kormann et al. (1998), a realização de uma correta medição pelo sistema de medida da produtividade é dependente de uma correta calibração.

Segundo Molin (2000) os sistemas de medida do fluxo de grãos existentes no comércio se dividem nos que medem o fluxo de massa diretamente e os que medem indiretamente. No primeiro grupo se enquadram os sensores que utilizam uma placa de impacto posicionada na cabeceira superior do elevador de grãos da colhedora, podendo a força existente ser medida por um potenciômetro ou uma célula de carga que é proporcional à quantidade de grãos passando pelo sistema e, o equipamento radiativo que utiliza um emissor de raios gama. O outro grupo é formado pelos sistemas que medem o fluxo de volume passando pelas taliscas do elevador através de sensores que utilizam um emissor de luz infravermelha interceptada pelas taliscas vazias ou as taliscas mais grãos e o sistema que mede o fluxo de volume através de uma roda de pás na saída do elevador em que a vazão é calculada com base no volume conhecido de cada compartimento de pás. Nestes sistemas o usuário deve informar a densidade da massa de grãos que estão sendo colhidos. Ainda, os fabricantes de monitores de produtividade se dividem em dois grupos distintos. Um grupo é representado pelos fabricantes de colhedoras, com produto restrito para suas máquinas. Outro grupo é representado pelos fabricantes independentes e que produzem equipamentos que podem ser instalados em qualquer marca e modelo de colhedora. 


\subsection{CONCEITO DE ERROS}

Dally et al. (1993) definem erro como sendo a diferença entre o valor verdadeiro e aquele medido de uma dada quantidade, como deslocamento, pressão, temperatura e outras. O erro é inevitável em qualquer sistema de medidas. Os autores afirmam que um sistema de Instrumentação eletrônica bem projetado permite limitar o erro para um valor que é aceitável em termos de acurácia requerida em análises de engenharia ou controle de processos.

O verdadeiro valor da medida de uma quantidade, normalmente é desconhecido. Em vista disso, uma quantidade é medida diversas vezes, calcula-se a média das medidas e determina-se o erro de cada leitura pela diferença entre cada valor medido e a média. De posse desses valores faz-se o estudo de sua distribuição. Doebelin (1966), relata que em condições normais espera-se que a distribuição de erro siga a curva de Gauss. Propõe que se organizem os erros medidos em ordem crescente, separando-os em classes de intervalo constante. Com os dados assim organizados utiliza a seguinte função:

$$
Z=\frac{\text { (Número de leituras em um intervalo / número total de leituras) }}{\text { Largura do intervalo. }}
$$

Os valores de Z, gerados para cada um dos intervalos, são colocados num gráfico tipo histograma. Neste caso, observa-se que a maior quantidade de medidas, em torno do valor médio, se encontra na parte central do histograma, distribuindo uma menor quantidade de valores nas extremidades do histograma. A área de uma particular barra no histograma é numericamente igual à probabilidade que uma particular leitura cairá no intervalo associado. A área de todo histograma deve então ser igual a 1, pois haverá $100 \%$ de probabilidade de que uma determinada leitura caia entre o menor e o maior valor, baseado nos dados disponíveis de uma determinada população. Se for possível fazer infinitas leituras dos valores de erros, pode-se diminuir o intervalo de classe para tão pequeno como se queira e ainda se terá um número razoável de 
leituras dentro de cada intervalo. Então, à medida que se diminui o intervalo, a curva do histograma ficará mais suave, aproximando-se da forma da curva de Gauss. Tomando-se o limite para este intervalo tendendo a zero, consegue-se uma função $Z=f(x)$ de densidade de probabilidade. Então, a probabilidade da leitura estar entre a e b será:

$$
\mathrm{P}(\mathrm{a}<\mathrm{x}<\mathrm{b})=\int_{b}^{a} f(x) d x
$$

O mesmo autor, ainda relata que a função de densidade ou de distribuição mais útil é a função normal ou de Gauss dada por:

$$
x=\int_{-\infty}^{x} f(x) d x
$$

A estatística considera como erro qualquer diferença de uma variável em relação a sua média, portanto erro é uma grandeza que pode assumir valores positivos ou negativos, pois pode ser gerado de valores das variáveis maiores ou menores do que a média. A função estatística que descreve o erro é denominada erro padrão e é computada com a seguinte equação.

$$
\sigma=\sqrt{\frac{\sum_{i=1}^{N}\left(x_{i}-\bar{x}\right)^{2}}{N-1}}
$$

onde:

ó = desvio padrão;

$x_{i}=$ valor individual de leitura;

$\bar{x}=$ valor médio da amostra;

$N=$ número total de leituras.

Ainda, segundo Doebelin (1966), para uma perfeita distribuição de Gauss, têm-se: 
$68 \%$ das leituras se encontram entre \pm ó da ì ;

$95 \%$ das leituras se encontram entre \pm 2 ó da ì ;

$99,7 \%$ das leituras se encontram entre \pm 3 ó da ì.

Sendo este último o valor usado no controle de qualidade, descartando-se os produtos maiores ou menores que 3 ó da ì, onde ì é a média das leituras.

Um sistema de medida é composto freqüentemente de uma cadeia de componentes os quais estão sujeitos a erros individuais. $\mathrm{O}$ erro total em um processo é a somatória dos erros acumulados em cada fase desse processo. Cada quantidade de medida possui um erro de mais ou menos uma variação $\left( \pm \triangle \mathrm{u}_{1}, \pm \triangle \mathrm{u}_{2}, \ldots \pm \triangle \mathrm{u}_{n}\right)$. A somatória destes erros causa uma variação $\triangle \mathrm{N}$ no resultado computado de $\mathrm{N}$, onde $\mathrm{N}$ é uma função conhecida das $\mathrm{n}$ variáveis independentes $u_{1}, u_{2}, \ldots . u_{h}$. Portanto a equação teórica de cálculo da somatória dos erros, onde todos os derivados parciais serão avaliados, respectivamente a cada valor conhecido de $u_{1}, u_{2}, \ldots . . u_{n}$, é dada pela equação 5 .

$$
E_{a_{r s s}}=\sqrt{\left(\Delta u_{1} \frac{\partial f}{\partial u_{1}}\right)^{2}+\left(\Delta u_{2} \frac{\partial f}{\partial u_{2}}\right)^{2}+\cdots \cdots+\left(\Delta u_{n} \frac{\partial f}{\partial u_{n}}\right)^{2}}
$$

Em que se $\triangle u_{i}$ representa um limite de \pm 3 vezes o desvio padrão em u, então $E_{\text {arss }}$ representa um limite de \pm 3 vezes o desvio padrão em $N$, com uma probabilidade de que $99,7 \%$ dos valores de $\mathrm{N}$ estejam dentro destes limites (Doebelin, 1966).

\subsection{ACURÁCIA DOS MONITORES DE PRODUTIVIDADE}

Pesquisadores têm se preocupado com variações nas medidas de fluxo de grãos devido à declividade do terreno e têm relatado problemas com tempo de atraso nas leituras de fluxo de grãos. Baerdemaeker et al. (1985), em experimentos de laboratório, trabalhou com medição de fluxo de grãos (trigo, milho e cevada) com medidor de fluxo tipo impacto, onde os resultados dos ensaios tiveram os desvios abaixo de $2 \%$. Quando analisado um único tipo de 
grão, as diferenças eram menores que $0,75 \%$. Utilizando os mesmos medidores de fluxo a diferentes declividades, relataram que para uma determinada posição longitudinal da colhedora os erros aumentavam à medida que a declividade transversal aumentava. Particularmente, quando o sistema era inclinado transversalmente de 0, 5, 10 e 15\% geraram erro na medição do fluxo de grãos da ordem de $0,-0,25,-0,54$ e-1,28\%, respectivamente.

Klemme et al. (1992) relataram inconstantes leituras dos grãos com sensor de produtividade ultra-sônico devido à declividade e ondulação do campo, sendo esse um sério problema em determinar acuradamente o fluxo de grãos através da colhedora.

Eliason et al. (1994) relataram, que as leituras do sensor de produtividade foram afetadas pelo tempo de atraso no transporte do fluxo de grão pela colhedora. Estes atrasos foram evidentes, não somente quando a máquina entrava ou saia da linha da cultura, mas também quando a colhedora reduzia a velocidade ou parava.

Em experimento conduzido em campo por Sanaei \& Yule (1996) sobre leituras de monitor de produtividade, foi relatado um tempo de atraso da leitura do sensor de fluxo do elevador devido ao tempo necessário para a massa cortada pela plataforma de corte poder ser trilhada e atingir a parte superior do elevador, onde ficava localizado o sensor. A velocidade de deslocamento da colhedora, a velocidade interna dos elementos trilhadores, condições da cultura e taxa de fluxo têm sido relacionados com o tempo de atraso entre a cultura sendo cortada e passando no sensor. Os autores enfatizaram que sempre que a colhedora estiver trabalhando em áreas de topografia acidentada e estiver equipada com um medidor de produtividade esta também deveria ser equipada com um sensor de declividade. Os autores realizaram uma série de ensaios onde a colhedora era colocada em cima de blocos a vários ângulos, para determinar o efeito da inclinação transversal e longitudinal no padrão do fluxo de grão dentro do elevador e o efeito nas leituras do sensor. Mudanças significativas nas leituras de produtividade foram registradas devido à variação 
de declividade. $\mathrm{Na}$ inclinação transversal houve um efeito marcante nas medidas de produtividade, enquanto as medidas de inclinação longitudinal indicaram menor efeito, mas ainda significantes em termos de precisão no mapa de produtividade. Afirmaram que a amplitude desta variação é particular para cada modelo de colhedora, onde o formato das taliscas do elevador, velocidade e ângulo do elevador têm maior efeito. Os autores sugeriram o desenvolvimento de um laboratório de ensaio equipado para investigar este problema.

Pesquisadores calibraram um monitor de produtividade a partir da comparação com pesos de uma carreta de pesagem, em condições normais de trabalho da colhedora (Wilcox, 1999a). A máquina colheu com três diferentes velocidades para provocar um baixo fluxo de grãos, um fluxo na capacidade de carga plena e um acima da carga plena. Não existiu diferença significativa entre os pesos registrados pela carreta e pelo monitor de produtividade na taxa de plena capacidade, existindo quando a colhedora trabalhou acima e abaixo da capacidade de plena carga. Os resultados mostraram que o monitor apresentou erros médios em relação ao peso do vagão de até $-12,6 \%$ nas condições de ensaio com a capacidade acima da carga plena e que o monitor de produtividade funciona bem se mantida uma velocidade constante. Ainda, em outra área experimental, trabalhando em terreno de 5 a $10 \%$ de declividade, 0 monitor de produtividade foi calibrado para seis diferentes velocidades da colhedora variando de 0,67 a $1,79 \mathrm{~m} \cdot \mathrm{s}^{-1}$ à intervalos de $0,22 \mathrm{~m} \cdot \mathrm{s}^{-1}$. Nos ensaios morro acima, com velocidade constante de deslocamento, o monitor de produtividade registrou menor produtividade. Observaram que o monitor de produtividade mostrou uma diferença média de $1,045 \mathrm{~m}^{3}$.ha ${ }^{-1}$ quando comparadas as produtividades com a colhedora deslocando-se morro acima com a colhedora deslocando-se morro abaixo, enquanto que a carreta de pesagem não registrou diferença significativa entre ambos. $O$ erro entre 0 monitor de produtividade e a carreta de pesagem quando se deslocando morro abaixo foi da ordem de $-0,3 \%$ e apesar de haver diferenças significativas 
quando se deslocando morro acima, o erro médio ficou em torno de $-2,2 \%$.

Com a crescente necessidade de avaliação dos sistemas de monitoramento da produtividade para se conhecer a confiabilidade dos resultados dos mapas de produtividade gerados, estudos têm sido realizados para averiguar sua acurácia através de ensaios realizados em campo ou bancada de ensaios. A necessidade de melhoria do sistema de coleta de dados registrados pelo monitor de produtividade fica evidenciada no trabalho de Blackmore \& Marshall (1996), discutindo dois grupos de erros de um total de seis citados. Um erro é devido ao desconhecimento da largura útil de corte sendo colhida a cada instante e o outro erro é devido ao tempo que a massa de grãos demora a percorrer os mecanismos internos da colhedora. Os autores recomendaram técnicas para diminuir esses erros utilizando filtragem dos dados. Tal filtragem exige conhecimento do campo, da colhedora, da cultura, do GPS e outras características, para avaliar os dados e filtrar aqueles que um especialista não consideraria razoáveis, como por exemplo, pontos extremos, distantes da leitura anterior. Com relação ao erro no tempo de atraso, os autores comentam que, mesmo que se faça uma correção, o tempo corrigido pode não ser o correto e, portanto, toda produtividade estaria defasada desta quantidade. O tempo de atraso pode ser variável, dependendo das condições de colheita e então um intervalo de tempo constante não seria satisfatório. Ainda podem ocorrer perdas de dados devido à paralisação da coleta de dados no final de cada linha, quando do levantamento da plataforma.

Em ensaio de bancada, realizado por Kormann et al. (1998), com trigo a $14 \%$ de grau de umidade, foi analisada a acurácia do sistema de medidas de produtividade para quatro diferentes equipamentos a diferentes condições de operação. Foram avaliados dois medidores de fluxo de volume (RDS Ceres $2 \mathrm{e}$ Class Quantimeter 2), que têm por princípio a leitura da altura da coluna de grão sendo transportadas pelas taliscas, sendo convertido pela massa específica dos grãos em fluxo de massa. Os outros dois equipamentos avaliados medem o fluxo de massa (AgLeader Yield Monitor 2000 e 
Dronningborg Flowcontrol), sendo o primeiro pelo princípio de medida de força/impulso, pelo impacto do material em uma chapa ligada a uma célula de carga. Onde o impulso é o produto da massa pela velocidade, calculando-se assim, o fluxo de massa. Outro equipamento de medida do fluxo de massa usa o princípio radiométrico, através da absorção de raios gama pela massa de grãos, onde o grau de absorção corresponde ao peso de grãos passando pelo sensor. Os resultados mostraram erros médios de calibração menores que $3 \%$. A baixas taxas de processamentos $\left(10 t . h^{-1}\right)$ aconteceram maiores desvios ( 3 a $7 \%$ ). Os sistemas de medições volumétricos resultaram em desvios padrões menores em média do que o medidor de fluxo de massa. Os autores também investigaram o efeito das inclinações transversais e longitudinais da colhedora, com processamento constante $\left(20 \mathrm{t}^{-1} \mathrm{H}^{-1}\right)$ influenciando nas leituras dos medidores de produtividade. Medidas de fluxo com 5, 10 e 15 graus de inclinação transversal à esquerda e à direita e inclinação longitudinal, com 5 repetições, como também combinações dessas inclinações foram estudadas. A menor alteração para influências de inclinação foi exibida pelo sistema de medição radiométrica Dronningborg Flow Control. Os dois sistemas de medição de volume são equipados, para compensação destas influências, com um ou dois sensores de declividade. Os dados apresentados sugerem que há maior efeito de leitura do sensor em inclinações transversais do que em inclinações longitudinais. Contudo, os erros causados pela inclinação transversal e longitudinal não podem ser compensados sobre todas as condições. Nesta consideração, os sistemas de medidas de forças ocupam uma posição intermediária entre os medidores radiométrico e volumétrico.

Uma bancada de ensaio foi construída por Arslan \& Colvin (1998) a fim de comparar a acurácia de um monitor com sensor de fluxo por impacto com dados registrados em uma balança eletrônica. Para simular o fluxo de grãos na bancada foram utilizados um condutor helicoidal, um elevador de grãos, e um condutor helicoidal superior que descarregava o grão em um tanque de pesagem com quatro células de carga. O elevador de grãos foi aumentado de 
0,85m para criar espaço físico debaixo do condutor helicoidal. A capacidade de alimentação do sistema girou em torno de $5 \mathrm{~kg} \cdot \mathrm{s}^{-1}$. Concluíram que a duração dos ensaios influencia na calibração do monitor, sendo que tempos menores que 20s não possibilitavam calibração adequada. A inserção de várias taxas de fluxo na calibração do sistema, também foi decisiva para se conseguir uma melhor calibração. Ensaios desenvolvidos com a maior duração possível, com estreita variação da taxa de fluxo pareceu ser o melhor modo para alcançar melhor acurácia. A correlação entre o monitor de produtividade e a balança foi de $R^{2}=0,99$. Os dados apresentaram uma amplitude de variação de $0,18 \%$ a $9,18 \%$, com variação média de $2,11 \%$.

Arslan \& Colvin (1999) continuaram o trabalho com a bancada de ensaio anterior procurando verificar quais os fatores que afetavam a acurácia da leitura do sensor de produtividade na calibração do monitor e observar a resposta deste às variações nos padrões de fluxo. Observaram que a taxa mínima de fluxo, obtendo leituras confiáveis, era da ordem de $1,7 \mathrm{~kg} \cdot \mathrm{s}^{-1}$. A taxas de fluxo constante, variando de 0,5 a $5,0 \mathrm{~kg} . \mathrm{s}^{-1}$, dentro dos limites utilizados na calibração, a percentagem de erro de totalização entre monitor de produtividade e a balança foram menores que $4 \%$ na maioria dos ensaios. Com a Interrupção do fluxo de grão durante o experimento para introduzir uma entrada em degrau a quatro taxas de fluxo diferentes, observaram que o monitor de produtividade respondeu rapidamente as mudanças de taxa de fluxo. Para ensaios com variações da taxa de fluxo ao longo do tempo, para observar a resposta do sensor de produtividade com relação àbalança, foi observado em um estudo de caso dos vários ensaios, um aumento do erro médio de 6,9\%, quando analisado todo o ensaio com duração de sessenta segundos, para $13,8 \%$ quando analisado um determinado trecho de sete segundos do gráfico. Foi notado um aumento no erro médio, em percentagem, dos ensaios de taxa de fluxo constante para os ensaios de entrada em degrau e desta para os ensaios com variação da taxa de fluxo. O erro médio global de todos os ensaios foi de $3,2 \%$. 
Wilcox (1999b), reporta um trabalho onde houve uma colheita de milho com grau de umidade em torno de $15 \%$ e outra em torno de $25 \%$, que foram feitas utilizando uma colhedora equipada com monitor com sensor de impacto calibrado para as devidas grau de umidades. Para graus de grau de umidade em torno de $15 \%$ o erro encontrado foi da ordem de $-0,4 \%$, quando comparado com o peso total real. Para o grau de umidade em torno de $25 \%$ foram encontrados erros médios de $-2,2 \%$, embora a amplitude do erro tenha variado de $-8,4 \%$ a $5,8 \%$ quando isoladas pequenas áreas.

Buscando determinar a acurácia de um monitor de produtividade com sensor de fluxo volumétrico, Molin et al. (2000) obtiveram dados totalizados de cada tanque da colhedora na colheita de milho de dois anos consecutivos, os quais eram pesados em um vagão graneleiro posicionado sobre um balança eletrônica e comparados com os dados gerados pelo monitor. Foram observados picos de erros em torno de $8,0 \%$, entretanto o erro médio encontrado foi de $-0,5 \%$ com desvio padrão $2,79 \%$ para a colheita do ano de 1998 e -1,06\% com desvio padrão de 3,11\% para o ano de 1999 .

Balastreire \& Amaral (2000) propuseram uma bancada de ensaio para calibração de monitores de produtividade onde é possível testar as condições normalmente encontradas nas colhedoras comerciais nacionais, sendo a bancada um corpo rígido, simulando uma colhedora na condição nivelada.

Um ensaio de sistema de medidas de produtividade sob condições dinâmicas de taxas de fluxo foi conduzido por Burks et al. (2001) para avaliar um monitor de produtividade com sensor de fluxo de placa de impacto. Os resultados mostraram que o sensor de produtividade teve um erro, baseado na quantidade de massa acumulada, menor do que $4 \%$, em condições normais de operação de 4,2 a $16,9 \mathrm{~kg} \cdot \mathrm{s}^{-1}$, para as condições de fluxos variando em degraus e taxas de fluxo de rampa. Quando ensaiados fluxos bem acima $\left(20 \mathrm{~kg} . \mathrm{s}^{-1}\right) \mathrm{da}$ taxa de calibração de $12,7 \mathrm{~kg} \cdot \mathrm{s}^{-1}$ exibiu erros significativos. Foi encontrado que fluxos variados (patamares de fluxos) tiveram erros máximos aproximadamente de $5 \%$, enquanto que os oscilantes (aumentando e diminuindo gradativamente) 
ao redor de $2,5 \%$. Isto foi devido ao fato que o ensaio com fluxo variado manteve fluxo acima das taxas utilizadas na operação da calibração por longo período. Portanto, quando trabalhando com fluxos elevados houve um grande erro de leitura. Os resultados destes ensaios indicam que o sensor de fluxo de massa registra acuradamente a massa total acumulada de fluxo por um amplo limite de taxas de fluxo de entrada e demonstra boa leitura instantânea de fluxo. 


\section{MATERIAL E MÉTODOS}

\subsection{Construção da Bancada de ENSAIO}

A bancada de ensaio, para avaliação de sistema de mensuração da produtividade de grãos (monitores de produtividade) constou de um tanque alimentador de grãos, um condutor helicoidal para grãos limpos, um elevador de taliscas e uma balança, constituída de um tanque de pesagem, suspenso por uma célula de carga de $2.000 \mathrm{~kg}$. Para manter o tanque suspenso pela célula de carga e fixar o elevador na posição de trabalho foram construídas duas estruturas de ferro, sendo uma para o tanque de pesagem e outra para o elevador. Os dois tanques, alimentador e de pesagem, foram construídos isoladamente do resto do corpo da bancada de ensaio, sendo cada parte uma unidade.

A bancada de ensaio desenvolvida para ser utilizada nos ensaios é apresentada na sua forma final na Figura 2. 


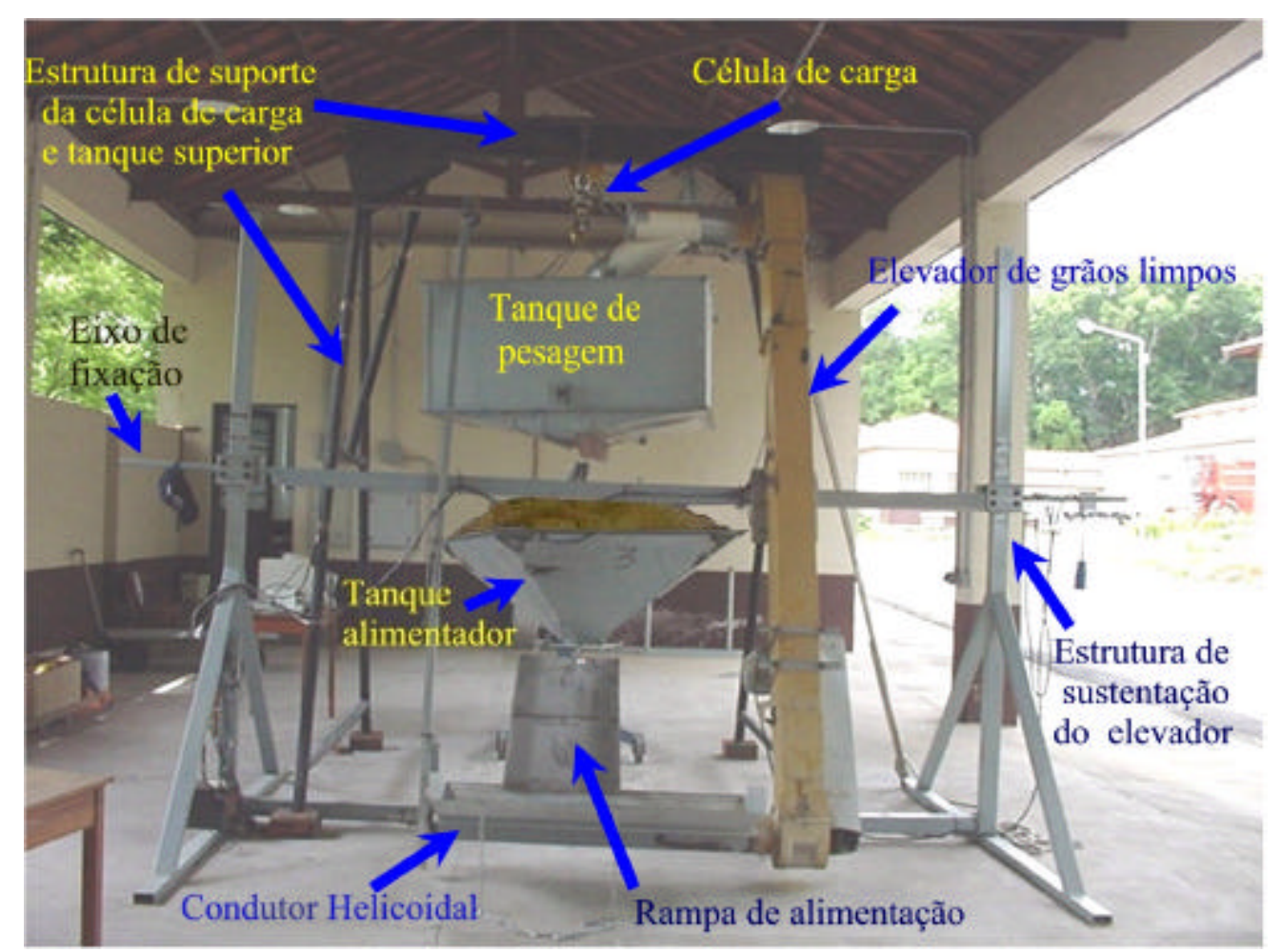

Figura 2 - Constituição da bancada desenvolvida e utilizada nos ensaios.

\subsubsection{Tanque alimentador de grãos}

Para construção do tanque alimentador de grãos foram realizados préensaios com um tanque de madeira com as mesmas características de angulação do tanque definitivo. O objetivo do pré teste do reservatório de madeira, mostrado na Figura 3, foi definir a área de abertura da comporta, necessária para propiciar uma vazão máxima de escoamento do milho, próxima de $9,72 \mathrm{~kg} . \mathrm{s}^{-1}\left(35.000 \mathrm{t} \cdot \mathrm{h}^{-1}\right)$ apenas pela ação da força gravitacional. Dos prétestes determinou-se que a abertura de seção quadrada necessária para a vazão de $9,5 \mathrm{~kg} \cdot \mathrm{s}^{-1}$ era de $15876 \mathrm{~mm}^{2}$, correspondente a um quadrado de lado de $126 \mathrm{~mm}$. Definiu-se, então, que o tanque de alimentação definitivo deveria ser construído com uma comporta de abertura de seção quadrada de 0 a $140 \mathrm{~mm}$, para garantir uma margem de segurança. 


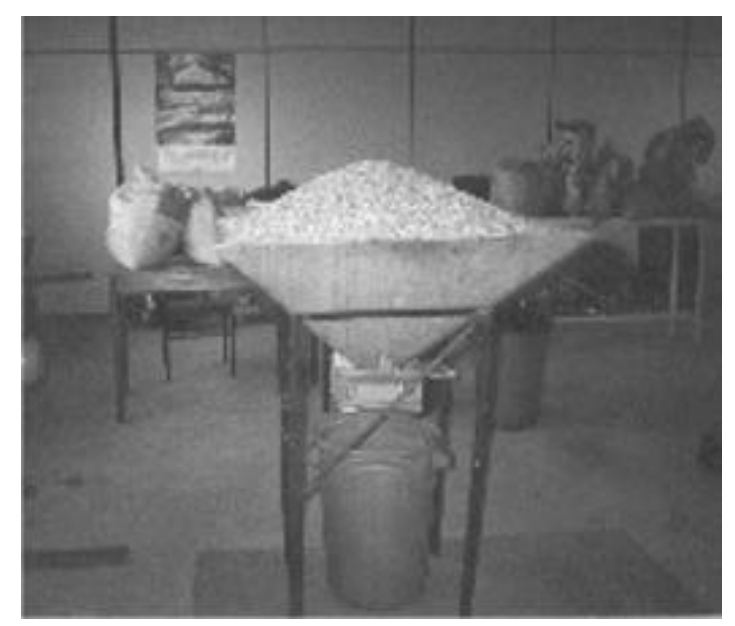

Figura 3 - Tanque de madeira para determinação da seção de área quadrada da comporta.

O tanque alimentador de grãos foi construído em chapa galvanizada de $1,50 \mathrm{~mm}$ de espessura. Sua estrutura é constituída de ferro cantoneira de $31,75 \mathrm{~mm} \times 4,76 \mathrm{~mm}\left(11^{\prime} \times 3 / 16^{\prime \prime}\right)$ e $31,75 \mathrm{~mm} \times 3,17 \mathrm{~mm}\left(1 \frac{1 / 4}{4} \times 1 / 8^{\prime \prime}\right)$ em suas laterais e bases, respectivamente. Possui ainda dois tubos de $\left.31,75 \mathrm{~mm}\left(1 \frac{1}{4}\right)^{\prime}\right)$ de diâmetro, soldados em suas diagonais, servindo de travamento e suporte para manter o tanque suspenso por um guindaste hidráulico. É constituído de duas partes, conectadas por parafusos. A primeira parte é de seção quadrada de $1400 \mathrm{~mm}$ de lado por $400 \mathrm{~mm}$ de altura. A segunda parte, conectada à parte inferior da primeira, por cantoneiras de ferro, possui a forma de uma pirâmide invertida, com laterais inclinadas de $45^{\circ}$ (Figura 4). Inicia com uma seção quadrada de $1400 \mathrm{~mm}$ diminuindo até $140 \mathrm{~mm}$ de lado, onde possui uma comporta com abertura, quadrada, variável de 0 a $19600 \mathrm{~mm}^{2}$. A altura do tronco de pirâmide é de $633 \mathrm{~mm}$.

Os primeiros ensaios, incluindo vazões altas, acima de $5,3 \mathrm{~kg} \cdot \mathrm{s}^{-1}$, foram com o tanque constituído das duas partes, em que, devido ao seu tamanho não havia espaço físico para loca-lo debaixo do tanque de pesagem, ficando cada qual em lados diferentes da estrutura de suporte do elevador. Para melhorar a operacionalidade da bancada de ensaio foi necessário reduzir a capacidade do tanque alimentador do sistema para os tanques poderem ficar sobrepostos e 
permitir a descarga do de pesagem para o de alimentação por meio da força gravitacional. Portanto, para maior facilidade de manuseio dos ensaios, a parte superior do tanque alimentador foi retirada, utilizando-se apenas a parte inferior, em forma de pirâmide invertida e com capacidade para $0,459 \mathrm{~m}^{3}$ de milho, permitindo a sobreposição dos tanques.

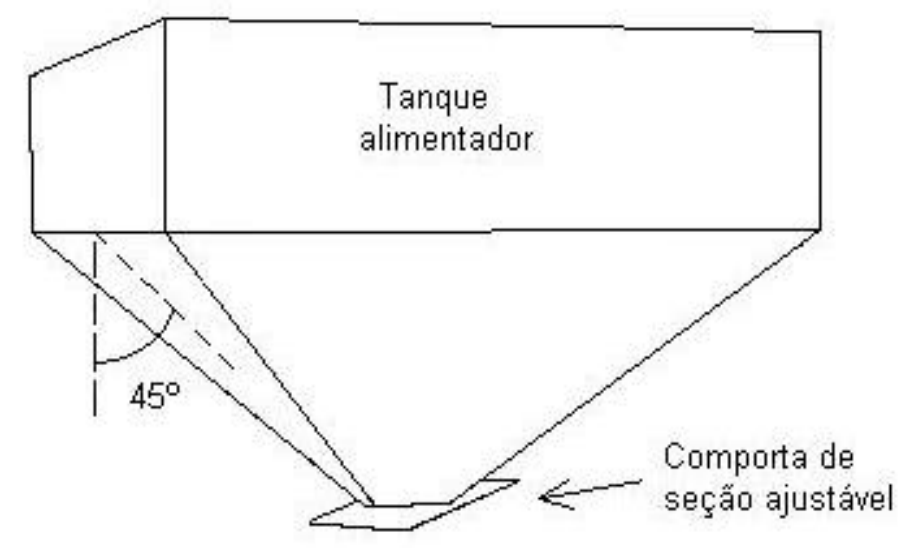

Figura 4 - Tanque de alimentação que fica suspenso por guindaste hidráulico.

A comporta, localizada na base do tanque de alimentação, foi construída com duas chapas com corte em forma de "V", sobrepostas de tal forma que, para qualquer abertura, a seção de área de saída permanecesse sempre quadrada. Esta abertura é regulada por meio de uma manivela que aciona um eixo de dupla rosca, sendo uma chapa da comporta ligada a este eixo por uma porca com rosca direita e a outra por uma de rosca esquerda. O passo da rosca resultou uma variação de $20,2 \mathrm{~mm}$ na diagonal da abertura quadrada (Figura 5). Esta comporta com chapas cortadas em forma de "V" é referida neste texto como comporta de seção ajustável.

Existe ainda uma tampa deslizante de abertura rápida (comporta de gaveta) situada logo abaixo da comporta de seção ajustável, para o sistema ser acionado instantaneamente, após ter sido selecionada uma abertura, na comporta anterior, para propiciar uma vazão desejada.

A comporta foi graduada com valores de 1 a 10 , com sensibilidade de 0,5. Cada unidade corresponde a uma volta na manivela de abertura da 
comporta. A área estimada, baseada no passo de rosca do eixo da manivela, para cada unidade graduada na escala é mostrada na Tabela 1.

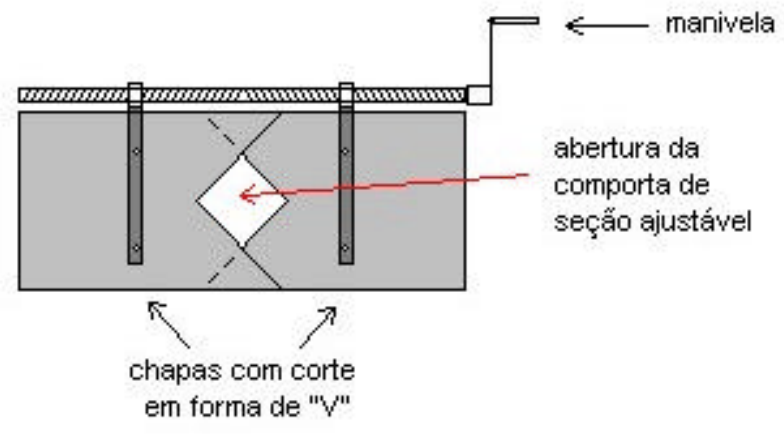

Figura 5 - Esquema da comporta de seção ajustável acionada pela manivela.

Tabela 1. Áreas estimadas para as diversas aberturas da comporta.

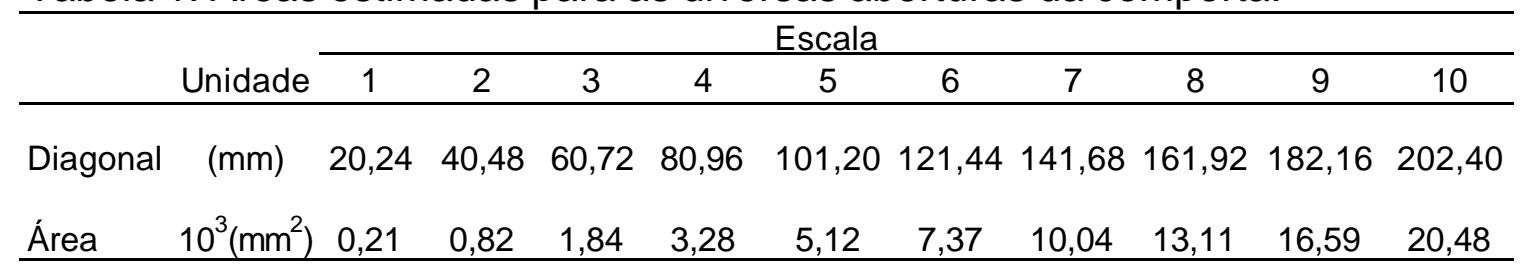

\subsubsection{Estrutura, elevador de taliscas e condutor helicoidal}

Foram utilizados um elevador de taliscas e um condutor helicoidal (rosca sem fim) com passo e diâmetro de $130 \mathrm{~mm}$, ambos originais de uma colhedora New Holland, modelo TC 57.

O elevador foi fixado à estrutura da bancada por sua parte central através de um flange, fixa a uma barra de ferro de seção retangular de $80 \mathrm{~mm}$ por $40 \mathrm{~mm}$ e de $3400 \mathrm{~mm}$ de comprimento, perpendicular ao elevador. Dentro desta barra, passa um eixo de $30 \mathrm{~mm}$ de diâmetro por $4500 \mathrm{~mm}$ de comprimento, sendo este conjunto, barra e eixo, denominado barra de fixação do elevador. As pontas do eixo são fixas nos dois pilares. Os pilares, de seção quadrada de $80 \mathrm{~mm}$ de lado, são sustentados por uma sapata com barra de ferro de seção retangular de $80 \mathrm{~m}$ por $40 \mathrm{~mm}$ e $3000 \mathrm{~mm}$ de comprimento e são unidos em sua base por uma barra de travamento, de seção quadrada, com 
$80 \mathrm{~mm}$ de lado por $3500 \mathrm{~mm}$ de comprimento, delimitando o vão livre de área de trabalho da bancada. O conjunto de dois pilares, barra de travamento e barra de fixação é a estrutura de sustentação do elevador, conforme a presentado ra Figura 6.

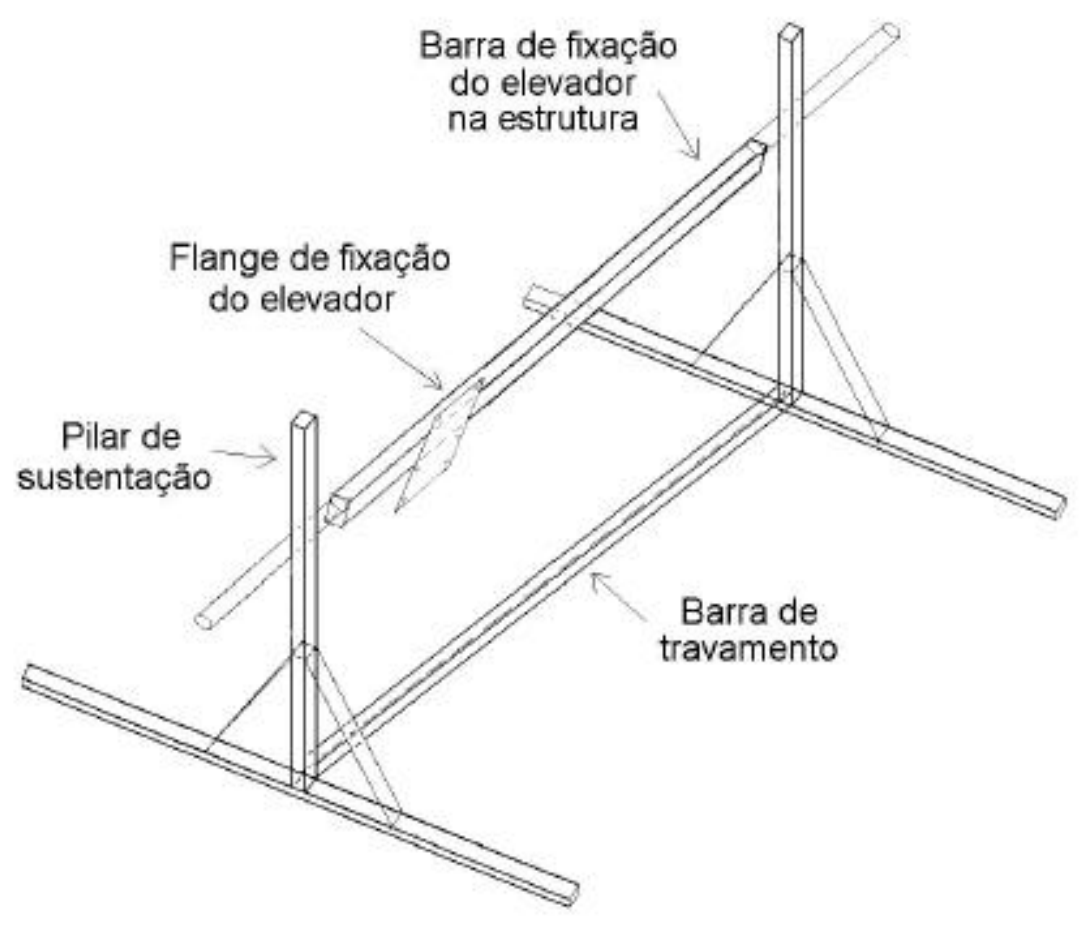

Figura 6 - Estrutura de sustentação do elevador.

O elevador é fixado no flange a $1000 \mathrm{~mm}$ de um dos pilares. Paralelo ao elevador, distante $1550 \mathrm{~mm}$, é disposta uma barra de ferro, com seção em forma de "U", onde são fixadas as caixas de rolamentos dos eixos condutores helicoidais, de alimentação na parte inferior e de descarga, na parte superior.

Para transporte dos grãos através do condutor helicoidal, foi construído um fundo de chapa calandrada com raio de $75 \mathrm{~mm}$ e de $1,5 \mathrm{~mm}$ de espessura, simulando as mesmas condições da colhedora, com ângulos fornecidos pelo fabricante. A esta chapa calandrada foram rebitadas duas outras, uma de cada lado, na forma de rampas, para direcionamento dos grãos provenientes do 
tanque alimentador para o condutor helicoidal. A Figura 7(a) mostra este esquema.

Os flanges de travamento da barra de fixação do elevador ao pilar são presos por parafusos, colocados um de cada lado do pilar, ficando o eixo situado entre um flange e o pilar, apresentado na Figura 7(b). Este flange possui uma distância mínima calculada entre parafusos que permite seu deslocamento para cima e para baixo no pilar até um ângulo útil de 15ㅇ․

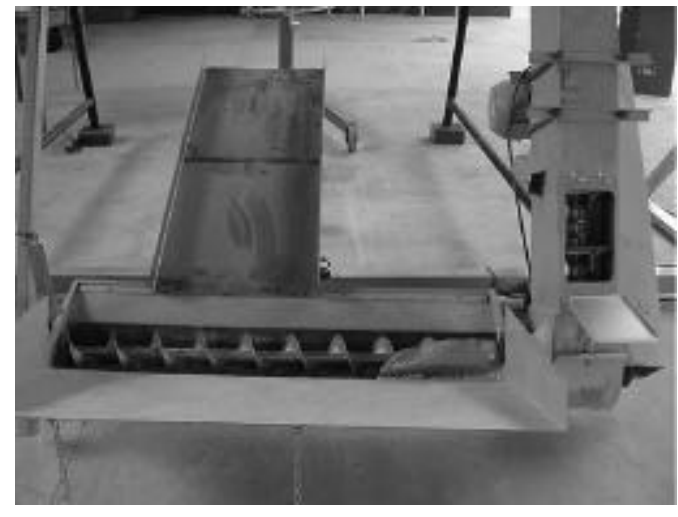

(a)

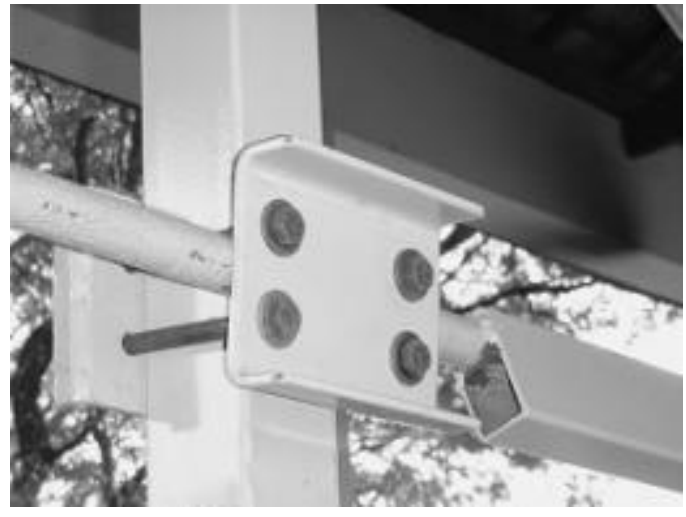

(b)

Figura 7 - Condutor helicoidal e rampas de alimentação (a); detalhe do flange de travamento do eixo de fixação do elevador (b).

A estrutura de sustentação do elevador é ajustável, podendo variar suas inclinações transversais e longitudinais, para simular diferentes condições topográficas no campo. A posição padrão do elevador, na bancada de ensaio, simula sua posição na colhedora quando esta está em nível, formando um ângulo de $67,5^{\circ}$ com a horizontal. A Figura 8 mostra a locação do elevador, em sua posição padrão, na estrutura de sustentação.

No posicionamento transversal, simulando inclinação da colhedora à direita e à esquerda, a angulação na estrutura é feita levantando ou abaixando a barra (eixo) de fixação do elevador, soltando ambos flanges que fixam o eixo no pilar e movimentando-o com um guindaste mecânico até a altura desejada e fixando-o novamente. Quanto ao posicionamento longitudinal do elevador, este 
é fixado por meio de uma corda esticada entre um ponto na parte superior do elevador e um ponto na base de suporte de sua estrutura. Para mudança de sua angulação, basta puxar ou soltar a corda até o posicionamento desejado. Neste ato o eixo de fixação do elevador no pilar pivota entre o flange e o pilar, podendo ser facilmente modificado.

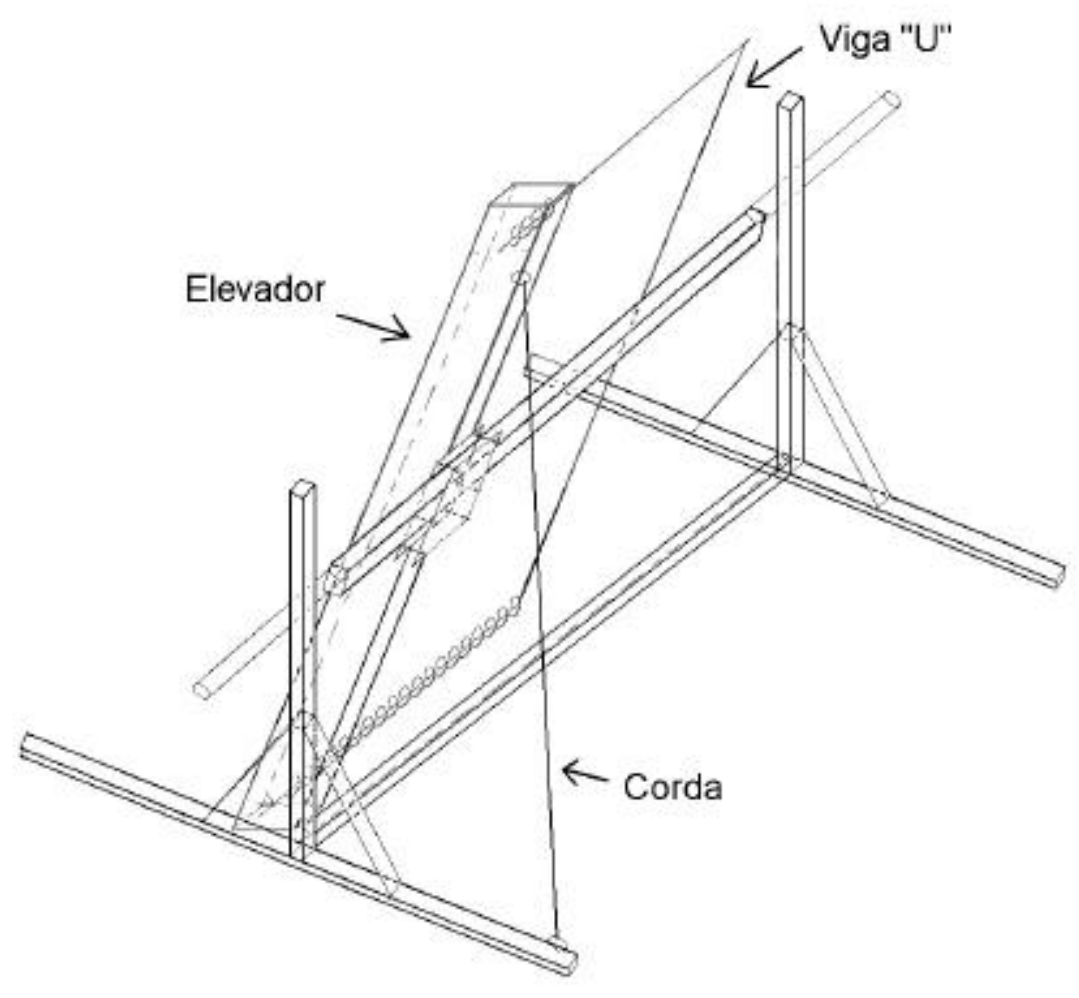

Figura 8 - Esquema da posição do elevador de taliscas adaptado a um suporte de inclinações transversal e longitudinal ajustáveis.

O conjunto apresenta capacidade máxima para transporte de milho em torno de $33.000 \mathrm{~kg} \cdot \mathrm{h}^{-1}$, limitada pela abertura da entrada de grãos no elevador alimentado pelo condutor helicoidal. É acionado por um motor elétrico de $2,20 \mathrm{~kW}$, de rotação nominal de $1150 \mathrm{rpm}$, adaptado junto à parte inferior do elevador de taliscas. A rotação média do condutor helicoidal e da roda denteada acionadora do elevador é 440rpm, conforme recomendação do fabricante da 
colhedora, resultando em velocidade tangencial média das taliscas de $2,84 \mathrm{~m} . \mathrm{s}^{-}$ 1, a uma freqüência de 16,65 taliscas. ${ }^{-1}$.

\subsubsection{Tanque de pesagem}

O tanque de pesagem possui forma quadrada, com o fundo inclinado para o centro, com capacidade de $1,47 \mathrm{~m}^{3}$, localizado na parte superior do sistema, sustentado por um cavalete de $3,6 \mathrm{~m}$ de altura e entre os dois é utilizada uma célula de carga.

Este tanque também foi construído com chapas e cantoneiras de ferro iguais à do tanque de alimentação. Possui uma altura útil de $750 \mathrm{~mm}$ e uma seção de área quadrada de $1400 \mathrm{~mm}$ de lado. Na parte inferior apresenta uma comporta basculante com largura de $200 \mathrm{~mm}$ por $1400 \mathrm{~mm}$ de comprimento.

\subsection{INSTRUMENTOS ANEXADOS À BANCADA DE ENSAIO}

\subsubsection{Célula de carga}

Foi utilizada uma célula de carga marca Kyowa, com capacidade para $2.000 \mathrm{~kg}$, com sensibilidade de $0,2 \mathrm{mV}$ por $1 \mathrm{~V}$, que trabalha para tração e compressão, com entrada mínima de 0,1kg, capaz de fornecer até 64 dados por segundo, transmitindo sinais para um coletor de dados.

Os valores gerados com a célula de carga são utilizados como massa em todo o estudo, desprezando a variação da gravidade com relação ao nível do mar. Esse procedimento permite comparar as massas lidas da célula de carga (balança) com as massas das leituras do sensor de fluxo de volume encontradas a partir da densidade do material utilizado.

\subsubsection{Coletor de dados}

Foi utilizado um coletor de dados CR10X da marca Campbell Scientific, inc. que possui uma memória de $2 \mathrm{Mb}$. Os dados enviados pela célula de carga, em intervalos de tempo pré-estabelecidos, são temporariamente armazenados em suas memórias e, posteriormente, transferidos, via cabo, para um 
computador através do programa PC208W, fornecido pelo fabricante do coletor de dados. Este foi programado para registrar 8 dados por segundo da célula de carga, fornecendo informações de data, hora e milivolts.

\subsubsection{Monitor de produtividade e sensores}

Um monitor de produtividade da marca RDS, modelo Ceres 2 (esquema demonstrativo da Figura 9), foi utilizado para coletar dados fornecidos dos sensores de fluxo de volume, velocidade, inclinação, grau de umidade e plataforma e armazená-los e em disquete de 1,44 Mb. O monitor possui programa específico transformando os sinais dos sensores em informações de quantidade de produto processado a cada instante.

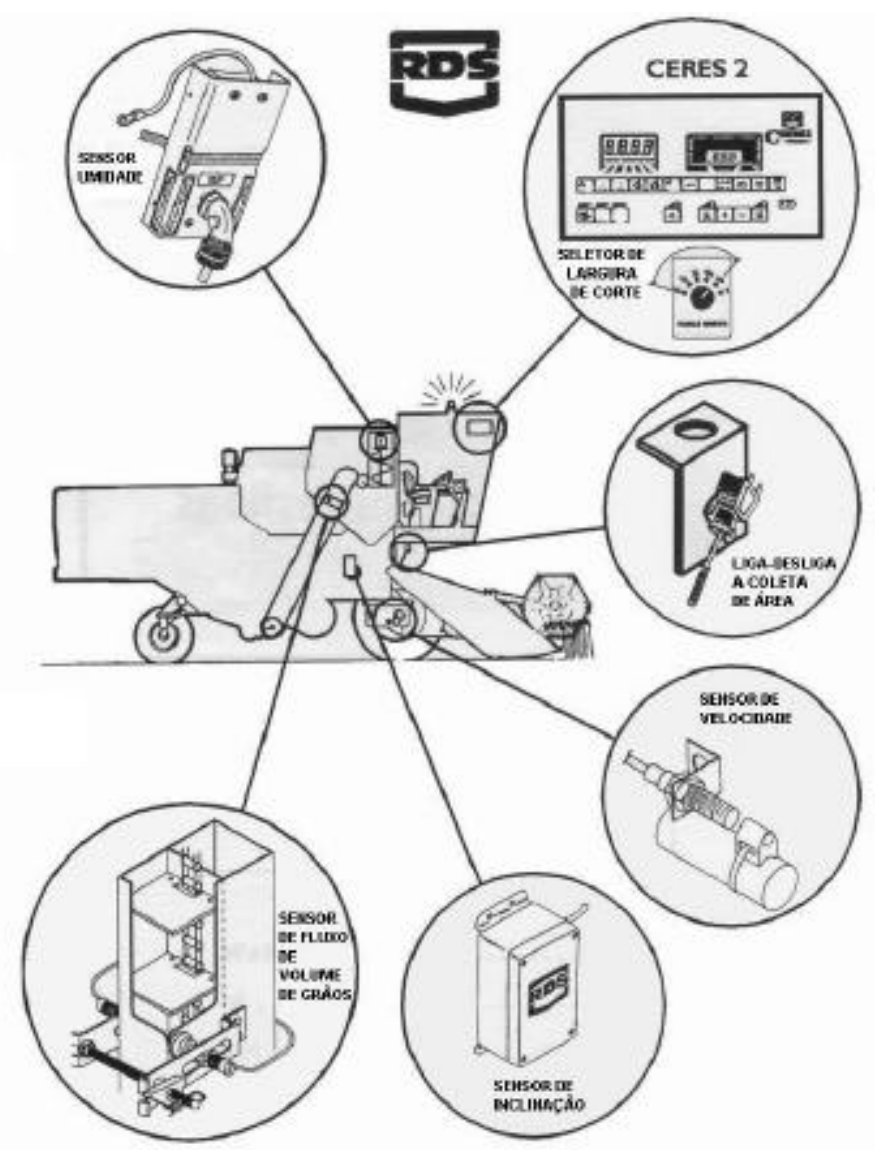

Figura 9 - Esquema do conjunto que forma o monitor RDS Ceres 2 utilizado nos ensaio, mostrando o posicionamento dos sensores na colhedora. Fonte: Manual RDS. 
Os arquivos gerados pelo monitor de produtividade, a cada leitura, fornecem os dados do número do arquivo, largura de plataforma da colhedora, produtividade em t.ha ${ }^{-1}$, grau de umidade do grão em percentagem, produção em toneladas, latitude e longitude.

O sensor de fluxo de volume é um sensor ótico, com um transmissor e um receptor, instalado no topo do elevador. Um facho de luz infravermelho é transmitido através do elevador de um lado para o outro. O receptor detecta quando o facho de luz passa livremente e quando ele é bloqueado. Quanto mais grãos existir na talisca, maior é o tempo que o facho é bloqueado. $O$ sensor mede a quantidade de grãos passando pelas taliscas do elevador através da percentagem de bloqueio do facho de luz.

O sensor de velocidade de deslocamento da colhedora é operado magneticamente, sendo um sistema contador de pulsos.

O sensor de inclinação mede o ângulo transversal da colhedora, enviando informações para que o monitor faça a correção das leituras de fluxo de volume. A correção é necessária devido à geometria da coluna de grãos formada sobre as taliscas dentro do elevador, que muda com a inclinação da colhedora, influenciando na percentagem de corte de luz, conforme esquema apresentado na Figura 10. O sensor de inclinação é provido de um pêndulo alojado numa caixa metálica fechada e mergulhado em silicone líquido para amortecer o seu movimento.

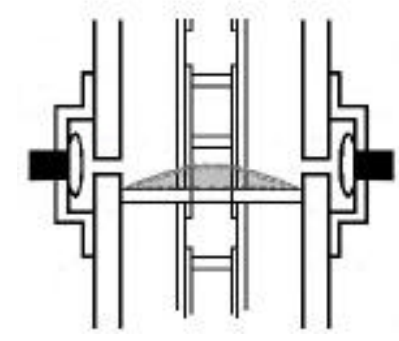

(a)

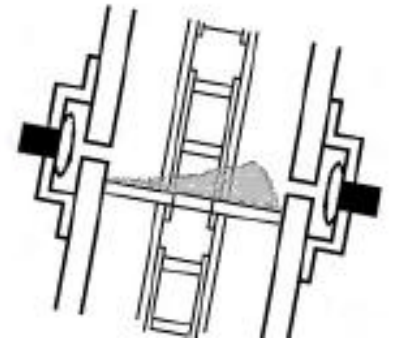

(b)

Figura 10 - Geometria de posição dos grãos nas taliscas do elevador para a posição em nível (a) e inclinado transversalmente àdireita (b). 
O sensor de grau de umidade trabalha por meio da condutividade elétrica da água contida nos grãos. Trata-se de um dispositivo por onde os grãos passam, sendo medida sua condutividade, a qual é convertida em valores de grau de umidade pelo monitor.

O sensor de plataforma é responsável por acionar e interromper a coleta de dados no sistema sempre que a plataforma da colhedora está ou não em posição de operação, definida pela altura da mesma.

Os sensores foram adaptados à bancada de ensaio seguindo as orientações de seu fabricante. O transmissor e receptor de luz infravermelha do sensor de fluxo de volume são instalados em um furo de $20 \mathrm{~mm}$ de diâmetro de cada lado do elevador, localizado a $284 \mathrm{~mm}$ abaixo do seu eixo superior e a $48 \mathrm{~mm}$ da sua face traseira. $O$ sensor deve ser posicionado de tal forma que 0 facho de luz seja interceptado somente pelas taliscas e não pelos suportes das taliscas. O sensor de velocidade foi instalado num suporte fixo próximo ao semi eixo exposto do condutor helicoidal. O imã do sensor foi fixado no semi-eixo, através de uma fita de aço, de acordo com recomendação do fabricante. $\mathrm{Na}$ bancada de ensaio, a caixa contendo o sensor de inclinação foi fixada num suporte instalado na parte central posterior do corpo do elevador. O sensor de grau de umidade foi instalado na saída do elevador. O sensor de altura da plataforma foi simulado através de um interruptor que ao ser ligado acionava a coleta de dados no monitor, representando a colhedora com a plataforma abaixada em posição de operação. Este mesmo interruptor acionava, concomitantemente, a coleta de dados da balança no coletor de dados. A posição de instalação dos sensores na bancada de ensaio é mostrada na Figura 11. 


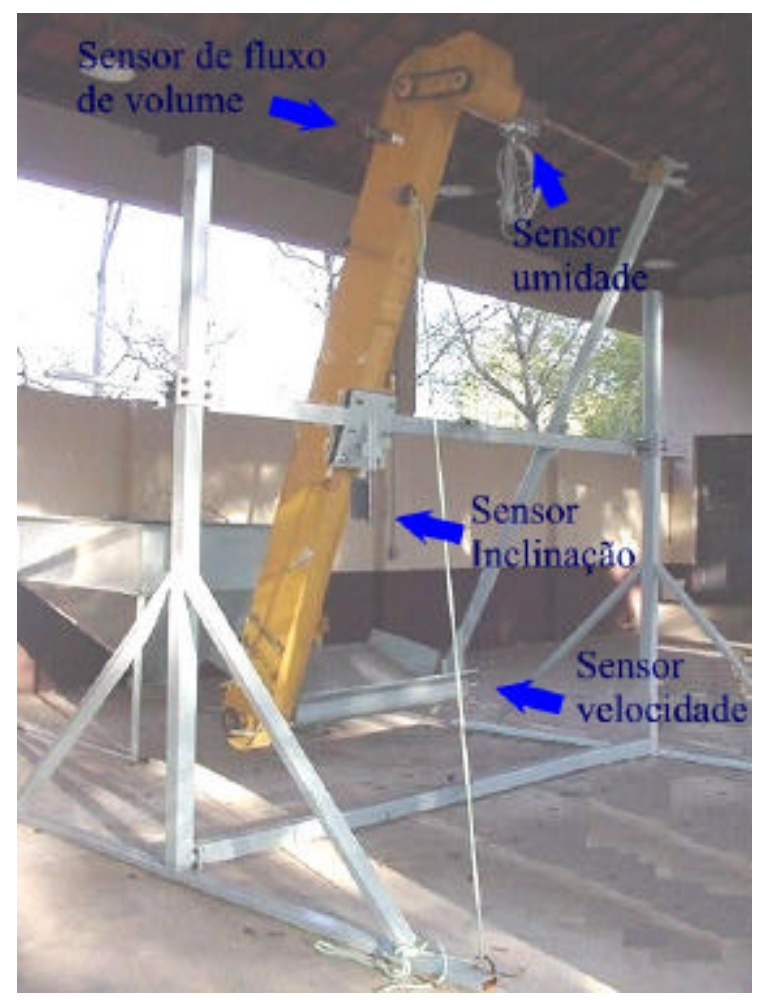

Figura 11 - Posição de instalação dos sensores de fluxo de volume, velocidade, inclinação e grau de umidade na bancada de ensaio.

Ainda, quanto ao sensor de fluxo de volume, a geometria do suporte das taliscas de transporte dos grãos no elevador pode influenciar nas medições do volume de grãos. Cada talisca é fixada à corrente do elevador por uma mão francesa, que não permite uma leitura constante do sensor de fluxo de volume de grãos, devido ao balanço da corrente, lendo variações na percentagem de corte de luz infravermelha emitida pelo sensor. Para eliminar esse efeito, por sugestão do fabricante do monitor, foi fixada uma chapa galvanizada, com seção retangular de $39 \mathrm{~mm} \times 66 \mathrm{~mm}$ num dos lados da mão francesa, em cada uma das taliscas, para que a percentagem de escuridão (corte de luz) seja constante. A Figura 12 mostra detalhe das taliscas dentro do elevador. 


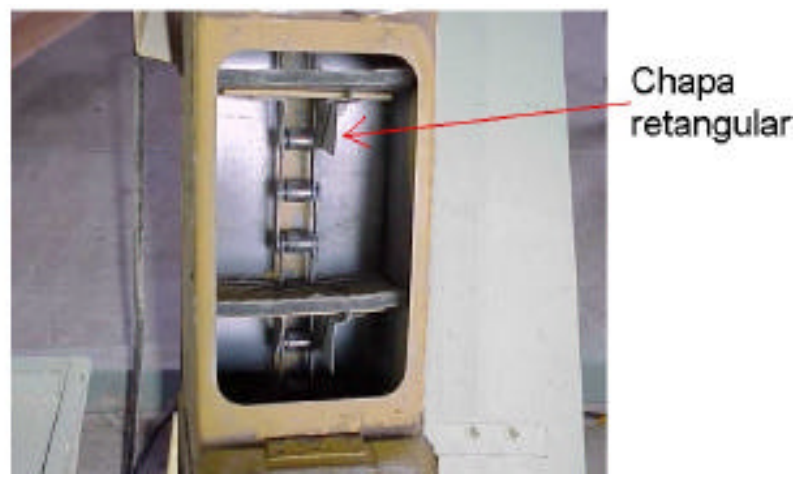

Figura 12 - Vista das taliscas dentro do elevador.

\subsection{Calibração}

\subsubsection{Calibração estática da célula de carga}

A célula de carga foi utilizada no experimento para obter a curva de calibração do tanque alimentador e para confrontar as leituras realizadas pelo monitor de produtividade, tendo sido considerada como medida de massa ideal. Para sua calibração tomourse como referência o equipamento Instron 4466, de ensaio de tração e compressão (em anexo A é apresentado o certificado de calibração da célula de carga do Instron), disponível no Laboratório de Instrumentação Agrícola do Departamento de Engenharia Rural da ESALQ/USP. A célula de carga foi fixada ao equipamento de ensaio de tração e compressão conforme apresentado na Figura 13.

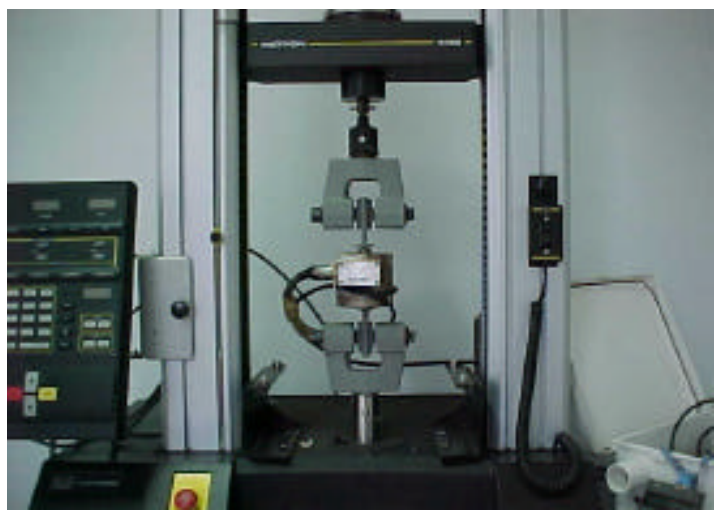

Figura 13 - Vista da calibração da célula de carga no equipamento de ensaio de tração e compressão Instron. 
A cada variação imposta anotava-se o valor correspondente em milivolts $(\mathrm{mV})$ fornecido pela célula de carga através do visor do coletor de dados. Este procedimento foi realizado, aplicando e retirando carga na célula de carga por intermédio do equipamento de ensaio de tração e compressão. $O$ ensaio foi realizado com carga até $1.000 \mathrm{~kg}$, limitada pelas características do equipamento de ensaio. Este limite era suficiente, visto que nos ensaios foram aplicadas cargas menores que $750 \mathrm{~kg}$. De posse dos valores de entrada em massa e saída em milivolts, obteve-se a curva de calibração da célula de carga.

\subsubsection{Calibração dinâmica da célula de carga}

A calibração dinâmica da célula de carga consistiu em desenvolver um ensaio normal do monitor de produtividade, com a taxa de alimentação de $5,3 \mathrm{~kg} \cdot \mathrm{s}^{-1} \mathrm{e}$, no final do ensaio, imediatamente após terminar o escoamento de milho do elevador para o tanque de pesagem, com massa total de aproximadamente $577 \mathrm{~kg}$, deixar ligado o coletor de dados e lançar sobre a massa de grãos, massas conhecidas de 2,0, de 1,0 ou de $0,5 \mathrm{~kg}$ e observar seus efeitos. Foram executadas 3 repetições para cada uma das massas conhecidas de 2,0, 1,0 e 0,5kg.

\subsubsection{Curva de calibração do tanque alimentador}

A curva de calibração do tanque de alimentação, com capacidade de $1000 \mathrm{~kg}$, suspenso por um guindaste hidráulico, foi conseguida determinando-se a vazão da quantidade de grãos escoada num intervalo de tempo conhecido, em cinco aberturas da comporta de seção ajustável, previamente medidas com paquímetro, para dois diferentes níveis de altura de grãos.

A coleta de dados foi feita ajustando-se a abertura, de geometria quadrada, da comporta de seção ajustável, para um valor de escala prédeterminado e, abrindo-se, repentinamente, a comporta de gaveta subjacente a esta, no instante que um cronômetro era disparado. Após, decorrido o intervalo de 10 segundos, a comporta de gaveta era fechada. Os dados eram coletados através do coletor de dados, que fornecia medidas de massa, mostradas no 
visor, as quais eram anotadas no início e final do processo. Com esses dados era determinada a vazão para a respectiva abertura da comporta de seção ajustável, através da diferença de massa inicial e final dividida pelo tempo de 10 segundos.

Para checar se havia influência da quantidade (altura) de milho contida no tanque, na vazão, foram efetuadas medidas com o tanque apresentando dois diferentes níveis de altura de grãos. Uma com o tanque carregado com $525 \mathrm{~kg}$ e outra com $112 \mathrm{~kg}$ de milho, suficiente apenas para desenvolver ensaios com todas as aberturas.

Considerando que no ensaio com o tanque apresentando menor quantidade de grão o tempo de coleta era $10 \mathrm{~s}$, de um total de $12 \mathrm{~s}$ possíveis pela quantidade de grãos, ainda sobravam 2 s para se eliminar o efeito do fim do fluxo de grãos no tanque, situação em que o fluxo não ocupava toda a seção de abertura da comporta, não sendo mais, a vazão, constante.

De posse dos dados de vazão para cada abertura da comporta de seção ajustável e a cada nível de altura do produto, foi feita a análise estatística no esquema fatorial $2 \times 5$ ( 2 alturas e 5 aberturas da comporta de seção ajustável) com 4 repetições, para verificar se a vazão era constante ou não, durante todo o escoamento do tanque. Com esses dados foi calculada a curva de calibração do tanque de alimentação.

\subsubsection{Configuração e calibração do monitor de produtividade}

O monitor de produtividade possui dois módulos de configuração, onde são inseridas variáveis para cada tipo de cultura, colhedora e fatores intrínsecos dos sensores. Os valores das variáveis utilizadas para configurar os dois módulos para os ensaios são apresentadas na Tabela 2.

No modo de operação do monitor, as configurações que antecedem a utilização do equipamento foram todas feitas de acordo com o seu manual. Dos dados existentes no modo de operação, os que necessitam ser indicados dependendo da cultura e das suas características, são: o tipo de cultura, o grau 
de umidade seca padrão do produto, o fator de correção da grau de umidade e a densidade do material.

Tabela 2. Fatores utilizados nos dois módulos de configuração do monitor.

\begin{tabular}{|c|c|c|c|}
\hline \multicolumn{2}{|c|}{ Calibração no módulo 1} & \multicolumn{2}{|c|}{ Calibração no módulo 2} \\
\hline Fatores & Valores & Fatores & Valores \\
\hline Constante velocidade & 0,4545 & Unidade de peso & $\begin{array}{c}\text { Toneladas } \\
\text { (stand) }\end{array}$ \\
\hline Largura de corte (m) & 4,00 & Unidade de medida & Métrica (met) \\
\hline Largura parcial/cheia & Cheia & $\begin{array}{l}\text { Sensor grau de } \\
\text { umidade }\end{array}$ & Ligado \\
\hline$\%$ largura plataforma & 1 & Calibração "C" & $\mathrm{H}-7,907$ \\
\hline Suavização & 1 & Calibração "O” & $\mathrm{H}-2$ \\
\hline Tempo de atraso & 0 & $\begin{array}{l}\text { Correção grau de } \\
\text { umidade }\end{array}$ & 0 \\
\hline Modo de saída dos dados & Dinâmico & $\begin{array}{l}\text { Correção da grau de } \\
\text { umidade mínima }\end{array}$ & 0 \\
\hline Inclinação a direita & $-0,3$ & & \\
\hline Inclinação a esquerda & $-0,3$ & & \\
\hline $\mathrm{PC}$ & Mostrad os Tabela 14 & & \\
\hline Modo de armazenagem & Armazenagem (store) & & \\
\hline
\end{tabular}

Para ensaiar o monitor de produtividade foi inicialmente feito o ajuste da tara do sistema que consta da leitura do sensor de fluxo de volume com as taliscas do elevador passando vazias. Para adequar a curva de corte de luz à quantidade de produto processado na calibração, se ajustou no monitor, em seu modo de operação, a constante do fator de calibração dos grãos, para que a curva de percentagem de corte de luz, lida pelo sensor de fluxo de volume, seja ajustada àquantidade de produto processado passando pelo sensor.

A calibração foi feita variando-se 5 vezes a taxa de fluxo sendo processada no sistema, ou seja, seis vazões diferentes no mesmo ensaio. A partir do monitor calibrado foram levantados todos os dados de ensaio dos sensores, mantendo sempre a mesma tara e o mesmo fator de calibração dos grãos.

De posse dos dados de vazão do tanque alimentador, juntamente com simulação da capacidade teórica de uma colhedora, equipada com o elevador utilizado nos ensaios, com uma plataforma para milho de 4 linhas, em que 0 espaçamento da cultura fosse de um metro entre linhas, foram estimados os 
valores de taxas de fluxo limites passando no elevador, apresentados na Tabela 3, representativos das condições reais de campo no Brasil. Estas taxas limites foram calculadas para determinar o intervalo de calibração do monitor.

Tabela 3. Simulação de taxas de fluxo no elevador a partir de valores limites de produtividades.

\begin{tabular}{cccc}
\hline $\begin{array}{c}\text { Velocidades da } \\
\text { colhedora } \\
\mathrm{m} \cdot \mathrm{s}^{-1}\end{array}$ & $\begin{array}{c}\text { Produtividades } \\
\mathrm{kg} \cdot \mathrm{ha}^{-1}\end{array}$ & $\begin{array}{c}\text { Processamentos da } \\
\text { colhedora } \\
\mathrm{kg} \cdot \mathrm{h}^{-1}\end{array}$ & $\begin{array}{c}\text { Fluxos do } \\
\text { elevador } \\
\mathrm{kg} \cdot \mathrm{s}^{-1}\end{array}$ \\
\hline 1,94 & 2860 & 8000 & 2,22 \\
1,39 & 4000 & 8000 & 2,22 \\
1,67 & 9580 & 23000 & 6,40 \\
1,39 & 11500 & 23000 & 6,40 \\
\hline
\end{tabular}

A massa média de grãos em cada ensaio para calibração do sistema era de $426 \mathrm{~kg}$, correspondente à capacidade do tanque de alimentação por ocasião dos ensaios. A calibração foi feita de acordo com o manual do fabricante, com 6 diferentes taxas de alimentação durante a leitura da massa, a saber: 2,22, 2,83, 3,55, 4,37, 5,30, e 6,36 kg.s ${ }^{-1}$, correspondentes às aberturas da comporta de seção ajustável do tanque alimentador de 6169, 7374, 8654, 10037,11522 e $13109 \mathrm{~mm}^{2}$, respectivamente, as quais foram obtidas regulandose a manivela de abertura da comporta de seção ajustável, com variação de 0,5 em 0,5 , na faixa de escala de 5,5 a 8,0. A Figura 14, mostra a escala para abertura da comporta de seção ajustável. O tempo total de fluxo de milho para cada ensaio de calibração foi de 102s, sendo o intervalo de tempo, 17s, mantido igual para cada um dos fluxos.

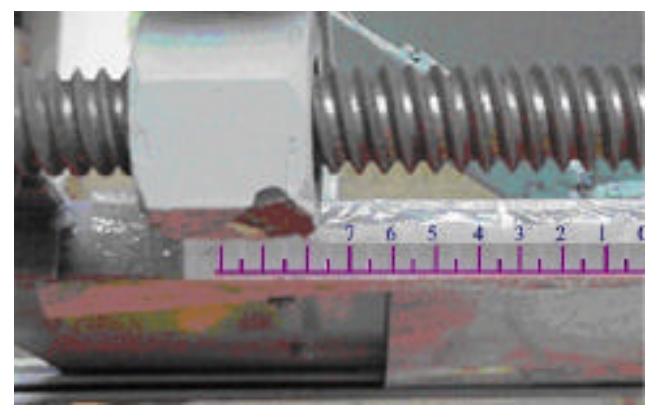

Figura 14 - Escala graduada para abertura da comporta de seção ajustável. 
A calibração foi realizada com leituras onde eram ligados o elevador e o monitor e, em seguida, a coleta de dados pelo interruptor comum àbalança e ao monitor. Após um intervalo de tempo de 60 s, com o monitor coletando dados com as taliscas correndo vazias abria-se repentinamente a comporta de gaveta, para uma abertura pré-estabelecida na comporta de seção ajustável (vazão). A cada intervalo de 17 segundos movia-se, rapidamente, a manivela de abertura para outra posição, variando a abertura da comporta de seção ajustável, para uma súbita mudança na vazão. Após a última mudança de abertura, a coleta de dados no monitor continuava até terminar o transporte de milho para o tanque superior (balança). Então o sistema era desligado.

\subsection{EnSAIOS}

\subsubsection{Sensor de velocidade}

Para se conhecer o funcionamento do sensor de velocidade foi determinada a equação que rege a constante de velocidade gerada no monitor. O valor da constante de velocidade é apenas função do número de voltas dadas pela roda num espaço pré-determinado $(100 \mathrm{~m})$. Portanto, simulou-se vários valores de números de pulsos ou voltas da roda, anotando-se em cada vez a constante de velocidade gerada no monitor. Com isto foi possível gerar a curva de calibração do sensor de velocidade. O ensaio foi realizado com o sensor de velocidade instalado em uma carreta tracionada por um trator.

O ensaio do sensor de velocidade foi feito pela comparação entre a velocidade mostrada no monitor e a velocidade calculada quando se percorria uma distância de 100m, marcando-se o tempo com um cronômetro de pulso, que possui uma sensibilidade de centésimos de segundo. Foram realizadas oito leituras com velocidades constantes. 


\subsubsection{Sensor de fluxo de volume}

Foram realizados ensaios para verificação da eficiência do monitor de produtividade para fluxos de grãos de milho constantes e variáveis sendo transportados pelo elevador, com este em nível e também apresentando diferentes inclinações. Todos os ensaios foram realizados comparando as leituras de massa geradas pelo monitor e a massa registrada pela balança. As leituras de corte de luz realizadas pelo sensor de fluxo de volume são convertidas em massa pelo monitor através de uma combinação da densidade da massa de grãos informada e de interações de leituras realizadas com o sensor de inclinação transversal, sensor de grau de umidade dos grãos e com o sensor de velocidade.

Quando a colhedora opera em condições topográficas adversas, o monitor de produtividade usa para cálculo do fluxo de massa a interação entre o sensor de fluxo de volume e o sensor de inclinação. A avaliação desta interação foi feita simulando-se a inclinação da colhedora inclinando-se o elevador transversalmente a $5^{\circ}$ e $10^{\circ}$ à direita. Trabalhourse com o elevador inclinado transversalmente à direita deduzindo serem simétricas as condições de transporte de grãos no elevador tanto inclinado transversalmente à direita quanto à esquerda. Considerando que grande parte das áreas cultivadas possui declividades até $10^{\circ}$, este foi o limite máximo de angulação estudado. A inclinação $5^{\circ}$ foi escolhida por ser intermediária entre a de $10^{\circ}$ e a de quando a colhedora está em nível ( $0^{\circ}$ ).

Os ensaios com fluxo constante de grãos constituíram das leituras de massas realizadas quando a abertura da comporta de seção ajustável do tanque de alimentação foi mantida em uma mesma posição durante toda a coleta de dados. Foram realizadas 3 repetições de cada taxa de fluxo constante. Na condição com o elevador na posição transversal em nível, foram utilizadas as mesmas taxas da calibração e outras três (uma abaixo, uma intermediária e uma acima das da calibração), conforme esquema da Tabela 4. 
Para o elevador simulando as inclinações transversais de $5^{\circ}$ e $10^{\circ}$ à direita, 0 ensaio foi realizado com três das taxas de fluxo constante, conforme Tabela 4.

Tabela 4. Taxas de fluxo aplicadas a partir do tanque de alimentação para ensaios do sensor de fluxo de volume com taxas constantes.

\begin{tabular}{cccc}
\hline $\begin{array}{c}\text { Inclinações } \\
\text { do elevador }\end{array}$ & $\begin{array}{c}\text { Escalas da } \\
\text { comporta }\end{array}$ & $\begin{array}{c}\text { Áreas de abertura } \\
\text { da comporta }\left(\mathrm{mm}^{2}\right)\end{array}$ & $\begin{array}{c}\text { Taxas de fluxo } \\
\left(\mathrm{kg} . \mathrm{s}^{-1}\right)\end{array}$ \\
\hline & 5,00 & 5324 & 1,70 \\
& 5,50 & 6169 & 2,22 \\
& 6,00 & 7374 & 2,83 \\
$0^{\circ}$ & 6,50 & 8654 & 3,55 \\
& 6,75 & 9496 & 3,94 \\
& 7,00 & 10037 & 4,37 \\
& 7,50 & 11522 & 5,30 \\
& 8,00 & 13109 & 6,36 \\
& 8,50 & 14811 & 7,54 \\
$5^{\circ}$ & 6,00 & 7374 & 2,83 \\
& 7,00 & 10037 & 4,37 \\
& 7,50 & 11522 & 5,30 \\
$10^{\circ}$ & 6,00 & 7374 & 2,83 \\
& 7,00 & 10037 & 4,37 \\
& 7,50 & 11522 & 5,30 \\
\hline
\end{tabular}

A análise das médias dos fluxos foi feita dentro de um intervalo de tempo aproximado de 23s após a estabilização do sistema, em cada ensaio do monitor, utilizando-se intervalos de 21 s a 44 s para a análise.

Para simulação da variação do fluxo de grãos, criando diferentes patamares de fluxo em um mesmo ensaio, representando uma variação de produtividade no campo, foram feitas duas variações de taxas de fluxo onde se iniciava com a comporta de seção ajustável previamente regulada para uma determinada vazão e durante o ensaio mudava-se a abertura por duas vezes, em intervalos de 32s, tempo determinado pela capacidade máxima de carga do tanque. Portanto, em cada experimento eram estudadas três taxas de fluxo 
diferentes. Foram ensaiadas três seqüências de alimentação de taxas de fluxo pelo tanque alimentador: uma ascendente, com taxas médias de alimentação de aproximadamente 2,83, 4,37 e 5,30 kg.s ${ }^{-1}$ (conseguidas com uma abertura da comporta de seção ajustável nos pontos de escala 6,0, 7,0 e 7,5); uma alternada com taxas de 5,30, 2,83 e 4,37 kg. $\mathrm{s}^{-1}$ (referentes a uma abertura da comporta de seção ajustável nos pontos de escala 7,5, 6,0 e 7,0); e uma terceira, descendente, com as taxas de alimentação de aproximadamente 5,30, 2,83 e 2,22kg.s ${ }^{-1}$ (conseguidas com uma abertura da comporta de seção ajustável nos pontos de escala 7,5, 6,0 e 5,5). Essas seqüências foram as mesmas tanto para o elevador em nível como inclinado transversalmente.

\subsubsection{Determinação do grau de umidade dos grãos}

Com relação ao grau de umidade dos grãos de milho foi feita uma primeira determinação para aferir este parâmetro no monitor, no início dos trabalhos e, eventualmente, durante o período de ensaios foram feitas algumas amostragens para verificar se havia variação do grau de umidade. Foi utilizado o método gravimétrico, com a secagem durante aproximadamente 24 horas, em estufa mantida a $105^{\circ} \mathrm{C}$ para determinação do grau de umidade dos grãos.

\subsubsection{Processamento e análise dos dados}

Para processamento dos dados da balança, gravados no coletor de dados e os do monitor, armazenados em disquete (exemplo apresentado no Anexo B), foram desenvolvidos dois programas computacionais em Visual Basic 6.0 , os quais filtravam automaticamente os dados úteis dos arquivos de entrada e geravam planilhas com os cálculos pré-estabelecidos para o desenvolvimento deste trabalho. Os formulários de entrada de dados destes programas são mostrados nas figuras F1 e F2 do Anexo C. Também foi utilizado o programa Excel (Microsoft) para cálculos diversos.

O programa para processar os dados medidos pela balança foi denominado "Processamento de dados da balança, versão 1.0" (PDbal-1.0) e 
aquele utilizado para processar os dados gerados no monitor foi denominado "Processamento de dados do Monitor, versão 1.0" (PDmon-1.0).

Para cada repetição dos tratamentos estudados, o monitor gerava um arquivo de dados, que servia de entrada para o programa PDmon-1.0 e como saída este gerava três arquivos. O primeiro, com os dados dos parâmetros de entrada, simplesmente convertendo as unidades do arquivo do monitor e eliminando linhas com dados não utilizáveis neste trabalho. O segundo com os valores pontuais de cada parâmetro registrado com o tempo no arquivo do monitor (a cada 2,63s em média) para construção dos gráficos de fluxo de grãos em função do tempo e o outro com valores médios calculados de dados registrados em intervalos de aproximadamente 23s, a partir do segundo arquivo, para análises estatísticas e regressão. Em vista do fato de não se ter controle da variável tempo no monitor de produtividade, optou-se por fazer esta média com o número fixo de nove linhas a partir da nona linha do programa, o que propiciava um tempo inicial médio de 22s. O intervalo de tempo entre dados, para o programa PDmon-1.0, era fornecido como um valor de entrada, previamente calculado. As saídas dos programas forneciam, entre outros, número do arquivo do monitor, ângulo de inclinação do elevador na posição transversal, ponto de abertura na escala da comporta de seção ajustável, fluxo de grãos em $\mathrm{kg} . \mathrm{s}^{-1}$ lido pelo sensor, tempo de cada coleta de dados e número de registros.

O programa Pdbal-1.0, também gerava 3 arquivos de dados. Um com valores pontuais de dados de cada parâmetro a partir de média móvel de 46 linhas de dados, correspondendo a um intervalo de $5,75 \mathrm{~s}$, que foi o melhor método encontrado, de uma série de testes, para se realizar o tratamento dos dados. O segundo, fornecia valores médios de fluxos a cada intervalo de tempo de 2,875s, a partir dos resultados do primeiro arquivo, para construção de gráficos de fluxo de grãos medido pela balança em função do tempo. O outro arquivo gerava a média dos valores do intervalo de $21,13 \mathrm{~s}$ a $44,13 \mathrm{~s}$ de cada ensaio, ou seja, um valor médio de cada ensaio calculado em um período de 
23s. As saídas destes programas forneciam, entre outros, o dia, número do arquivo do monitor, fluxo de grãos em kg.s ${ }^{-1}$ de uma média móvel de 46 dados, tempo de cada coleta e tempo total de coleta dentre outros.

Para análise dos dados foram feitos estudos de comparação de médias, análises de regressão e análises estatísticas das médias em esquema fatorial (inclinação do elevador, leituras das taxas de fluxo lida pelos sistemas do monitor e da balança e repetições). Para comparação entre médias de leituras do monitor e da balança foi calculado o erro relativo conforme equação 6 .

$$
\text { Erro relativo }(\%)=\underline{(\text { Fluxo monitor }- \text { Fluxo balança })} \times 100
$$

$$
\text { Fluxo balança }
$$

Para cálculos das médias, regressões e desenvolvimento de gráficos foram utilizadas as funções de estatística do programa Excel (Microsoft). Para as análises fatoriais e de regressões, foi utilizado o programa ESTAT, desenvolvido pelo Departamento de Ciências Exatas da FCAV-UNESP, Jaboticabal-SP.

Foram realizadas três análises fatoriais com taxas constantes de escoamento de grãos, com o sistema simulando uma colhedora em nível e em diferentes declividades transversais para três taxas de alimentação. Foi utilizado um esquema fatorial $3 \times 2$, com 3 repetições. Os tratamentos foram combinações de 3 inclinações transversais do elevador: nível, $5^{\circ}$ àdireita $\left(+5^{\circ}\right)$ e $10^{\circ}$ à direita $\left(+10^{\circ}\right)$ e dois sistemas de medidas do fluxo de grãos (balança e monitor de produtividade). Esta análise foi realizada para três taxas de fluxo de milho obtidas com a comporta de seção ajustável aberta nos pontos da escala de $6,0,7,0$ e 7,5 correspondentes aos fluxos de alimentação de aproximadamente $2,83,4,37$ e $5,30 \mathrm{~kg} \cdot \mathrm{s}^{-1}$, respectivamente e as médias foram comparadas pelo teste de Tukey. Foram calculados os erros relativos em módulo do monitor em relação àbalança para cada taxa de fluxo referente æ̀̀ aberturas da comporta estudadas. 
Outra análise no esquema fatorial $(7 \times 2$, com 3 repetições) foi utilizada para se conhecer a influência das diferentes taxas de fluxo de volume de grãos na leitura dos dois sistemas (leituras do sensor e da balança), quando o elevador se encontrava em nível, na posição padrão. Os 14 tratamentos constituíram das combinações de 7 taxas de fluxo para as aberturas da comporta de seção ajustável para os pontos da escala $(5,5,6,0,6,5,6,75$, $7,0,7,5$, e 8,0) e os dois sistemas de medidas de fluxo (balança e monitor de produtividade). Foram calculados os erros relativos em módulo para cada taxa de fluxo referente æ̀s aberturas da comporta estudadas.

Para análise das taxas de fluxo variadas, além dos gráficos se utilizou uma análise estatística das médias calculadas em cada um dos três trechos onde era mantida constante a taxa de fluxo de alimentação, calculada a partir de dados separados graficamente nestes períodos constantes de fluxo, e calculada a média do fluxo do monitor e da balança em cada um dos três trechos por ensaio. Foi estimado o erro relativo em módulo do monitor com relação àbalança para cada trecho constante e obtida a média dos erros dentro de cada ensaio e para cada taxa de alimentação para todos os ensaios, tanto com o elevador em nível como inclinado a $+5^{\circ}$ e $+10^{\circ}$. 


\section{RESULTADOS E DISCUSSÃO}

A bancada de ensaio desenvolvida para ser utilizada nos ensaios foi eficiente para simular a colhedora em diversas condições de inclinações, devido ao fácil manejo de variação da angulação do elevador da bancada de ensaio, conforme a posição inclinada de 10ำ da Figura 15.

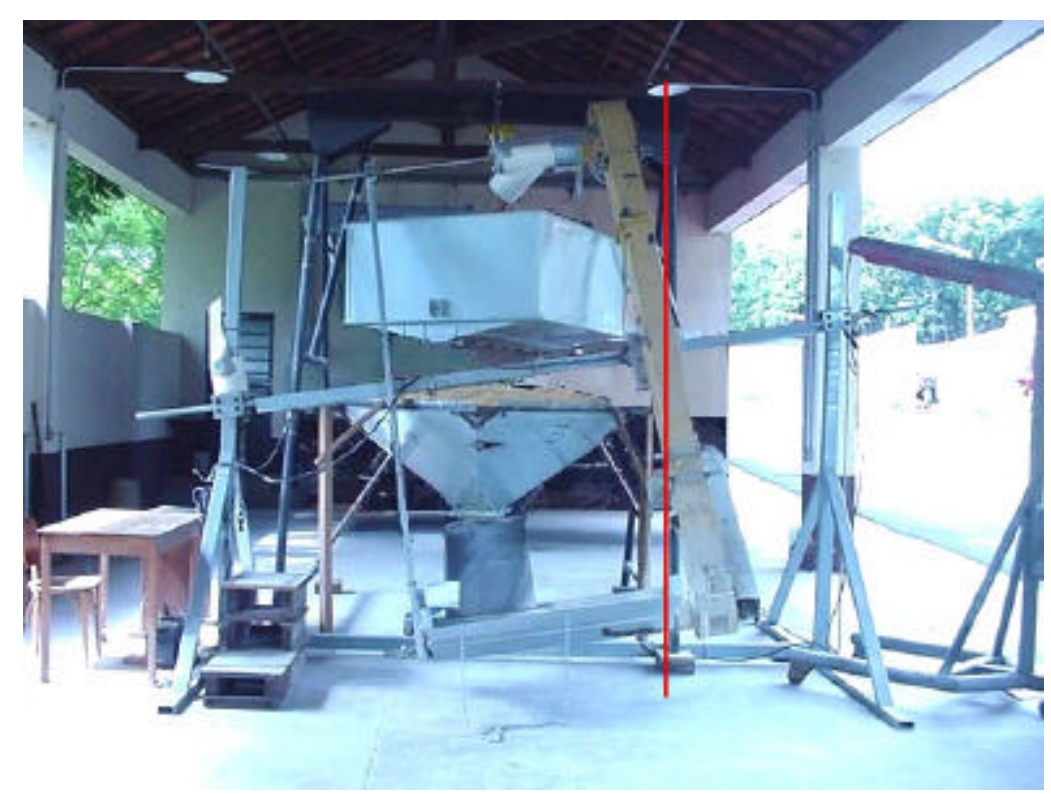

Figura 15 - Elevador inclinado a $10^{\circ}$ na bancada de ensaio, simulando uma colhedora em terreno acidentado de $10^{\circ}$. A linha vermelha indica a posição do elevador na bancada quando da simulação de uma colhedora em nível.

Os pré-ensaios foram desenvolvidos inicialmente com um sistema de bancada com alta capacidade de tempo de alimentação de fluxo de grãos para os ensaios, com o tanque alimentador constituído de suas duas partes, com volume de 1,243 $\mathrm{m}^{3}$, ficando seu eixo vertical deslocado de $2,20 \mathrm{~m}$ do eixo vertical do tanque de pesagem, o que acarretava a necessidade de ao término 
de cada ensaio reabastecer o tanque alimentador por meio do elevador com um operador desviando a carga de grãos.

Este sistema, mostrado na Figura 16, embora apresente a vantagem de um intervalo de tempo menor para a massa de grãos escoar do tanque de alimentação até o local do sensor de fluxo e de possibilitar um tempo mais longo de ensaio, devido a maior capacidade do tanque, possui desvantagens. A excessiva recirculação dos grãos por ser o reabastecimento do tanque de alimentação feito através do elevador, aumenta a intensidade de quebra de grãos, além do tempo despendido de aproximadamente 1,0h por ensaio e excessiva mão-de-obra no momento de recarregar o tanque de alimentação. Este sistema também expõe o operador a risco de acidente pela necessidade de ficar desviando o fluxo de grão para o tanque de alimentação, suportando-se sobre a barra de fixação do elevador.

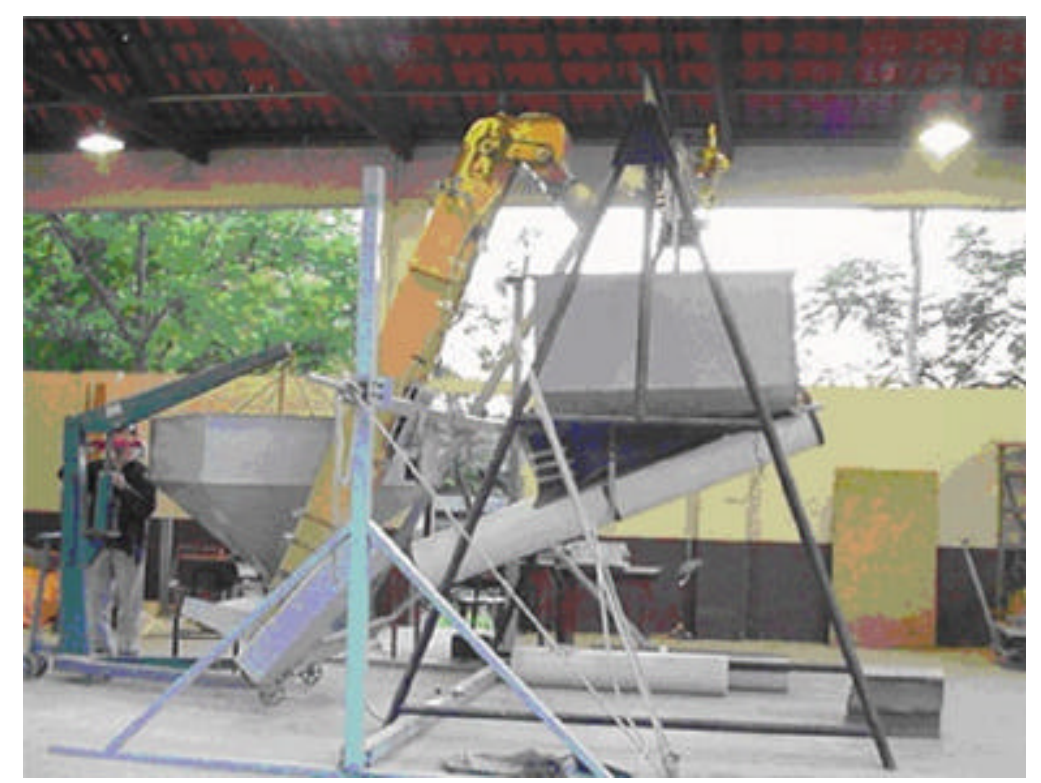

Figura 16 - Sistema inicial de bancada de ensaio, apresentando os tanques de alimentação e de pesagem em lados distintos da estrutura de sustentação do elevador.

Para facilitar o manuseio, considerando que ensaios preliminares mostraram ser possível trabalhar com tanque de menor capacidade, foi retirada a seção quadrada de $1,4 \mathrm{~m}$ por $0,4 \mathrm{~m}$ de profundidade do tanque de 
alimentação, ficando somente a parte inferior, em forma de pirâmide invertida, com capacidade de $0,658 \mathrm{~m}^{3}$, ou $500 \mathrm{~kg}$ de milho à massa específica de $760 \mathrm{~kg} \cdot \mathrm{m}^{-3}$. Esta carga máxima é obtida com um excesso de milho na parte central do tanque.

Neste sistema, os grãos do tanque de alimentação são descarregados numa chapa inclinada (rampa de $1,5 \mathrm{~m}$ de comprimento por $0,5 \mathrm{~m}$ de largura) com regulagem na sua extremidade superior, através de um suporte, conduzindo os grãos ao condutor helicoidal e deste para o elevador que os descarrega no tanque de pesagem. Nesta situação o tanque de alimentação é posicionado embaixo do tanque de pesagem, com uma pequena defasagem de posição, ficando os dois do mesmo lado da estrutura de sustentação do elevador. Portanto, o reabastecimento do tanque de alimentação é feito por gravidade, ajustando um tanque sob o outro e abrindo a comporta do tanque superior. Neste processo, embora a defasagem de tempo do início da alimentação e início da leitura ser maior, a quebra de grãos é acentuadamente menor e o tempo total de cada rodada de ensaio é bem menor, em torno de 24 minutos por ensaio. Isto foi essencial para se trabalhar com o volume de milho disponível, mantendo suas características até o final do ensaio.

Este segundo sistema ainda demanda arrastar o tanque de alimentação de um a dois metros, na hora do reabastecimento, para centralizar os dois tanques para a descarga; um processo moroso e pesado. $O$ ideal seria um sistema onde o tanque alimentador descarregasse os grãos diretamente em cima do condutor helicoidal e os tanques ficassem sobrepostos, sendo o reabastecimento feito diretamente por gravidade, sem a necessidade de locomover o tanque de alimentação. Para isto seria necessário mudar o sistema da estrutura de sustentação do elevador, eliminando os suportes que ficam no meio do sistema, como a barra de fixação do elevador preso aos pilares e a barra em forma de "U". Uma possível solução seria colocar os dois pés de sustentação de um mesmo lado do elevador, deixando-o em balanço. 
$\mathrm{Na}$ tentativa de simplificar o sistema de construção e coleta de dados, a balança foi constituída de um tanque de pesagem suspenso na sua parte central por uma única célula de carga. Isso apresentou grandes dificuldades de manuseio, exigindo centralização da carga de grãos sendo descarregada no tanque de pesagem. Sugere-se que a balança seja utilizada com 4 apoios, com uma célula de carga em cada um.

Durante todo o experimento foram processados em torno de $95.000 \mathrm{~kg}$ de grãos, entre ajustes do sistema, pré-ensaios e ensaios. A partir do momento em que se começou a gerar dados considerados válidos para o ensaio, foram processados $51.000 \mathrm{~kg}$. Portanto, para se avaliar como ensaiar o sistema, fazer ajustes necessários na bancada de ensaio foram processados $44.000 \mathrm{~kg}$ de grãos. Considerando-se em média o valor de $500 \mathrm{~kg}$ (capacidade do tanque alimentador) por rodada do sistema obtêm-se em torno de 190 ensaios, mostrando a dificuldade enfrentada para o acerto do sistema e entendimento do processo de funcionamento. Foi necessário peneirar por três vezes todo o estoque de grãos, eliminando-se as partículas, para manter a granulometria do material trabalhado.

\subsection{Calibração estática da Célula de carGa}

Para garantir a confiabilidade dos dados gerados pela célula de carga foi feita a sua calibração que consistiu em ler-se o valor mostrado no visor do coletor de dados, tanto acrescentando quanto retirando cargas conhecidas, determinando-se a equação de regressão pelo método dos quadrados mínimos.

$\mathrm{Na}$ Tabela 5 são apresentados os resultados dos registros do coletor de dados no ensaio de adição e redução de cargas. A partir destes foi construído o gráfico da curva da célula de carga, apresentada na Figura 17, e calculada a equação de regressão. A equação segue, segundo Doebelin (1966), a equação geral de instrumento de primeira ordem:

$$
q_{o}=m q_{i}+b,
$$


onde:

$\mathrm{q}_{\mathrm{o}}$ = saída em $\mathrm{mV}$,

$\mathrm{m}$ = coeficiente angular ou declividade da reta;

$\mathrm{q}_{\mathrm{i}}=$ entrada em $(\mathrm{kg})$;

$\mathrm{b}=$ interseção da ordenada.

Tabela 5. Dados registrados pelo coletor de dados na calibração da célula de carga.

\begin{tabular}{cccc}
\hline \multicolumn{2}{c}{ Adicionando cargas } & \multicolumn{2}{c}{ Reduzindo cargas } \\
Cargas & $\begin{array}{c}\text { Voltagens de saída } \\
\mathrm{mg}\end{array}$ & $\begin{array}{c}\text { Cargas } \\
\mathrm{Kg}\end{array}$ & $\begin{array}{c}\text { Voltagens de saída } \\
\mathrm{mV}\end{array}$ \\
\hline 0,000 & $-0,00063$ & 0,000 & $-0,00063$ \\
10,401 & 0,00837 & 10,707 & 0,00871 \\
50,986 & 0,04872 & 51,496 & 0,04939 \\
101,972 & 0,09907 & 102,481 & 0,10074 \\
203,943 & 0,20077 & 204,453 & 0,20244 \\
305,915 & 0,30147 & 306,425 & 0,30380 \\
407,886 & 0,40284 & 408,702 & 0,40484 \\
509,858 & 0,50420 & 510,878 & 0,50588 \\
611,830 & 0,60624 & 611,830 & 0,60691 \\
713,801 & 0,70630 & 714,821 & 0,70862 \\
815,773 & 0,80900 & 816,793 & 0,81033 \\
917,745 & 0,91039 & 918,764 & 0,91070 \\
1019,716 & 1,01180 & 1019,716 & 1,01180 \\
\hline
\end{tabular}

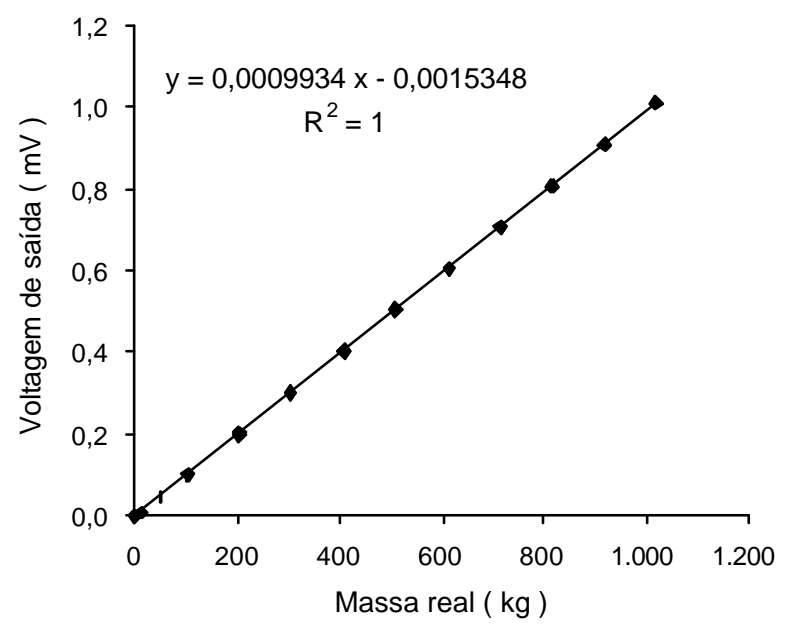

Figura 17 - Curva de calibração da célula de carga. 
Calculou-se a sensibilidade estática ( $\mathrm{k}$ ) através da declividade da curva de calibração, visto que em instrumento de primeira ordem $\mathrm{k}=\mathrm{m}$. O coeficiente de determinação $R^{2}=1$, mostra que os dados possuem distribuição normal e são de alta acurácia. Aplicando-se os valores de qo na equação (saída em mV), obtêm-se um valor de $\mathrm{q}_{i}$ estimada (entrada em $\mathrm{kg}$ ). Esta massa lida pelo equipamento durante os ensaios do tanque de alimentação e do monitor de produtividade é a massa procurada.

As estimativas dos erros na calibração estática, são calculadas conforme metodologia de Doebelin (1966) e mostradas na Tabela 6. O erro ao acaso do equipamento, considerando-se três vezes o valor do desvio padrão da amostra do sinal de entrada, fornece uma variação possível de cada valor com uma garantia de que $99,7 \%$ dos valores se encontram dentro deste limite. Os cálculos dos erros foram todos feitos baseando-se em uma massa inicial de $407,89 \mathrm{~kg}$, por estar em torno da massa média sustentada pela célula de carga durante os ensaios.

Tabela 6. Parâmetros de caracterização da célula de carga.

\begin{tabular}{ll}
\hline Parâmetros analisados & \multicolumn{1}{c}{ Valores } \\
\hline Sensibilidade estática $(\mathrm{m}=\mathrm{k})$ & $0,00099 \mathrm{mV} \cdot \mathrm{kg}^{-1}$ \\
Desvio padrão do sinal de saída $\left(\mathrm{sq}_{0}\right)$ & $0,60983 \mathrm{Kg}$ \\
Desvio padrão do sinal de entrada $\left(\mathrm{sq}_{\mathrm{i}}\right)$ & $0,60983 \mathrm{Kg}$ \\
Erro relativo $\left(\frac{\Delta e_{o}}{e_{o}}\right)$ & $-0,00202$ \\
Erro ao acaso $\left(3 . \mathrm{sq}_{\mathrm{i}}\right)$ & $\pm 1,829 \mathrm{~kg}$ \\
Erro sistemático & 0,0 \\
Erro total & $\pm 1,829 \mathrm{~kg}$ \\
\hline
\end{tabular}

\subsection{Calibração dinÂMica dA CÉLULA de CARGA}

Os dados de calibração dinâmica, efetuada com adição de massas de $2,0,1,0$ ou de $0,5 \mathrm{~kg}$ sobre a massa de grãos no tanque de pesagem carregado com carga total em torno de $577 \mathrm{~kg}$, foram processados aproveitando-se apenas 
os registros do coletor de dados do instante após o lançamento da massa conhecida no tanque, até o momento em que o coletor de dados foi desligado, em torno de 30 segundos, tempo suficiente para a estabilização do sistema, de acordo com observações preliminares.

$\mathrm{Na}$ Tabela 7 são apresentados os dados da média da massa suportada pela célula de carga, desvio padrão, os picos máximos e mínimos e o erro

Tabela 7. Parâmetros estatísticos obtidos no ensaio de calibração dinâmica da célula de carga.

\begin{tabular}{|c|c|c|c|c|c|c|c|c|}
\hline \multirow{2}{*}{$\begin{array}{c}\text { Massas } \\
\text { adicionadas }\end{array}$} & \multirow{2}{*}{ Médias } & \multirow{2}{*}{$\begin{array}{l}\text { Desvios } \\
\text { padrões }\end{array}$} & \multirow{2}{*}{$\begin{array}{l}\text { Picos } \\
\text { máximos }\end{array}$} & \multirow{2}{*}{$\begin{array}{l}\text { Picos } \\
\text { mínimos }\end{array}$} & \multicolumn{2}{|c|}{ Desvios } & \multicolumn{2}{|c|}{ Erros } \\
\hline & & & & & Superiores & Inferiores & Superiores & Inferiores \\
\hline & & & $-\mathrm{kg}-$ & & & & & \\
\hline 2 & 580,04 & 2,22 & 584,94 & 572,85 & 4,90 & $-7,19$ & 0,84 & $-1,24$ \\
\hline 2 & 576,76 & 2,95 & 583,26 & 571,51 & 6,49 & $-5,25$ & 1,13 & $-0,91$ \\
\hline 2 & 578,40 & 5,04 & 589,63 & 569,48 & 11,23 & $-8,91$ & 1,94 & $-1,54$ \\
\hline 1 & 573,58 & 0,60 & 575,22 & 572,53 & 1,64 & $-1,05$ & 0,29 & $-0,18$ \\
\hline 1 & 578,72 & 2,75 & 583,60 & 573,86 & 4,88 & $-4,85$ & 0,84 & $-0,84$ \\
\hline 1 & 575,49 & 1,73 & 578,55 & 572,85 & 3,07 & $-2,64$ & 0,53 & $-0,46$ \\
\hline 0,5 & 573,97 & 1,35 & 577,21 & 571,50 & 3,23 & $-2,47$ & 0,56 & $-0,43$ \\
\hline 0,5 & 578,85 & 1,68 & 581,57 & 575,19 & 2,72 & $-3,66$ & 0,47 & $-0,63$ \\
\hline 0,5 & 575,68 & 1,20 & 577,88 & 573,85 & 2,20 & $-1,83$ & 0,38 & $-0,32$ \\
\hline
\end{tabular}

superior e inferior que foram determinados utilizando-se os dados dos $5 \mathrm{~s}$ seguintes ao lançamento da massa conhecida sobre a massa de grãos, para cada adição de massa.

Como o coletor de dados foi programado para gravar 8 dados por segundo e o fluxo máximo utilizado nos ensaios do monitor de produtividade foi de $7,76 \mathrm{~kg} \cdot \mathrm{s}^{-1}$, deduz-se que o máximo incremento de leitura do fluxo de grãos no presente experimento foi de aproximadamente $1 \mathrm{~kg}$ por registro.

Os picos máximo e mínimo gerados nas adições de massa de $1 \mathrm{Kg}$ forneceram, com relação à média, desvio superior de 4,88 e inferior de 4,85, concluindo que o máximo desvio para esta adição seria de $\pm 4,85 \mathrm{~kg}$. Nesta condição o erro relativo é de $0,84 \%$, ficando os dados (exceto com adição de carga de $2,0 \mathrm{~kg}$ ), com erros menores que $1 \%$. 
Foi realizada também, uma comparação entre massas médias obtidas no intervalo dos $5 \mathrm{~s}$ após adição de carga e as massas médias padrões obtidas após a estabilização do sistema, no mesmo ensaio, para verificar os desvios das leituras. O tempo de 30s de coleta, após o lançamento da massa, foi para permitir um intervalo de pelo menos 10 s estáveis, no final do ensaio, onde não há influência dos picos e o sistema se encontrava estabilizado. Nestes últimos 10s foi calculada a massa média padrão suportada pela célula de carga, para cada adição de massa, mostradas na Tabela 8.

Tabela 8. Massa média padrão e desvio padrão para os dados coletados nos últimos 10 s no ensaio de calibração dinâmica da célula de carga.

\begin{tabular}{ccc}
\hline Massas médias & $\mathrm{kg}$ & Desvios padrões \\
\hline \multicolumn{5}{c}{580,338} & & 0,267 \\
576,695 & & 0,469 \\
578,572 & & 0,613 \\
573,792 & & 0,153 \\
578,863 & & 0,387 \\
575,545 & & 0,291 \\
574,005 & 0,237 \\
578,850 & 0,242 \\
575,711 & 0,501 \\
\hline
\end{tabular}

As médias geradas pelo intervalo dos 5 s após adição de carg a (Tabela 7), comparadas com as médias dos últimos 10s (Tabela 8), mostram que os picos máximos e mínimos tendem a um equilíbrio pois a maior diferença encontrada foi no ensaio com adição de massa de $2 \mathrm{~kg}$, obtendo uma diferença de $0,300 \mathrm{~kg}$, correspondente a $0,051 \%$ com relação a massa total.

Para melhor visualização desse efeito, é mostrado na Figura 180 gráfico obtido quando lançoutse, repentinamente, massa conhecida de $1 \mathrm{~kg}$, sobre a massa de grãos contidas no tanque de pesagem. Observa-se que o lançamento foi feito logo após o momento em que parou o fluxo de grãos do elevador para o tanque de pesagem e o coletor de dados permaneceu ligado por aproximadamente mais 30 segundos. 


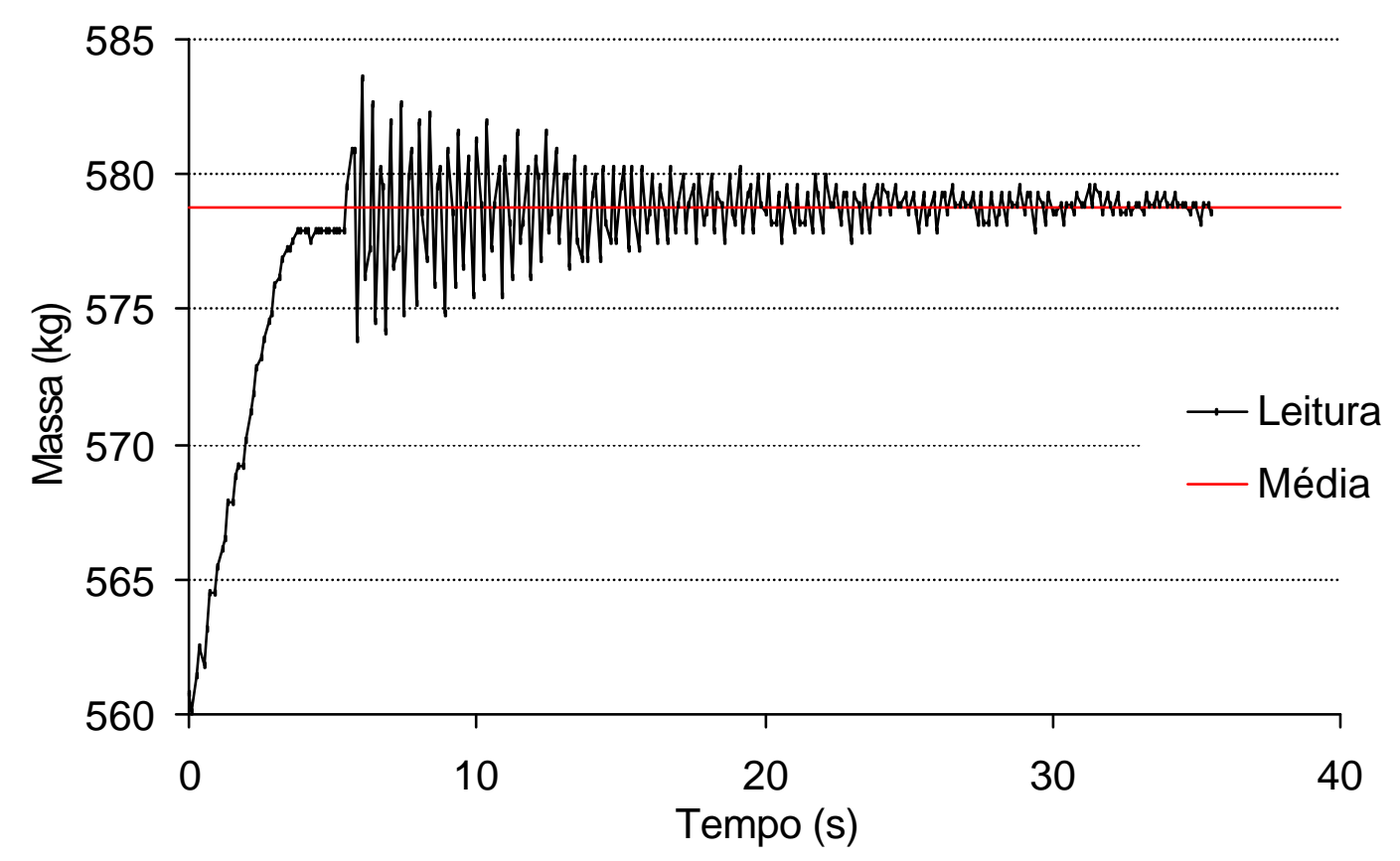

Figura 18 - Calibração dinâmica da célula de carga, com adição, de massa de $1,0 \mathrm{~kg}$ sobre a massa de grãos.

A célula de carga responde imediatamente ao sinal de entrada, fornecendo um sinal de saída e detectando variações rápidas de massa como nos ensaios realizados, mostrando-se útil para estudos dessa natureza.

\subsection{Calibração do tANQUE de ALIMENTAÇÃo}

A calibração do tanque de alimentação foi feita para se detectar a influência da altura da coluna de grãos dentro do tanque na vazão e determinar a equação de regressão que rege o comportamento da escala de abertura da comporta de seção ajustável, para o tipo de grãos utilizado no ensaio.

Devido a erros de ajustes na construção do sistema da comporta de seção ajustável, não se utilizou para cálculo da vazão a área de seção quadrada baseada no passo de rosca do eixo de acionamento da manivela. Para confiabilidade dos dados da área de seção quadrada, foram utilizados os valores médios, medidos com um paquímetro com sensibilidade de $0,05 \mathrm{~mm}$, de três leituras medidas de cada abertura da escala criada, de 1 a 10. 
Os valores de área em função da escala são apresentados no gráfico da Figura 19. De posse dos dados das áreas para as escalas de 3 a 10 foi determinada a equação da curva, para estimativa da área de abertura da comporta de seção ajustável em função da escala.

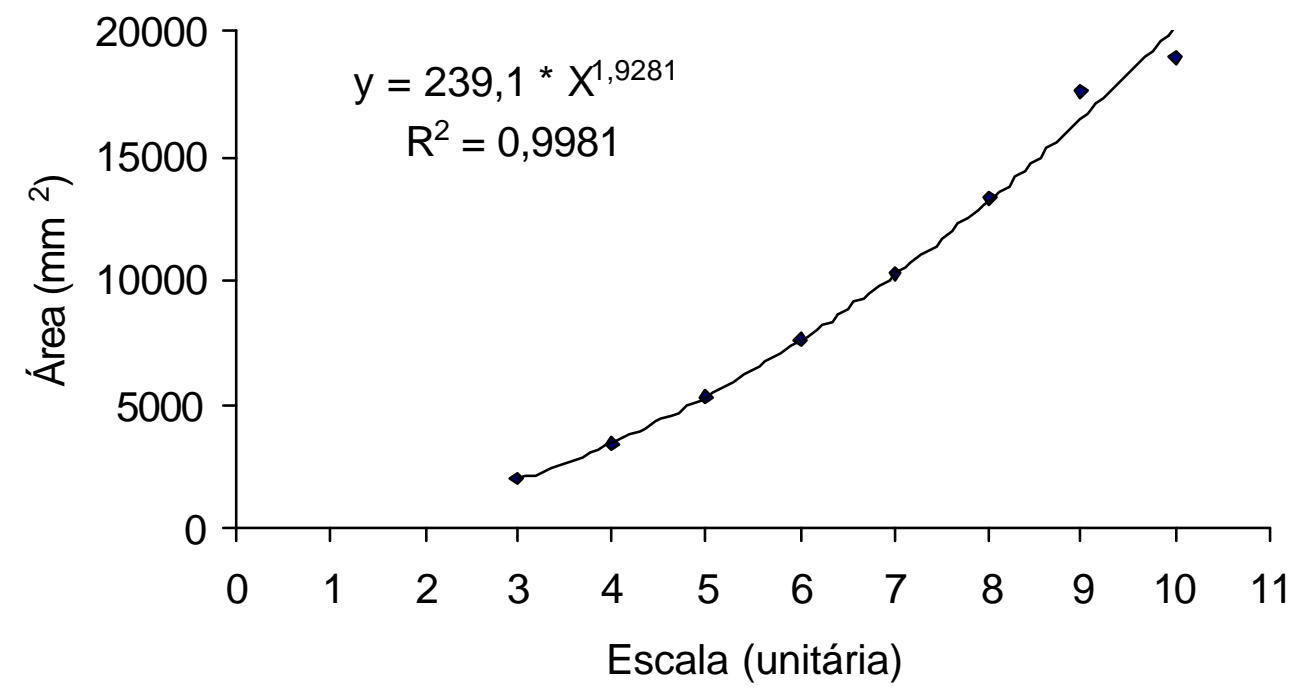

Figura 19 - Curva de calibração da área de abertura da comporta de seção ajustável do tanque alimentador, em função da escala.

Com os valores medidos das áreas de abertura da comporta, foram realizados ensaios de vazão a partir das aberturas, correspondentes aos valores de escala 2, 4, 6, 8 e 10. Na Tabela D1, em anexo, são apresentados os valores de vazões encontrados para cada abertura da comporta de seção ajustável.

Os resultados da análise estatística com delineamento no esquema fatorial $2 \times 5$ (2 alturas e 5 aberturas da comporta de seção ajustável), com 4 repetições, para verificar se havia influência da altura da coluna de grãos na taxa de fluxo de grãos de milho para diferentes aberturas da comporta de seção ajustável, são apresentados na Tabela 9. 
Tabela 9. Análise da variância dos dados de vazão de massa de grãos de milho em função da variação na seção e na coluna de grãos.

\begin{tabular}{lcrrrr}
\hline Causas de Variação & G.L. & \multicolumn{1}{c}{ S.Q. } & \multicolumn{1}{c}{ Q.M. } & \multicolumn{1}{c}{ F } \\
\hline Níveis (N) & 1 & 0,00083 & 0,00083 & 0,1214 & (n.s.) \\
Aberturas (A) & 4 & 96,65000 & 24,16250 & 3550,7000 & ** \\
Nx A & 4 & 0,02327 & 0,00582 & 0,8549 & (n.s.) \\
Resíduo & 30 & 0,20415 & 0,00681 & & \\
Total & 39 & 96,87500 & & & \\
\hline
\end{tabular}

Pela análise estatística pode-se verificar que não houve efeito significativo de altura da coluna de grãos de milho dentro do tanque alimentador para os fluxos estudados. O efeito de abertura foi, como esperado, altamente significativo e não existiram efeitos de interação entre alturas da coluna e aberturas da comporta de seção ajustável.

Para se estimar a vazão de grãos de milho em função da área de abertura da comporta de seção ajustável, foram estudados modelos de regressão, sendo sua análise apresentada na tabela 10.

Tabela 10. Regressão para vazão em função da abertura da comporta de seção ajustável.

\begin{tabular}{lcccc}
\hline Causas de variação & G.L. & S.Q. & Q.M. & F \\
\hline Regressão linear & 1 & 96,63000 & 96,63000 & 14696,58 \\
Resíduo & 38 & 0,24985 & 0,00658 & \\
Total & 39 & & & \\
\hline
\end{tabular}

Dos modelos estudados, com transformação dos dados em valores logarítmicos, o modelo linear foi o que melhor se ajustou aos dados e o resultado convertido para forma potencial é apresentado na Figura 20.

$O$ valor de $F$ para regressão linear, apresentado na Tabela 10, foi altamente significativo, mostrando que a equação apresentada na Figura 20 
estima a vazão de grãos de milho em função da abertura da comporta de seção ajustável, com $99 \%$ de confiabilidade.

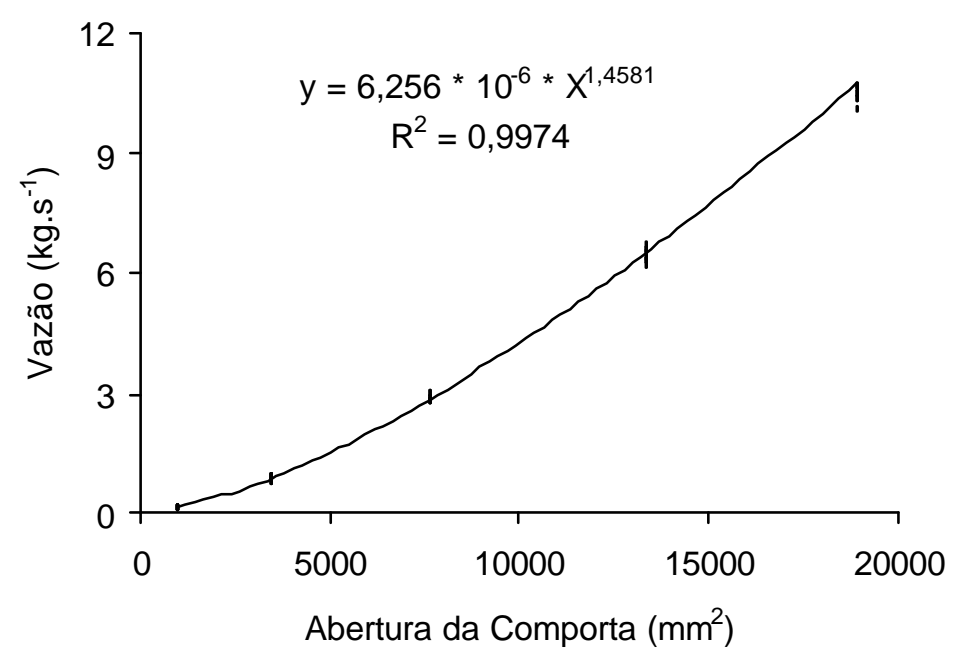

Figura 20 - Vazão para os grãos utilizados no ensaio, em função da abertura da comporta do tanque alimentador.

O tanque de alimentação, construído com comporta de seção quadrada variável, mostrourse satisfatório para fornecer uma vazão uniforme com o tempo durante os ensaios do monitor de produtividade, mesmo a baixas vazões. A equação de vazão em função da área de abertura da comporta de seção ajustável serve para simular uma determinada vazão de grãos desejada, representativa das condições de campo para comparar as leituras do monitor de produtividade com a massa sendo registrada na balança.

Para verificar como o sistema da bancada de ensaio registrou dados da balança, na saída do fluxo de grãos na parte superior do elevador, após uma alimentação de grãos constante com o tanque de alimentação, analisaram-se duas taxas de fluxo, uma baixa e outra alta. A Figura 21 mostra as curvas de massas acumuladas no tempo, registradas pela balança, e a Figura 22 mostra as curvas de taxas de fluxo ao longo do tempo para os mesmos dados, quando se manteve a comporta de seção ajustável do tanque alimentador aberta no ponto 5 da escala (área de $5324 \mathrm{~mm}^{2}$ ) e no ponto 7,5 (área de $11636 \mathrm{~mm}^{2}$ ) da escala. Os resultados evidenciam que o escoamento de grãos na comporta de 
seção ajustável era constante ao longo do tempo de ensaio, não variando com a altura da carga de milho no tanque para qualquer abertura da comporta.

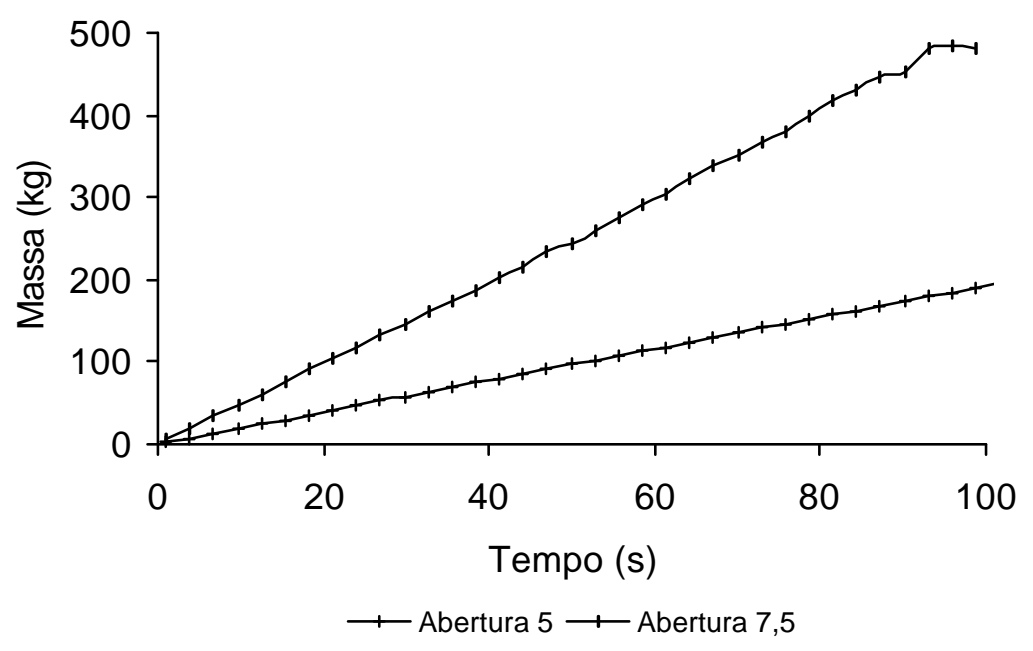

Figura 21 - Massas acumuladas de grãos de milho registradas pela balança com o sistema de alimentação da bancada sendo mantido constante para as aberturas da comporta de seção ajustável no ponto 5 e 7,5 da escala.

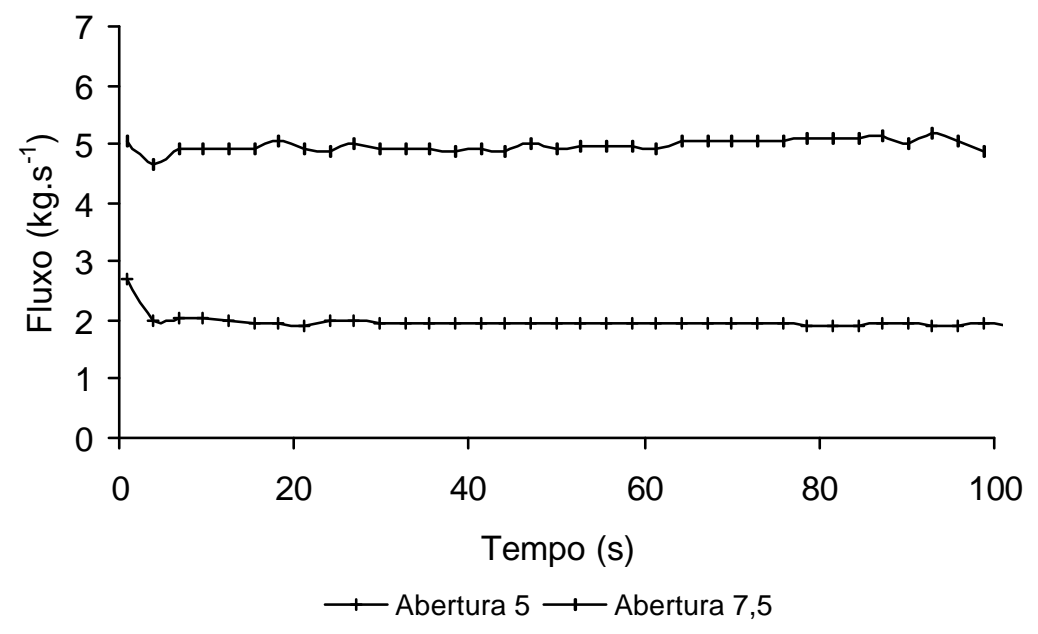

Figura 22 - Vazão de grãos de milho na comporta, registradas pela balança, para abertura da comporta no ponto 5 e 7,5 da escala. 


\subsection{Avaliação do SENSOR DE VELOCIDADE}

O sensor de velocidade $\infty \mathrm{m}$ seu imã fixado na árvore que aciona o redutor da roda dianteira da colhedora, é calibrado pelo número de voltas dado pela árvore, num espaço de cem metros. Portanto, é diretamente relacionado com o diâmetro da roda e possíveis redutores em função do local em que é instalado. Este sensor registra um pulso elétrico por volta do imã preso ao elemento girante.

Para determinar a curva de calibração do sensor de velocidade, simulourse vários valores de voltas na roda neste espaço, anotando-se a cada vez a constante de velocidade gerada no monitor. Dos dados coletados foi possível gerar a curva de calibração do sensor de velocidade, apresentada na Figura 23.

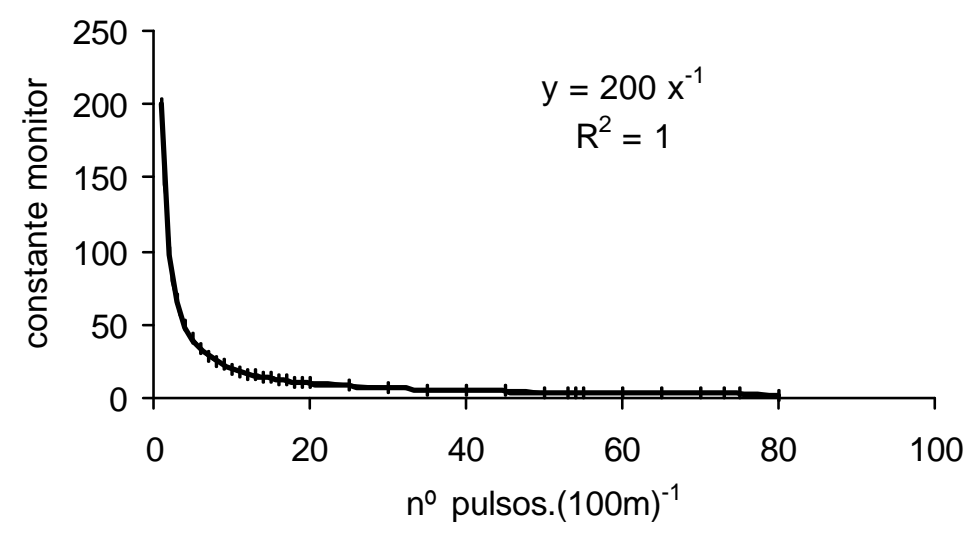

Figura 23 - Curva de calibração da constante do sensor de velocidade.

Observando-se a equação do gráfico, conclui-se que a calibração do sensor de velocidade é uma relação direta da constante 200 pelo número de pulsos. Sabendo-se que a calibração é gerada pelo número de pulsos elétricos no espaço de $100 \mathrm{~m}$, pode-se inferir que o sensor lê distância por pulsos. Para cálculo da velocidade, o monitor necessita registrar o tempo gasto por unidades de pulsos.

Portanto, a equação que calcula a velocidade da colhedora é dada por: 


$$
V=\frac{f c v^{*} n}{2000}
$$

onde:

$V=$ velocidade da colhedora em $\mathrm{km} \cdot \mathrm{h}^{-1}$;

$f C V=$ fator de constante de velocidade;

$n=$ pulsos por hora.

Os dados demonstrados na Tabela 11, são referentes ao ensaio do sensor de velocidade feito pela comparação entre a velocidade mostrada no visor do monitor e a velocidade calculada quando se percorreu uma distância de $100 \mathrm{~m}$ em um tempo conhecido, com velocidade constante. Neste ensaio o monitor foi alimentado com dois diferentes valores de constantes de velocidade, previamente, encontradas em ensaio de calibração. Foram encontradas duas constantes devido ao sensor ler apenas um pulso, por volta da roda, sendo que, dependendo de seu posicionamento inicial na árvore com relação ao imã que gerava o pulso de leitura do sensor, este poderia executar uma leitura a menos, ou uma a mais. Foram efetuadas quatro leituras a velocidade constante, num percurso de 100m, para as constantes de velocidade 3,774 e 3,704.

Tabela 11. Erros médios entre leituras de velocidades calculadas e leituras de velocidades mostradas no monitor de produtividade.

\begin{tabular}{|c|c|c|c|c|c|c|}
\hline & \multicolumn{3}{|c|}{ Constante 3,774} & \multicolumn{3}{|c|}{ Constante 3,704} \\
\hline & \multicolumn{2}{|c|}{ Velocidades } & \multirow{2}{*}{$\begin{array}{l}\text { Erros } \\
\text { relativos }\end{array}$} & \multicolumn{2}{|c|}{ Velocidades } & \multirow{3}{*}{$\begin{array}{c}\text { Erros } \\
\text { relativos } \\
\%\end{array}$} \\
\hline & Calculadas & Lidas & & Calculadas & Lidas & \\
\hline & \multicolumn{2}{|c|}{$\mathrm{km} \cdot \mathrm{h}^{-1}$} & $\%$ & \multicolumn{2}{|c|}{$\mathrm{km} \cdot \mathrm{h}^{-1}$} & \\
\hline & 5,85 & 6,00 & 2,56 & 5,32 & 5,30 & $-0,38$ \\
\hline & 7,31 & 7,40 & 1,23 & 6,24 & 6,30 & 0,96 \\
\hline & 7,35 & 7,50 & 2,04 & 6,73 & 6,70 & $-0,45$ \\
\hline & 8,92 & 9,00 & 0,90 & 9,89 & 10,00 & 1,11 \\
\hline Erros médios & & & 1,68 & & & 0,31 \\
\hline
\end{tabular}

A regressão dos dados entre leituras lidas no monitor em função das leituras reais, mostra o mesmo coeficiente de determinação de 0,9996 para as constantes de 3,774 e 3,074 . 
Os valores de erros médios relativos encontrados mostram o quanto é importante que se faça uma leitura correta da marcação da distância em campo, pois o incremento de apenas um pulso do sensor de velocidade na calibração, ou seja, no caso deste ensaio uma volta da roda, acarretou um aumento no erro médio de $0,31 \%$ para $1,68 \%$, para uma variância de 0,576 e 0,703, respectivamente. Em condições normais de uma colhedora, em que existe um redutor entre o eixo e a roda, o número de pulsos será bem maior, implicando em erro menor. O sensor de velocidade do monitor apresentou uma boa acurácia, quando bem calibrado apresentando erro médio relativo de $0,31 \%$.

\subsection{MONITOR DE PRODUTIVIDADE}

\subsubsection{Obtenção do intervalo de tempo por dado registrado}

A variável experimental utilizada para estudar a eficiência do monitor de produtividade foi o fluxo de massa, em toneladas por tempo de registro do monitor e que foi transformado em $\mathrm{kg}^{-1} \mathrm{~s}^{-1}$. Exemplo dos dados dos arquivos gerados pelo monitor de produtividade ensaiado são mostrados no Anexo B.

As primeiras tentativas de estudar os dados registrados pelo monitor, feitas calibrando-o para fornecer um dado por segundo, foram frustradas. Observou-se que o monitor, provavelmente, possui características próprias do tempo de registro de dados, coletando dados cujo tempo varia de arquivo para arquivo, possivelmente, devido a ausência de sinal de GPS.

Como era importante se conhecer o intervalo de tempo entre coleta dos dados para poder traçar os gráficos de taxa de fluxo em função do tempo, buscou-se avaliá-lo através de ensaios, quando o elevador ficava em funcionamento por um longo intervalo de tempo conhecido, sem transporte de grãos (taliscas vazias). Dos diversos arquivos gerados em cada ensaio, foram contados os números de linhas de registros durante o período do ensaio. Com estes dados foi possível obter informações do intervalo de tempo para cada 
dado coletado. Os dados são apresentados na Tabela 12 e observa -se que o monitor registrou, em média, um dado a cada 2,81s.

Tabela 12. Intervalo de tempo de cada dado gerado pelo monitor ensaiado.

\begin{tabular}{cccc}
\hline $\begin{array}{c}\text { Arquivos } \\
\left(\mathrm{n}^{\circ}\right)\end{array}$ & $\begin{array}{c}\text { Linhas de dados } \\
\text { (Quantidade) }\end{array}$ & $\begin{array}{c}\text { Tempos } \\
(\mathrm{s})\end{array}$ & $\begin{array}{c}\text { Relações } \\
(\mathrm{s} / \text { dado })\end{array}$ \\
\hline 32 & 87 & 238 & 2,74 \\
37 & 213 & 600 & 2,82 \\
38 & 213 & 600 & 2,82 \\
47 & 210 & 600 & 2,86 \\
50 & 105 & 300 & 2,86 \\
52 & 214 & 600 & 2,80 \\
Médias & & & 2,81 \\
\hline
\end{tabular}

A balança registrava um dado a cada $0,125 \mathrm{~s}$. Para construir os gráficos dos dados de massa de grãos medidos na balança e no monitor versus tempo, os valores de registro da balança foram somados a intervalos de tempo de 2,875s, que é o valor múltiplo de 0,125 mais próximo de 2,810s. A soma desta massa era dividida por $2,875 \mathrm{~s}$, gerando dados em $\mathrm{kg}_{\mathrm{s}} \mathrm{s}^{-1}$.

Posteriormente, percebeurse que a média de tempo de 2,81s não era mantida pelo monitor quando transportando grãos através do elevador com intervalos de tempo, entre 54 e 140 s, bem menores que aqueles apresentados na Tabela 12. Portanto, optourse por fazer a estimativa do intervalo de tempo entre dados gerados pelo monitor, através do tempo total de ensaio registrado pelo programa de coleta da balança dividido pela quantidade de dados gerados pelo monitor em cada arquivo do ensaio. $O$ intervalo de tempo médio entre dados do monitor de todos os ensaios realizados foi de 2,63 s, variando de 2,36 a 2,80 s.

Informações do fabricante indicam que o monitor deveria registrar um dado a cada distância linear igual àda largura da plataforma da colhedora, pois ele registra um dado para cada unidade de área quadrada, cujo lado corresponde àlargura da plataforma. Portanto, o tempo de registro de um dado no monitor deve ser função da velocidade da colhedora e da largura da 
plataforma. Assim, tendo-se uma plataforma de $4 \mathrm{~m}$ deslocando-se a uma velocidade constante de $1,67 \mathrm{~m} \cdot \mathrm{s}^{-1}$, obtêm-se um dado a cada $2,40 \mathrm{~s}$.

Embora, o intervalo de tempo de registro de dados da balança $(2,88 \mathrm{~s})$, seja diferente daqueles do monitor (de 2,36 a 2,80s), os dados puderam ser perfeitamente comparados em gráficos porque foram convertidos para quilogramas por segundo. O primeiro dado gerado pelo arquivo do monitor era considerado como tendo sido obtido no primeiro segundo registrado pela balança. As defasagens de leituras do sensor de fluxo de volume em relação às leituras da balança eram em torno de 1,50s. Essa defasagem inicial era devido à diferença de tempo entre a massa de grãos passando no sensor até ser pesado na balança e o tempo de início do intervalo de coleta de dados do monitor, a partir do momento que a chave era ligada, variando de 0,00 a 2,78s. O valor médio do fluxo calculado a partir da leitura da balança a cada 2,88s era feito baseado nos 2,88s anteriores, o que acarreta um recuo de 1,44s.

Ainda, analisando-se a equação que calcula a velocidade da colhedora (eq. 8), constata-se que a velocidade de deslocamento da colhedora é função do número de pulsos na unidade de tempo e do fator de calibração de velocidade ( $f c v)$ que, por sua vez, são funções do diâmetro da roda e possíveis redutores. Portanto, quando instalado em uma colhedora, uma vez determinada a constante de calibração, o número de pulsos gerados no monitor pelo sensor de velocidade será função apenas da velocidade imposta àcolhedora.

Para a simulação da velocidade na bancada de ensaio, em que a largura da plataforma era fixada atribuindo-se um valor desejado e que o sensor de velocidade era instalado na árvore do condutor helicoidal da bancada, com rotação constante, o número de pulsos do sensor de velocidade num intervalo de tempo era fixo e, portanto, a velocidade gerada pelo sensor era constante. Assim, ao atribuir-se diferentes valores do fator de calibração de velocidade no monitor, simulava-se diferentes velocidades.

Utilizando-se este procedimento, aliado ao conhecimento de que a colhedora gera um dado cada vez que percorre a distância igual à largura da 
plataforma, foram gerados dados de intervalo de tempo entre leitura no monitor, para comparar com aqueles dados obtidos dividindo-se o tempo total de ensaio pelo número de linhas (registros) geradas pelo monitor, como descrito anteriormente, e são apresentados na Tabela 13.

Tabela 13. Comparação entre intervalo de tempo por registro teórico e calculado para os dados gerados no monitor de produtividade em algumas situações simuladas dos parâmetros de colheita no monitor.

\begin{tabular}{|c|c|c|c|c|c|c|c|c|}
\hline $\begin{array}{c}\text { № } \\
\text { Arquivos }\end{array}$ & $\begin{array}{l}\text { Sinais } \\
\text { GPS }\end{array}$ & $\begin{array}{l}\text { Larguras } \\
\text { da } \\
\text { Plataforma } \\
\text { (m) }\end{array}$ & $\begin{array}{c}\text { Tempos } \\
\text { de } \\
\text { Coleta } \\
\text { (s) }\end{array}$ & $\begin{array}{l}\text { Fatores de } \\
\text { calibração } \\
\text { da } \\
\text { velocidade }\end{array}$ & $\begin{array}{c}\text { Velocidades } \\
\text { simuladas } \\
\left(\mathrm{m} \cdot \mathrm{s}^{-1}\right)\end{array}$ & $\begin{array}{l}\text { № de } \\
\text { dados }\end{array}$ & $\begin{array}{l}\text { Intervalos } \\
\text { de tempo } \\
\text { por } \\
\text { registro } \\
\text { teórico } \\
\text { (s) }\end{array}$ & $\begin{array}{l}\text { Intervalos } \\
\text { de tempo } \\
\text { por } \\
\text { registro } \\
\text { calculado } \\
\text { (s) }\end{array}$ \\
\hline 65 & $b^{*}$ & 4,00 & 60 & 0,45 & 1,67 & 24 & 2,40 & 2,50 \\
\hline 66 & b & 1,67 & 60 & 0,45 & 1,67 & 35 & 1,00 & 1,71 \\
\hline 67 & b & 1,00 & 60 & 0,27 & 1,00 & 37 & 1,00 & 1,62 \\
\hline 68 & $b$ & 6,00 & 60 & 1,62 & 6,00 & 37 & 1,00 & 1,62 \\
\hline 69 & $b$ & 6,00 & 60 & 1,62 & 6,00 & 36 & 1,00 & 1,67 \\
\hline 70 & b & 4,00 & 60 & 0,45 & 1,67 & 24 & 2,40 & 2,50 \\
\hline 71 & b & 6,00 & 60 & 1,62 & 6,00 & 19 & 1,00 & 3,16 \\
\hline 74 & $b$ & 6,00 & 60 & 0,45 & 1,67 & 16 & 3,60 & 3,75 \\
\hline 75 & $b$ & 4,00 & 60 & 0,45 & 1,67 & 24 & 2,40 & 2,50 \\
\hline 76 & $b$ & 4,00 & 60 & 0,45 & 1,67 & 24 & 2,40 & 2,50 \\
\hline 77 & jup2 & 1,67 & 60 & 0,45 & 1,67 & 20 & 1,00 & 3,00 \\
\hline 78 & jup2 & 1,00 & 60 & 0,45 & 1,67 & 23 & 0,60 & 2,61 \\
\hline 79 & jup2 & 0,17 & 60 & 0,45 & 1,67 & 26 & 0,10 & 2,31 \\
\hline 80 & $\mathrm{~b}$ & 0,17 & 60 & 0,45 & 1,67 & 26 & 0,10 & 2,31 \\
\hline 81 & jup2 & 0,17 & 60 & 0,45 & 1,67 & 62 & 0,10 & 0,97 \\
\hline 82 & jup2 & 4,00 & 60 & 0,45 & 1,67 & 24 & 2,40 & 2,50 \\
\hline 83 & jup2 & 0,10 & 60 & 0,45 & 1,67 & 27 & 0,06 & 2,22 \\
\hline 84 & jup2 & 4,00 & 60 & 0,45 & 1,67 & 24 & 2,40 & 2,50 \\
\hline
\end{tabular}

${ }^{*}$ Nesta configuração o monitor de produtividade simula valores de latitude e longitude.

Analisando-se as variáveis apresentadas na Tabela 13, observa-se que os dados calculados de tempo por registro nas duas metodologias, na tentativa de registrar um dado por segundo, mostraram diferenças significativas. Quando se simulou uma plataforma de $4 \mathrm{~m}$ de largura, a uma velocidade de $1,67 \mathrm{~m} \cdot \mathrm{s}^{-1}$, o sistema apresentou a menor diferença entre as duas metodologias.

Para demonstração das diferenças do intervalo de tempo entre coleta de dados feita a partir da divisão do tempo total do ensaio pelo valor total de 
linhas de dados gerados no monitor e pelo tempo fixo teórico do monitor a partir do deslocamento linear percorrido pela colhedora, foi elaborado o gráfico da Figura 24, demonstrativo da leitura do sensor para estas duas situações e mais os dados da balança, mostrando o deslocamento da curva. Nesse caso houve uma variação acidental no fluxo de grãos, em torno do tempo "20s", o que permite uma avaliação visual da acurácia do sistema.

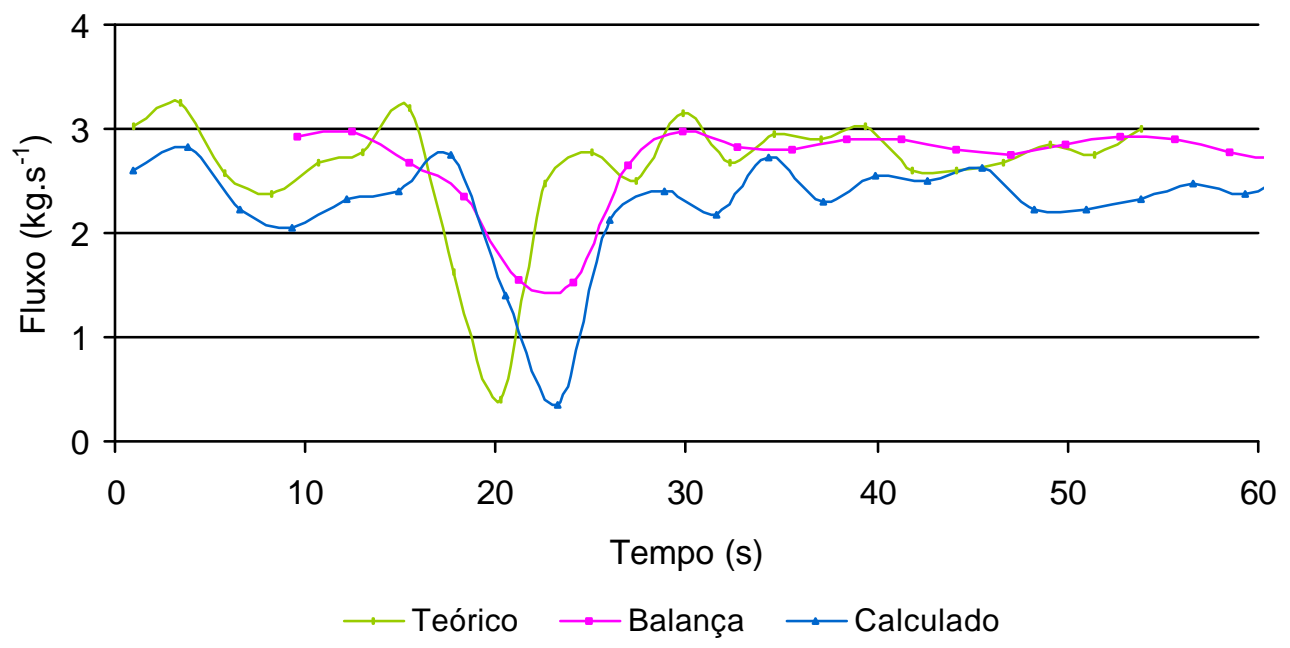

Figura 24 - Defasagem de tempo quando utilizando intervalos de tempo, entre dados gerados no monitor, teórico e calculado, comparados com aqueles da balança, para simulação da colhedora com plataforma de $4 \mathrm{~m}$ e velocidade de deslocamento de $1,67 \mathrm{~m} . \mathrm{s}-1$.

\subsubsection{Calibração operacional do monitor de produtividade}

$\mathrm{Na}$ calibração operacional, realizada seguindo metodologia descrita no manual do fabricante, foram utilizados 6 diferentes fluxos crescentes de grãos passando no elevador a intervalos regulares de 17s e o erro médio apresentado pelo monitor de produtividade foi de $1,85 \%$ em relação à balança. $O$ cálculo deste erro médio foi realizado pela diferença percentual da massa registrada no monitor de produtividade em relação à registrada na balança. Este foi o erro médio de três procedimentos de calibração, feitos seqüencialmente, com o mesmo fator de calibração dos grãos, igual a 11,1 , utilizado para todos os 
ensaios realizados neste trabalho. O exemplo de um gráfico de calibração é mostrado na Figura 25. Para verificação da calibração foi realizado o processo inverso com relação æ̀ taxas de fluxo aplicadas, rodando o sistema do maior para o menor fluxo. Este apresentou um erro médio de 2,97\%, mostrando baixo efeito de histerese do sistema.

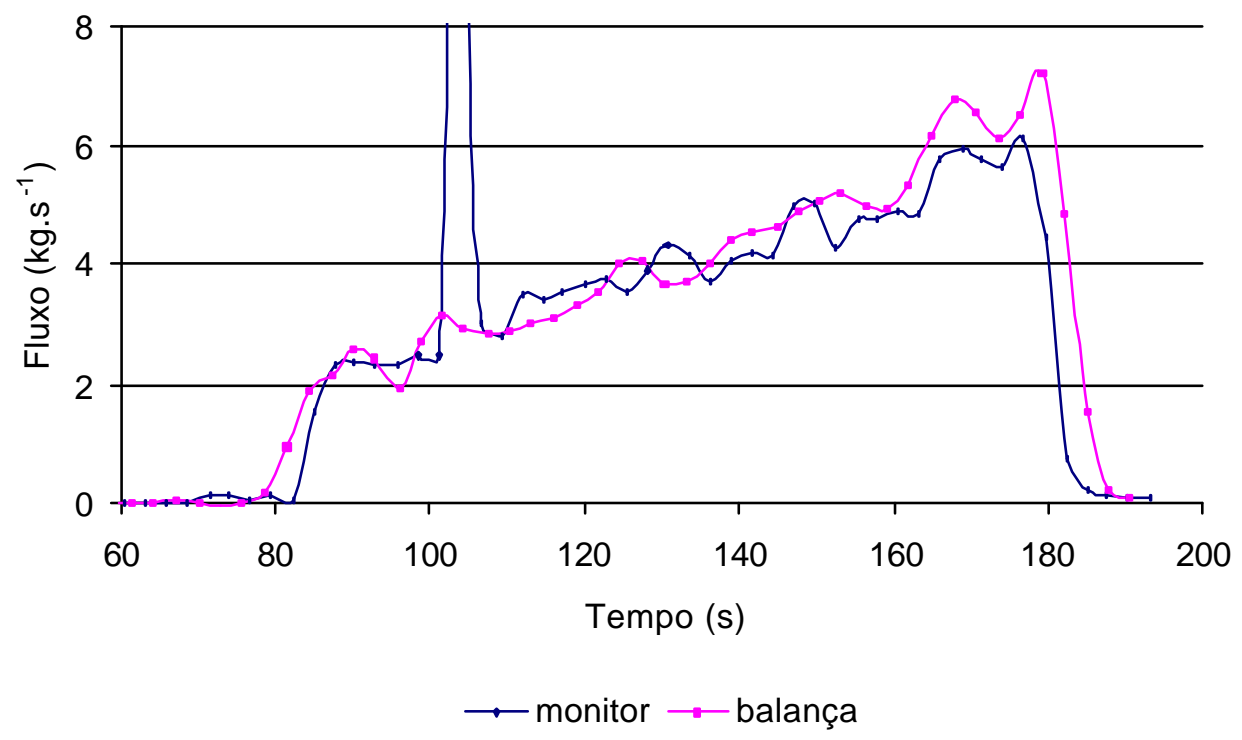

Figura 25 - Exemplo de um dos gráficos obtidos na realização da calibração do sistema, utilizando-se de 6 fluxos crescentes de grãos.

Quando se terminou a realização de todos os ensaios do monitor de produtividade no presente projeto, foram rodados ensaios com os mesmos procedimentos do ensaio de calibração do sistema, com as mesmas variações nas aberturas da comporta de seção ajustável, para verificar se este ainda permanecia calibrado. Este ensaio mostrou um erro médio de totalização do ensaio de $-2,04 \%$ e $-3,53 \%$, para as duas averiguações realizadas.

\subsubsection{Análise dos fatores de corte de luz}

O sensor de fluxo de volume mede a quantidade de grãos transportados pelo elevador proporcionalmente ao facho de luz bloqueado pelos grãos e taliscas, que é a percentagem de corte de luz (PC - como mencionado pelo manual do fabricante) lida pelo monitor. A PC é uma característica do 
monitor de produtividade, sendo que, para cada modelo de máquina colhedora existe uma curva de calibração de PC específica. A curva é corrigida para o produto sendo processado, através do fator de calibração do monitor que desloca a curva para cima ou para baixo para melhor se ajustar àmassa sendo processada pelo elevador.

Após a calibração do monitor de produtividade, os valores de PC utilizados foram os apresentados na Tabela 14.

Tabela 14. Valores de percentagens de corte de luz (PCt a PC5) utilizados durante os ensaios, registrado pelo monitor de produtividade.

\begin{tabular}{cccccc}
\hline PCt $^{*}$ & PC1 & PC2 & PC3 & PC4 & PC5 \\
\hline 22,50 & 28,29 & 32,60 & 39,79 & 46,26 & 52,62 \\
\hline
\end{tabular}

* PCt é o percentagem de corte de luz relativo àtara do elevador.

Com adição das chapas retangulares nas mãos francesas das taliscas do elevador, a tara do sistema alterou. Antes de se colocar as chapas para encobrir as mãos francesas, a percentagem de corte de luz era em torno de 7,80 a $12,48 \%$. Após a colocação das chapas observou um aumento dos valores de corte de luz para em torno de 27,12 a 31,96\%. Este resultado é razoável, visto que a distância entre taliscas era de aproximadamente $0,16 \mathrm{~m}$, e as chapas mediam $0,04 \mathrm{~m}$, que corresponde a uma cobertura de $24,37 \%$.

Durante os ensaios realizados com o elevador na posição padrão, sem inclinação transversal, foram anotados valores da PC, lidos no visor do monitor durante a realização de cada um dos ensaios de fluxo constante, tirando-se a média dos valores da PC, para as 3 repetições de cada taxa de fluxo, referente a uma dada abertura da comporta de seção ajustável. Cada uma destas PCs era referente a um determinado fluxo de grãos gerado pelo monitor e sendo aferido pela balança. $O$ gráfico da Figura 26 foi construído dos valores médios da PC com os valores médios, estimados pelo monitor, da quantidade de produto passando pelo sensor nos respectivos ensaios e para efeito de 
comparação, da PC com os valores médios medidos pela balança, que seria a medida ideal a ser realizada pelo monitor para cada PC.

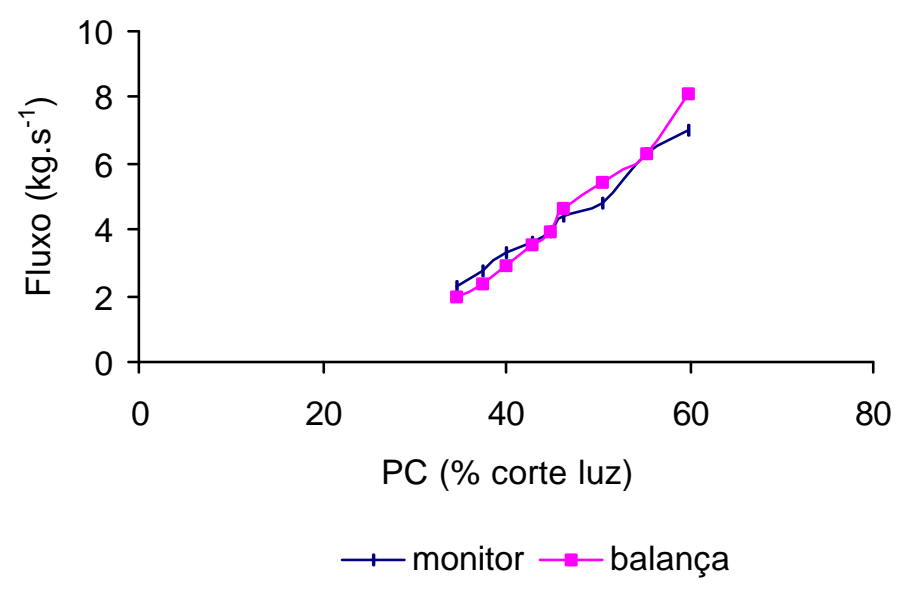

Figura 26 - Valores de percentagem de corte de luz (PC) versus fluxo de grãos de milho estimados pelo monitor e registrados pela balança.

Analisando o gráfico da Figura 26, observa-se que as linhas dos valores da PC referente aos fluxos relacionados à balança e ao monitor se cruzam, mostrando uma tendência de desvios acima e abaixo do valor de fluxo médio da calibração, em torno de $4 \mathrm{~kg} \cdot \mathrm{s}^{-1}$. Considerando que a balança é o sistema de medida padrão, deduz-se que o monitor sobreestima valores abaixo da percentagem de corte de luz em torno de 45 e subestima acima desse valor. $O$ ideal seria que as linhas fossem paralelas e coincidentes.

\subsection{Dados do Ensaio Principal}

\subsubsection{Ensaio com taxa de fluxo constante}

Os ensaios foram realizados com o elevador colocado, na condição longitudinal formando um ângulo de $67,5^{\circ} \mathrm{com}$ a horizontal e os gráficos de uma das 3 repetições dos 15 tratamentos realizados para taxas de fluxo constantes, são apresentados nas Figuras 27, 28 e 29, para as três condições de inclinações transversais do elevador. 


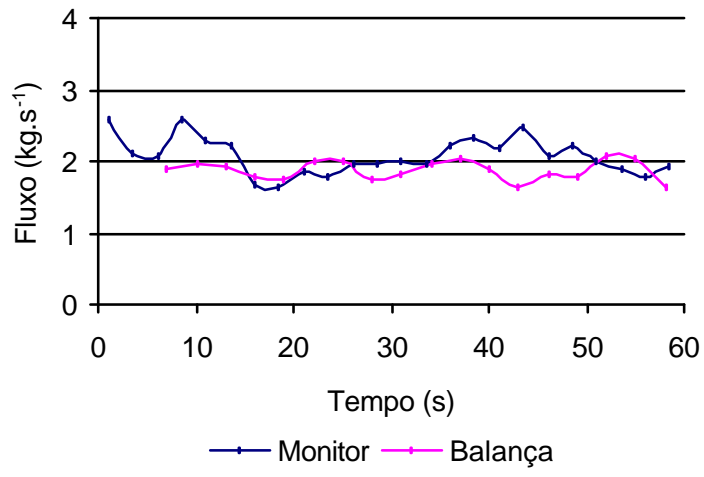

(a)

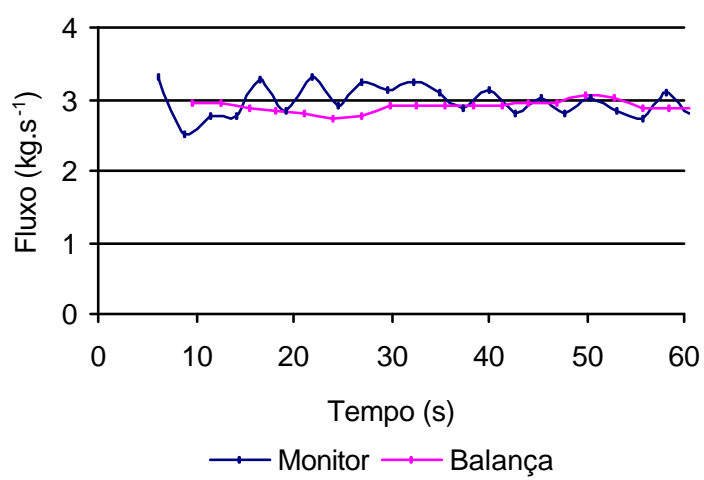

(c)

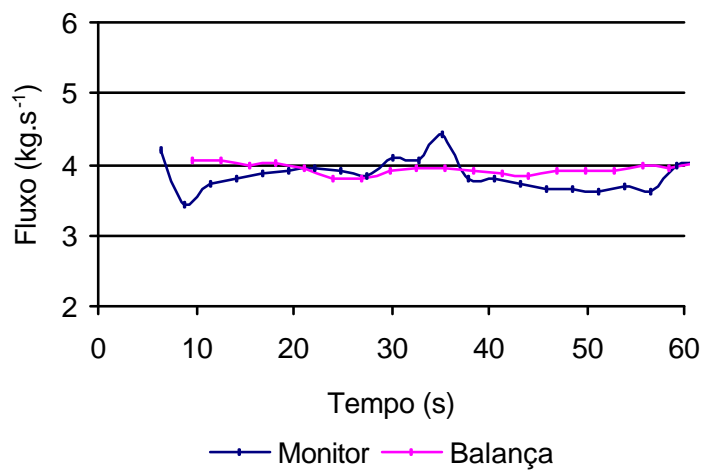

(e)

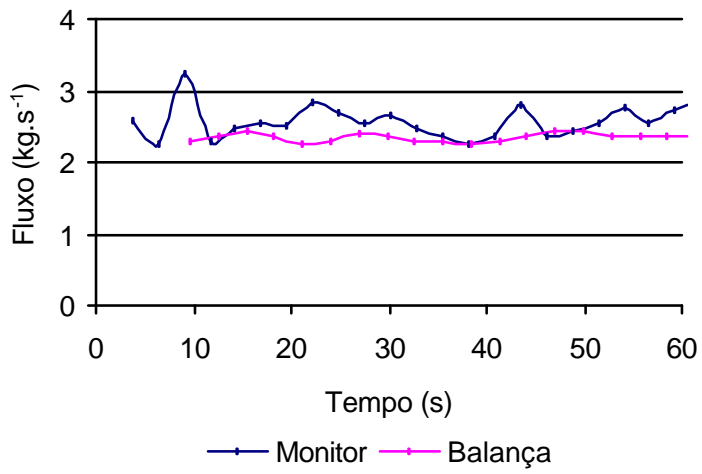

(b)

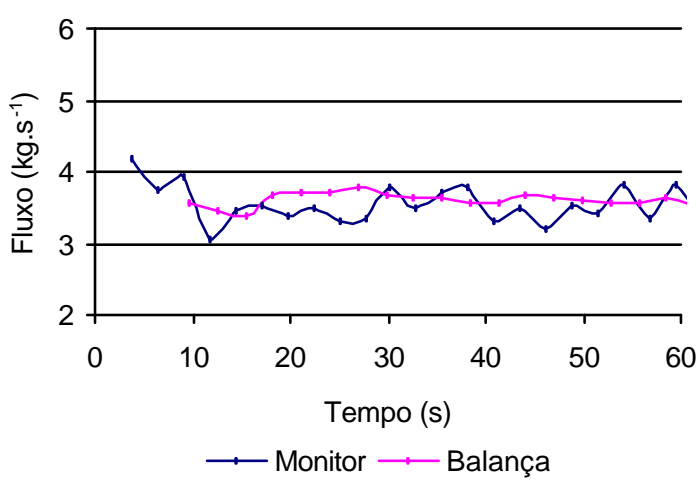

(d)

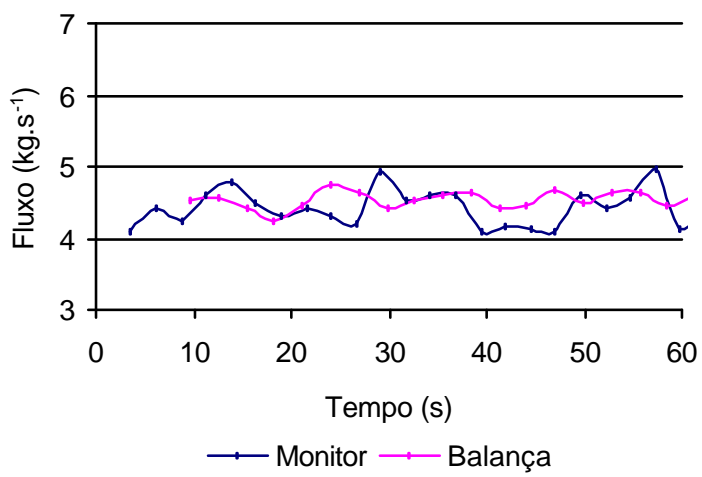

(f)

Figura 27 - Taxas constantes de fluxos de grãos para o elevador transversalmente em nível, referentes a uma das repetições do ensaio, para abertura da comporta de seção ajustável nos pontos de regulagem de escala (a) 5,0, (b) 5,5, (c) 6,0, (d) 6,5, (e) 6,75 e (f) 7,0. 


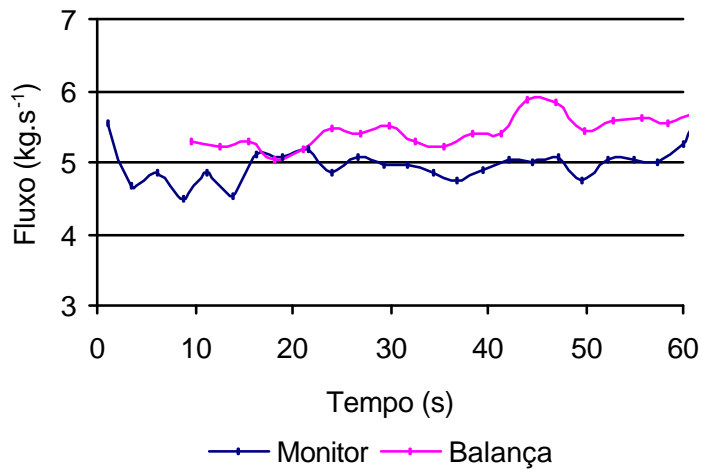

(a)

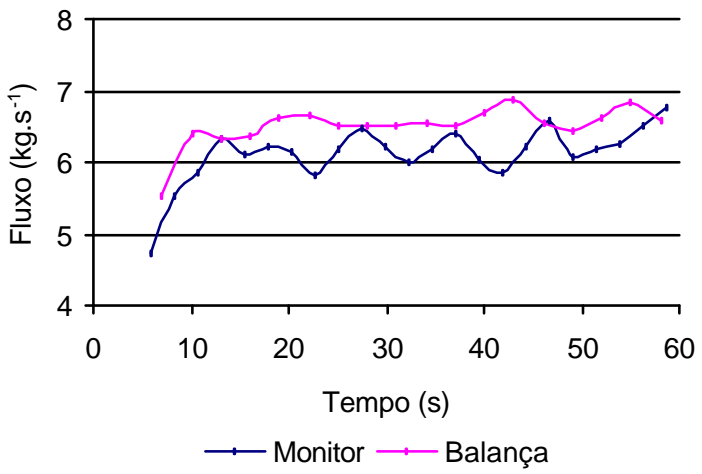

(b)

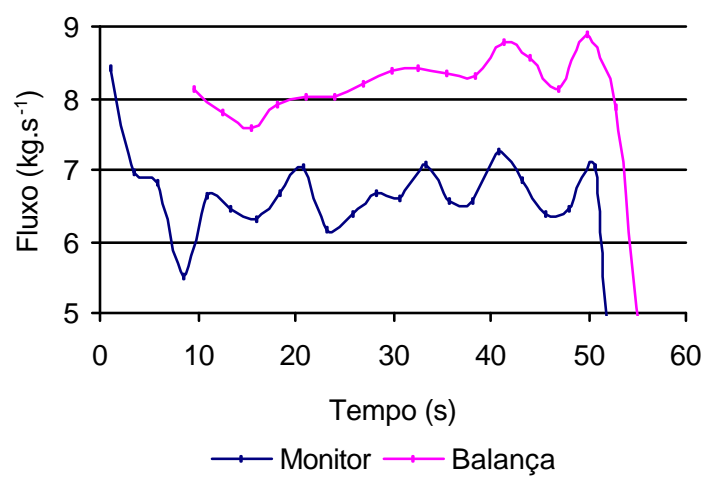

(c)

Figura 28 - Taxas constantes de fluxos de grãos para o elevador transversalmente em nível, referentes a uma das repetições do ensaio, para abertura da comporta de seção ajustável nos pontos de regulagem de escala (a) 7,5, (b) 8,0 e (c) 8,5. 


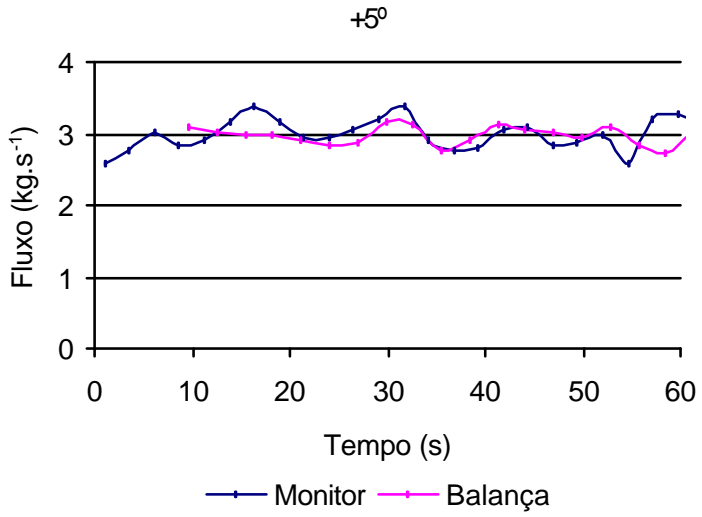

(a)

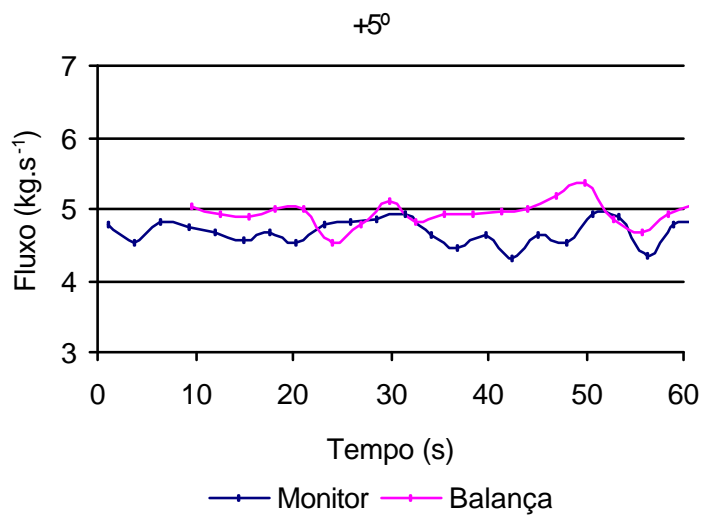

(c)

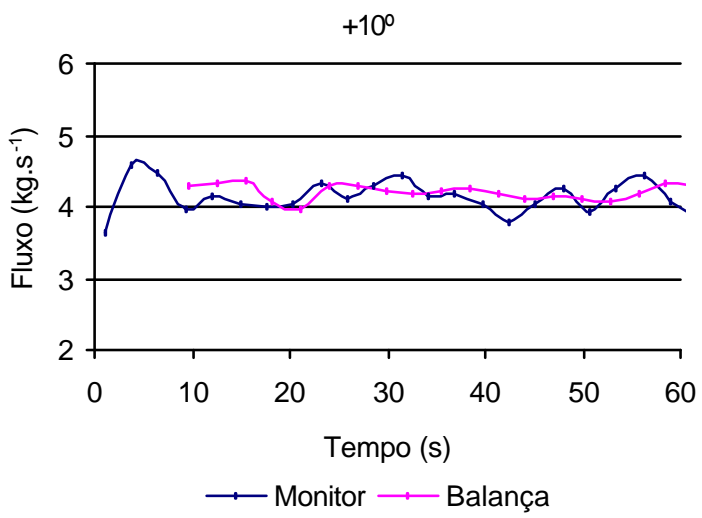

(e)

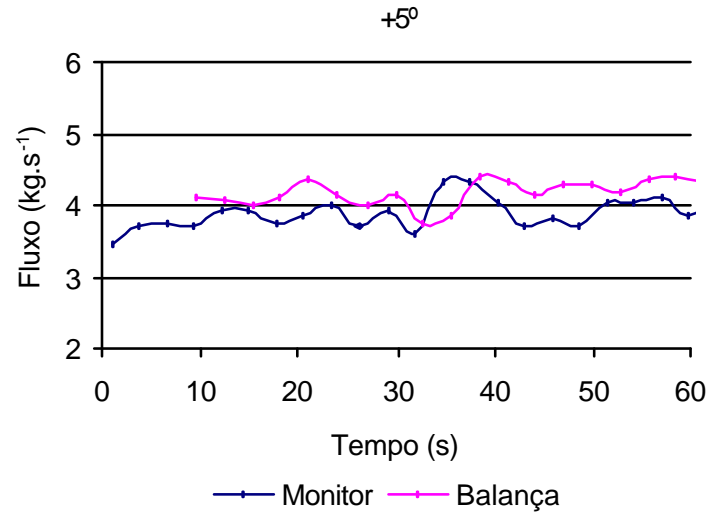

(b)

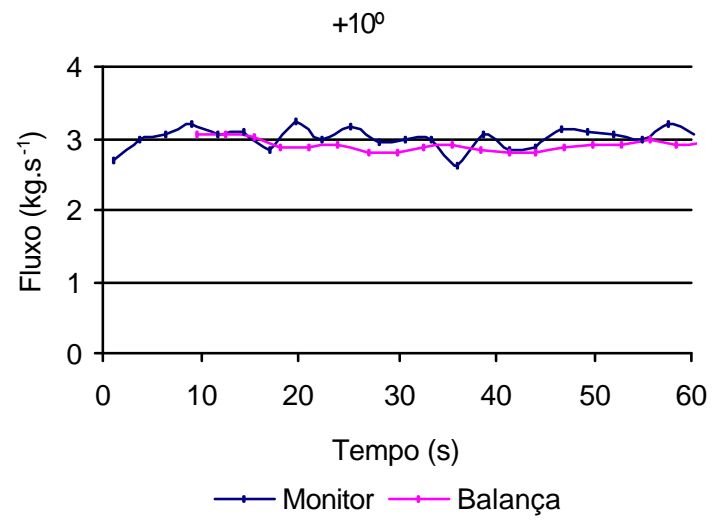

(d)

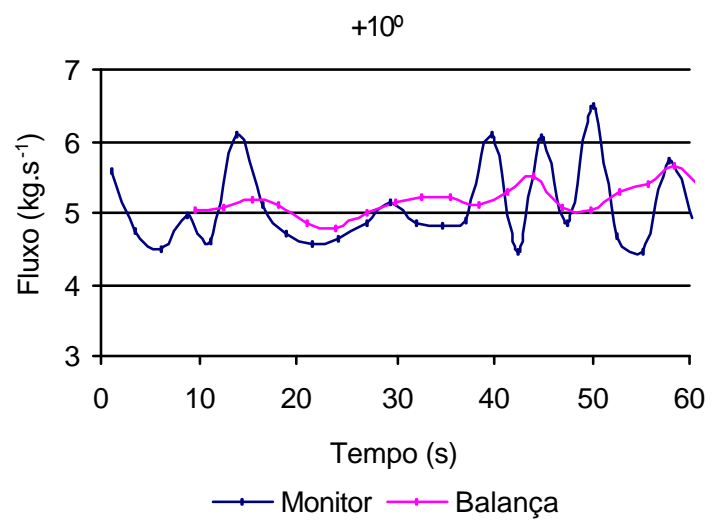

(f)

Figura 29 - Taxas constantes de fluxos de grãos, referentes, a uma das repetições do ensaio, para abertura da comporta de seção ajustável nos pontos de regulagem de escala (a) 6,0, (b) 7,0 e (c) 7,5 para inclinação transversal do elevador $+5^{\circ}$ e (d) 6,0 , (e) 7,0 e (f) 7,5 para inclinação transversal do elevador $+10^{\circ}$. 
Analisando-se as Figuras 27 a 29, pode-se observar que as leituras dos fluxos de grãos, tanto para o monitor como para a balança, tendem a permanecer constantes durante o período de ensaio.

Para realização dos ensaios a calibração do monitor de produtividade foi realizada segundo recomendações do fabricante, acumulando no monitor todos os grãos escoados para o tanque de pesagem e levando em consideração o tempo de enchimento e esvaziamento do elevador, enquanto que nos ensaios do monitor de produtividade com taxas de fluxo constantes e variadas, os fluxos nesses tempos não entraram nas análises.

Os dados médios obtidos a partir de ensaios realizados com grãos de milho na bancada de ensaio, para análises de fluxos constantes para as 3 condições de inclinações transversais com três alimentações diferentes através das aberturas da comporta de seção ajustável e mais seis valores de aberturas, para a posição do elevador transversalmente em nível, são apresentadas na Tabela 15. 
Tabela 15. Valores de dados médios gerados pelos programas PDmon-1.0 e PDbal-1.0 dos ensaios com fluxos constantes.

\begin{tabular}{|c|c|c|c|c|c|c|c|c|c|c|}
\hline \multirow[b]{2}{*}{$\begin{array}{l}\text { Número } \\
\text { Arquivo } \\
\text { monitor }\end{array}$} & \multirow[b]{2}{*}{$\begin{array}{l}\text { Inclinação } \\
\text { Elevador }\end{array}$} & \multirow[b]{2}{*}{$\begin{array}{l}\text { Escala da } \\
\text { comporta }\end{array}$} & \multicolumn{3}{|c|}{ DADOS BALANÇA } & \multicolumn{4}{|c|}{ DADOS MONITOR } & \multirow[b]{2}{*}{$\begin{array}{l}\text { Erro } \\
\text { relativo } \\
(\%)\end{array}$} \\
\hline & & & $\begin{array}{c}\text { Massa } \\
\text { por } \\
\text { ensaio } \\
(\mathrm{kg})\end{array}$ & $\begin{array}{l}\text { Tempo } \\
\text { ensaio } \\
\text { (s) }\end{array}$ & $\begin{array}{c}\text { Fluxo } \\
\text { balança } \\
\left(\mathrm{kg} \cdot \mathrm{s}^{-1}\right)\end{array}$ & $\begin{array}{c}\text { Massa } \\
\text { por } \\
\text { ensaio } \\
(\mathrm{kg})\end{array}$ & $\begin{array}{c}\text { Número } \\
\text { de } \\
\text { registros }\end{array}$ & $\begin{array}{l}\text { Intervalo } \\
\text { entre } \\
\text { registros } \\
\text { (s) }\end{array}$ & $\begin{array}{l}\text { Fluxo } \\
\text { Monitor } \\
\left(\mathrm{kg} \cdot \mathrm{s}^{-1}\right)\end{array}$ & \\
\hline 23 & $0^{\circ}$ & 5,00 & 113,87 & 60,00 & 1,885 & 124,46 & 24 & 2,50 & 2,091 & 10,95 \\
\hline 68 & $0^{\circ}$ & 5,00 & 215,43 & 120,12 & 1,848 & 246,55 & 46 & 2,61 & 2,008 & 8,65 \\
\hline 69 & $0^{\circ}$ & 5,00 & 223,15 & 119,38 & 1,962 & 254,49 & 46 & 2,60 & 2,128 & 8,49 \\
\hline 13 & $0^{\circ}$ & 5,50 & 132,97 & 66,00 & 2,129 & 153,95 & 24 & 2,75 & 2,426 & 13,94 \\
\hline 14 & $0^{\circ}$ & 5,50 & 135,32 & 60,00 & 2,292 & 157,94 & 25 & 2,40 & 2,748 & 19,87 \\
\hline 62 & $0^{\circ}$ & 5,50 & 268,50 & 119,25 & 2,319 & 310,42 & 45 & 2,65 & 2,633 & 13,53 \\
\hline 22 & $0^{\circ}$ & 6,00 & 175,68 & 60,00 & 2,913 & 185,63 & 23 & 2,61 & 3,175 & 8,97 \\
\hline 66 & $0^{\circ}$ & 6,00 & 362,78 & 129,75 & 2,872 & 400,97 & 50 & 2,60 & 3,170 & 10,39 \\
\hline 67 & $0^{\circ}$ & 6,00 & 331,89 & 119,63 & 2,879 & 365,35 & 45 & 2,66 & 3,046 & 5,80 \\
\hline 20 & $0^{\circ}$ & 6,50 & 214,65 & 59,00 & 3,589 & 237,67 & 25 & 2,36 & 4,035 & 12,43 \\
\hline 64 & $0^{\circ}$ & 6,50 & 417,85 & 119,87 & 3,641 & 436,87 & 45 & 2,66 & 3,626 & $-0,41$ \\
\hline 65 & $0^{\circ}$ & 6,50 & 413,80 & 120,75 & 3,632 & 431,75 & 46 & 2,63 & 3,697 & 1,80 \\
\hline 15 & $0^{\circ}$ & 6,75 & 247,16 & 60,00 & 4,019 & 246,41 & 24 & 2,50 & 4,241 & 5,50 \\
\hline 57 & $0^{\circ}$ & 6,75 & 410,83 & 108,13 & 3,931 & 419,36 & 41 & 2,64 & 4,017 & 2,19 \\
\hline 58 & $0^{\circ}$ & 6,75 & 417,20 & 111,00 & 3,864 & 431,93 & 42 & 2,64 & 4,071 & 5,36 \\
\hline 164 & $0^{\circ}$ & 7,00 & 346,45 & 81,88 & 4,552 & 345,07 & 32 & 2,56 & 4,422 & $-2,87$ \\
\hline 55 & $0^{\circ}$ & 7,00 & 416,91 & 101,50 & 4,423 & 408,71 & 38 & 2,67 & 4,193 & $-5,19$ \\
\hline 56 & $0^{\circ}$ & 7,00 & 366,54 & 88,37 & 4,203 & 361,71 & 35 & 2,52 & 4,256 & 1,26 \\
\hline 162 & $0^{\circ}$ & 7,50 & 354,85 & 69,25 & 5,444 & 329,14 & 27 & 2,56 & 4,952 & $-9,03$ \\
\hline 163 & $0^{\circ}$ & 7,50 & 367,94 & 71,75 & 5,515 & 340,87 & 28 & 2,56 & 4,968 & $-9,92$ \\
\hline 54 & $0^{\circ}$ & 7,50 & 417,56 & 97,38 & 5,272 & 388,80 & 36 & 2,70 & 4,651 & $-11,78$ \\
\hline 11 & $0^{\circ}$ & 8,00 & 387,15 & 60,00 & 6,587 & 339,37 & 25 & 2,40 & 6,273 & $-4,77$ \\
\hline 12 & $0^{\circ}$ & 8,00 & 449,64 & 69,00 & 6,502 & 416,05 & 28 & 2,46 & 6,403 & $-1,53$ \\
\hline 24 & $0^{\circ}$ & 8,00 & 412,49 & 65,00 & 6,515 & 376,89 & 26 & 2,50 & 6,028 & $-7,48$ \\
\hline 49 & $0^{\circ}$ & 8,50 & 409,33 & 52,13 & 8,276 & 354,13 & 21 & 2,48 & 7,023 & $-15,14$ \\
\hline 59 & $0^{\circ}$ & 8,50 & 428,95 & 57,25 & 8,335 & 352,92 & 23 & 2,49 & 6,889 & $-17,34$ \\
\hline 61 & $0^{\circ}$ & 8,50 & 424,24 & 57,12 & 8,366 & 356,19 & 23 & 2,48 & 6,819 & $-18,49$ \\
\hline 140 & $5^{\circ}$ & 6,00 & 287,32 & 101,88 & 2,982 & 305,02 & 40 & 2,55 & 3,009 & 0,90 \\
\hline 141 & $5^{\circ}$ & 6,00 & 317,20 & 102,37 & 3,220 & 354,79 & 37 & 2,77 & 3,214 & $-0,17$ \\
\hline 142 & $5^{\circ}$ & 6,00 & 302,09 & 99,63 & 3,151 & 319,49 & 37 & 2,69 & 3,326 & 5,54 \\
\hline 137 & $5^{\circ}$ & 7,00 & 438,70 & 102,37 & 4,423 & 436,58 & 38 & 2,69 & 4,332 & $-2,05$ \\
\hline 138 & $5^{\circ}$ & 7,00 & 426,62 & 100,88 & 4,110 & 405,31 & 36 & 2,80 & 3,942 & $-4,10$ \\
\hline 139 & $5^{\circ}$ & 7,00 & 438,03 & 102,00 & 4,422 & 431,77 & 39 & 2,62 & 4,094 & $-7,41$ \\
\hline 134 & $5^{\circ}$ & 7,50 & 479,99 & 99,25 & 4,892 & 460,03 & 36 & 2,76 & 4,674 & $-4,47$ \\
\hline 135 & $5^{\circ}$ & 7,50 & 477,31 & 97,00 & 4,963 & 450,74 & 36 & 2,69 & 4,853 & $-2,23$ \\
\hline 136 & $5^{\circ}$ & 7,50 & 477,31 & 94,13 & 5,130 & 451,06 & 36 & 2,61 & 5,146 & 0,33 \\
\hline 127 & $10^{\circ}$ & 6,00 & 323,79 & 118,75 & 2,820 & 343,84 & 44 & 2,70 & 2,905 & 3,02 \\
\hline 128 & $10^{\circ}$ & 6,00 & 373,48 & 131,87 & 2,840 & 404,04 & 49 & 2,69 & 2,937 & 3,42 \\
\hline 129 & $10^{\circ}$ & 6,00 & 340,90 & 120,75 & 2,884 & 357,99 & 45 & 2,68 & 2,939 & 1,91 \\
\hline 124 & $10^{\circ}$ & 7,00 & 441,29 & 105,00 & 4,228 & 448,64 & 38 & 2,76 & 4,155 & $-1,73$ \\
\hline 125 & $10^{\circ}$ & 7,00 & 445,30 & 107,62 & 4,169 & 440,18 & 39 & 2,76 & 4,026 & $-3,45$ \\
\hline 126 & $10^{\circ}$ & 7,00 & 448,64 & 107,87 & 4,339 & 425,61 & 35 & 3,08 & 3,703 & $-14,66$ \\
\hline 121 & $10^{\circ}$ & 7,50 & 378,24 & 77,38 & 5,167 & 364,45 & 30 & 2,58 & 4,928 & $-4,63$ \\
\hline 122 & $10^{\circ}$ & 7,50 & 457,77 & 92,12 & 5,214 & 451,32 & 37 & 2,49 & 5,338 & 2,37 \\
\hline 123 & $10^{\circ}$ & 7,50 & 445,66 & 89,88 & 5,192 & 456,06 & 35 & 2,57 & 5,211 & 0,35 \\
\hline
\end{tabular}


Observando os dados de erro relativo da Tabela 15, verifica-se que 0 monitor ora subestimou, ora superestimo o valor de fluxo registrado pela balança. Quando o elevador se encontrava transversalmente em nível, para as taxas de fluxo menores, as leituras do monitor foram maiores que as da balança, superestimando os valores. Já para as taxas maiores, houve uma inversão, indicando que o monitor subestimou os valores de fluxo proporcionalmente ao aumento das taxas de fluxo aplicadas. Esta inversão está entre as vazões correspondentes à abertura da comporta de seção ajustável nos pontos 6,75 e 7,00, correspondendo a uma taxa de fluxo de 3,9 e 4,5kg.s ${ }^{-1}$, respectivamente. O erro médio em módulo observado de todos os ensaios com fluxo constante, exceto para as duas condições extremas fora do limite da calibração, foi de 5,31\% com desvio padrão dos erros de 4,14.

O gráfico da Figura 30 mostra a dispersão dos erros em percentagem, o erro médio (não em módulo) e o desvio padrão dos erros dos dados obtidos no monitor de produti vidade quando confrontados com os obtidos pela balança.

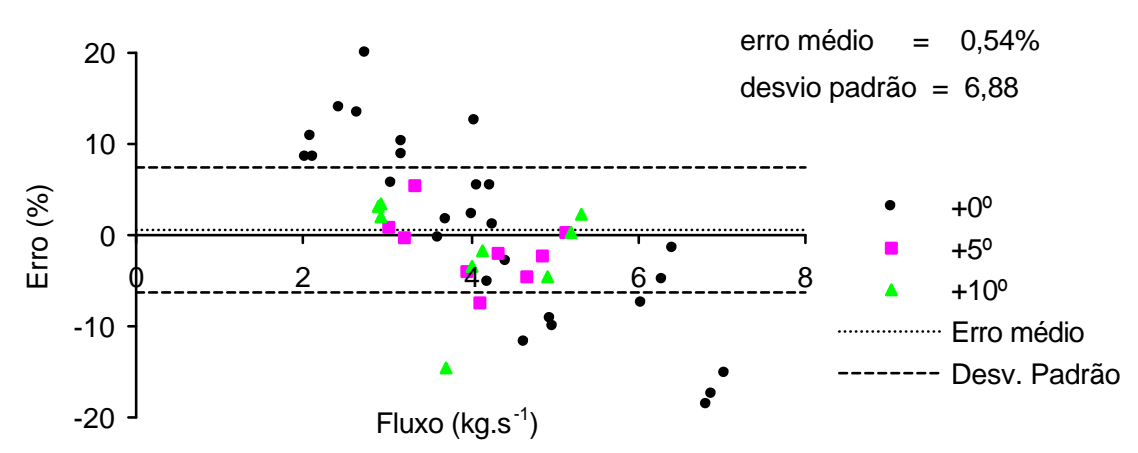

Figura 30 - Dispersão dos erros do fluxo, em percentagem, obtidos pelo monitor em relação ao fluxo obtido com a balança.

A calibração do monitor foi realizada para fluxos variando a abertura da comporta de seção ajustável de 5,5 a 8,0. Para se conhecer como o monitor trabalharia em áreas de lavoura em que não fosse utilizada toda amplitude de variação da produtividade local da área para a calibração do monitor, foram 
estudas taxas de fluxo fora do limite de calibração. Estabeleceu-se fluxo abaixo $\left(1,88 \mathrm{~kg} \cdot \mathrm{s}^{-1}\right)$ e acima $\left(8,32 \mathrm{~kg} \cdot \mathrm{s}^{-1}\right)$ deste limite, referentes æ̀े aberturas da comporta de seção ajustável com escala no ponto 5,0 e 8,5 respectivamente. Observa-se que o monitor não foi acurado ao registrar o fluxo de grãos de milho acima do limite de calibração, mostrando erros médios de $-15,14$ a-18,49\%. Já para o fluxo abaixo da calibração foram observados erros médios menores, apresentando valores médios de 8,49 a 10,95\%, indicando que o monitor não é confiável para leituras de fluxos de grãos fora dos limites de calibração concordando com Arslan e Colvin (1998). Quanto mais se afastar do fluxo médio de calibração, pior será a estimativa do fluxo.

Os erros calculados a partir de cada ensaio (com exceção dos ensaios com taxas de fluxo fora do limite de calibração) se distribuíram com a freqüência apresentada no gráfico da Figura 31

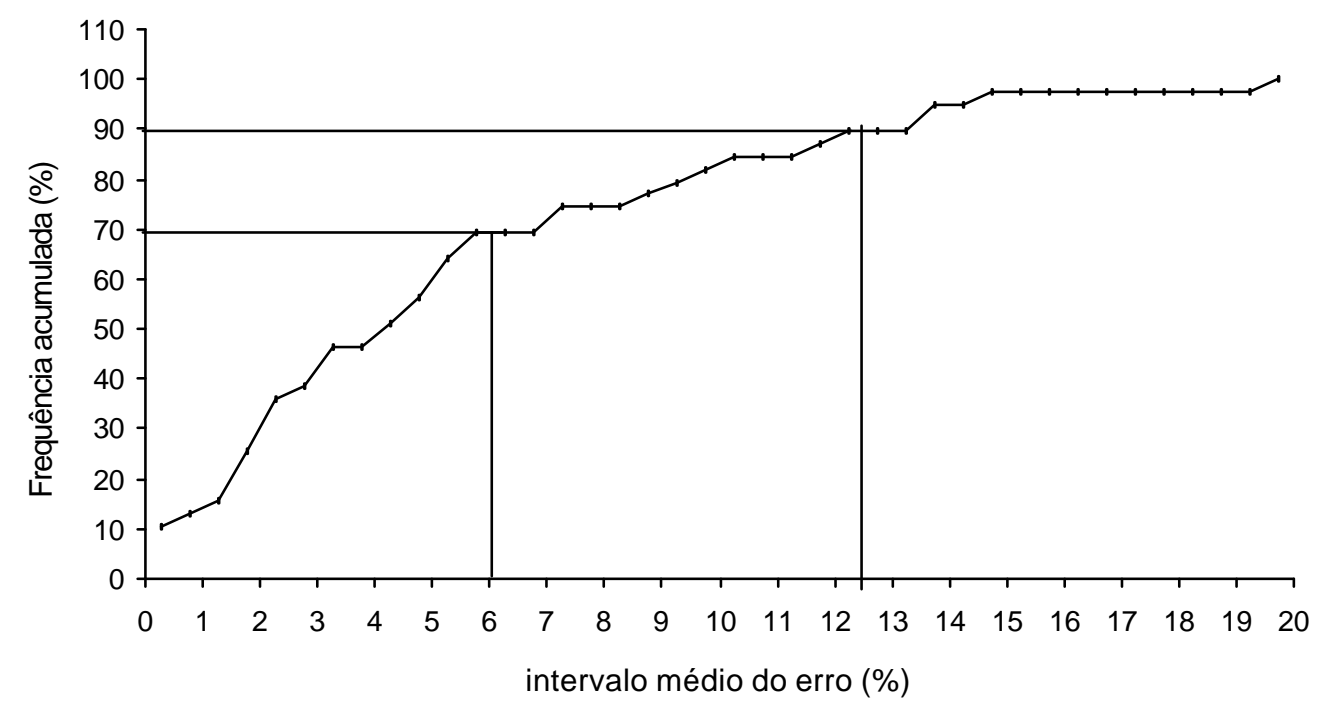

Figura 31 - Freqüência dos erros de leitura calculados para o monitor em relação aos dados da balança, a intervalos de $0,5 \%$.

Observando os dados de freqüência, verifica-se que o monitor de produtividade foi capaz de realizar leituras com erros pontuais menores que 
$12,5 \%$ em $90 \%$ dos dados e com erros menores que $6 \%$ em $70 \%$ dos dados levantados.

Com o gráfico da Figura 32, tem-se uma visualização da relação das leituras de taxas de fluxo constante de grãos realizadas pelo monitor e pela balança, com os dados de fluxo médio de cada ensaio para ambos os sistemas de medida, apresentados na Tabela 15.

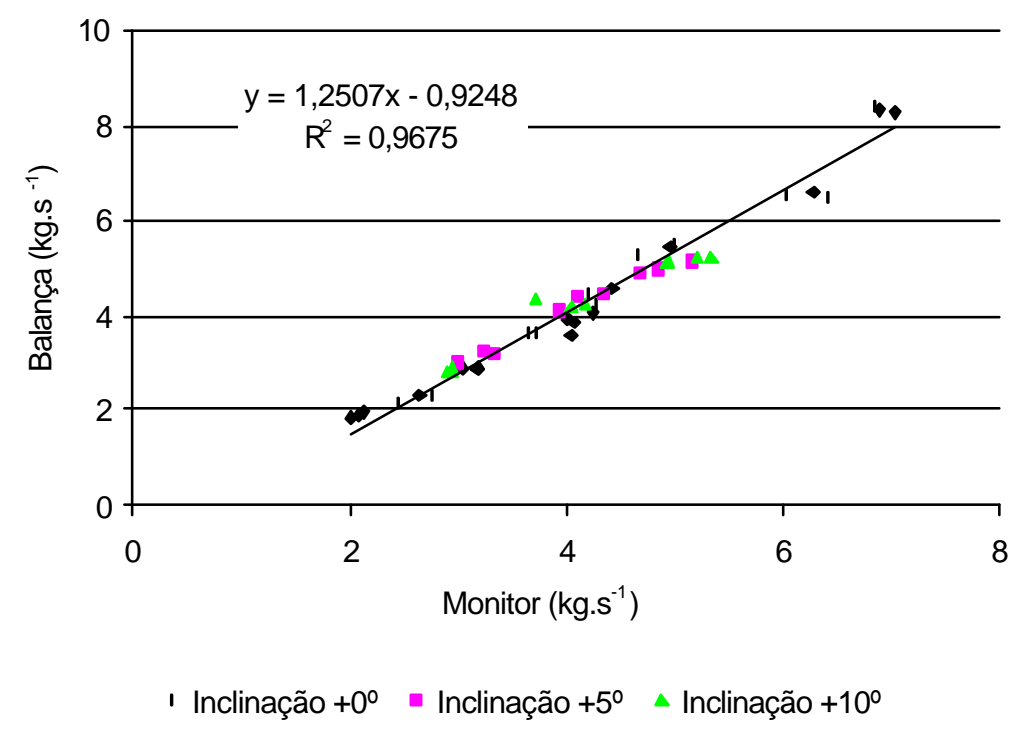

Figura 32 - Gráfico das taxas de fluxo médias constantes de grãos lidas pelo monitor em relação a aquelas lidas pela balança com os dados do elevador posicionado transversalmente $a+0^{\circ},+5^{\circ} \mathrm{e}+10^{\circ}$.

\subsubsection{Efeitos das inclinações transversais do elevador}

A Tabela 16, mostra o resultado estatístico da análise de variância de um esquema fatorial $3 \times 2$ ( 3 inclinações transversais do elevador e 2 sistemas de medidas do fluxo de grãos), com 3 repetições, para abertura da comporta de seção ajustável no ponto de escala 6,0 (com média geral do ensaio de $3,02 \mathrm{~kg} \cdot \mathrm{s}^{-1}$, desvio padrão de 0,09 e coeficiente de variação de $2,96 \%$ ). 
Tabela 16. Análise de variância da influência da inclinação transversal do elevador nas leituras de fluxos de grãos $\left(\mathrm{kg} . \mathrm{s}^{-1}\right)$ realizadas pelos sistemas de balança e sensor com a abertura da comporta de seção ajustável no ponto de escala 6,0 .

\begin{tabular}{ccccrrr}
\hline Causas de variação & G.L. & S.Q. & Q.M. & \multicolumn{1}{r}{ F } & \\
\hline Inclinação & 2 & 0,208 & 0,104 & 13,000 & ** \\
Sistema de medida & 1 & 0,075 & 0,075 & 9,359 & $*$ ** \\
Inclinação $~$ Sistema & 2 & 0,029 & 0,015 & 1,820 & n.s. \\
Tratamentos & 5 & 0,312 & 0,062 & & & \\
Resíduo & 12 & 0,096 & 0,008 & & \\
\hline
\end{tabular}

Os resultados da análise estatística da Tabela 16, mostram que houve um efeito significativo ao nível de $1 \%$ da inclinação do elevador sobre a leitura do sensor. $O$ efeito do sistema de medida também foi significativo ao rível de $1 \%$, mostrando haver diferença entre as leituras do monitor e da balança. A interação entre a inclinação e o sistema de medida não foi significativa.

A Tabela 17 mostra a mesma análise para a abertura da comporta no ponto de escala 7,0 (com média geral do ensaio de 4,22kg.s ${ }^{-1}$, desvio padrão de 0,17 e coeficiente de variação de 4,08\%). Observa-se que para esta abertura da comporta de seção ajustável não houve efeito significativo da inclinação do elevador. O sistema de medida apresentou significância ao nível de $5 \%$, indicando diferença entre as leituras da balança e do monitor e a interação entre a inclinação e o sistema de medida não teve influência significativa.

Tabela 17. Análise de variância da influência da inclinação transversal do elevador nas leituras de fluxos de grãos $\left(\mathrm{kg}^{-1} \mathrm{~s}^{-1}\right)$ realizadas pelos sistemas de balança e sensor com a abertura da comporta de seção ajustável no ponto de escala 7,0 .

\begin{tabular}{cccccc}
\hline Causas de variação & G.L. & S.Q. & Q.M. & \multicolumn{2}{c}{ F } \\
\hline Inclinação & 2 & 0,170 & 0,085 & 2,871 & n.s. \\
Sistema de medida & 1 & 0,170 & 0,170 & 5,719 & $*$ \\
Inclinação x Sistema & 2 & 0,025 & 0,012 & 0,418 n.s. \\
Tratamentos & 5 & 0,365 & 0,080 & & \\
Resíduo & 12 & 0,356 & 0,030 & & \\
\hline
\end{tabular}


Para a análise estatística com a abertura da comporta de seção ajustável no ponto de escala 7,5 (Tabela 18), a análise de variância mostrou que o efeito da inclinação não é significativo e tanto o sistema de medida como a interação entre inclinação do elevador e sistema de medida são significativos ao nível de $5 \%$ (com média geral do ensaio de $5,08 \mathrm{~kg} \cdot \mathrm{s}^{-1}$, desvio padrão de 0,16 e coeficiente de variação de $3,25 \%$ ).

Tabela 18. Análise estatística da influência da inclinação transversal do elevador nas leituras de fluxos de grãos $\left(\mathrm{kg}^{-1} \mathrm{~s}^{-1}\right)$ realizadas pelos sistemas de balança e sensor com a abertura da comporta de seção ajustável no ponto de escala 7,5 .

\begin{tabular}{|c|c|c|c|c|}
\hline Inclinações $(\stackrel{0}{)}$ & Balança & Monitor & Teste F & \\
\hline$+0^{\circ}$ & $5,410 \mathrm{~A} \mathrm{a}$ & $4,857 \mathrm{~B} \mathrm{a}$ & 16,804 & ** \\
\hline$+10^{\circ}$ & $5,191 \mathrm{~A} \mathrm{ab}$ & $5,159 \mathrm{~A} \mathrm{a}$ & 0,058 & n.s. \\
\hline$+5^{\circ}$ & $4,995 \mathrm{~A} \mathrm{~b}$ & $4,891 \mathrm{~A} \mathrm{a}$ & 0,598 & n.s. \\
\hline Teste F & 4,738 * & 3,001 & & \\
\hline
\end{tabular}

Letras maiúscula lê-se na horizontal, letras minúsculas lê-se na vertical.

Fatores seguidos por uma mesma letra, dentro do mesmo fator de variação, não diferem entre-si, ao nível de $5 \%$ pelo teste de Tukey.

$\mathrm{DMS}=0,2544$ para inclinações, $\mathrm{DMS}=0,1697$ para sistemas de balança e sensor.

O desdobramento da análise estatística da Tabela 18 para a abertura da comporta de seção ajustável no ponto de escala 7,5 mostra que houve uma diferença de $5 \%$ pelo teste de Tukey nas leituras realizadas pela balança entre as inclinações do elevador da posição $+0^{\circ}$ e $+5^{\circ}$, não sendo observada diferença significativa entre as leituras do sistema de medida do monitor. Quanto ao sistema de medida em cada inclinação transversal do elevador, houve diferença significativa ao nível de $5 \%$ na posição $+0^{\circ}$, não sendo observado o mesmo para o elevador inclinado transversalmente $a+5^{\circ} \mathrm{e}+10^{\circ}$, pelo teste de Tukey.

Para melhor entendimento das análises, na Tabela 19 são apresentadas as médias para inclinação e sistemas de medida das análises estatísticas realizadas para as aberturas da comporta de seção ajustável nos pontos de escala 6,0, 7,0 e 7,5, apresentadas anteriormente e seus erros relativos. 
Tabela 19. Análise estatística do teste de Tukey, para as médias de taxas de fluxo de grãos $\left(\mathrm{kg} . \mathrm{s}^{-1}\right)$ nos sistemas de medidas da balança e do monitor de produtividade e em cada inclinação transversal do elevador, para as aberturas da comporta de seção ajustável nos pontos de escala 6,0, 7,0 e 7,5 e seus erros relativos.

\begin{tabular}{|c|c|c|c|c|c|}
\hline Inclinações & \multirow{2}{*}{$\begin{array}{c}\text { Aberturas } \\
\text { da } \\
\text { comporta }\end{array}$} & \multicolumn{3}{|c|}{ Fluxos } & \multirow{2}{*}{$\begin{array}{c}\text { Erros médios } \\
\text { (\%) }\end{array}$} \\
\hline$(\stackrel{0}{)})$ & & balança & $\begin{array}{l}\text { monitor } \\
-\left(\mathrm{kg} \cdot \mathrm{s}^{-1}\right)\end{array}$ & médio & \\
\hline$+0^{\circ}$ & 6,0 & 2,888 & 3,131 & $3,009 \mathrm{a}$ & 8,39 \\
\hline$+10^{\circ}$ & 6,0 & 2,848 & 2,927 & $2,888 \mathrm{a}$ & 2,78 \\
\hline$+5^{\circ}$ & 6,0 & 3,118 & 3,183 & $3,150 \mathrm{~b}$ & 2,09 \\
\hline Médias & & 2,951 a & $3,080 \mathrm{~b}$ & & 4,42 \\
\hline$+0^{\circ}$ & 7,0 & 4,393 & 4,290 & $4,342 \mathrm{a}$ & $-2,27$ \\
\hline$+10^{\circ}$ & 7,0 & 4,246 & 3,961 & $4,103 \mathrm{a}$ & $-6,61$ \\
\hline$+5^{\circ}$ & 7,0 & 4,318 & 4,123 & $4,220 \mathrm{a}$ & $-4,52$ \\
\hline Médias & & $4,319 a$ & $4,125 \mathrm{~b}$ & & 4,47 \\
\hline$+0^{\circ}$ & 7,5 & 5,410 & 4,857 & $5,134 \mathrm{a}$ & $-10,24$ \\
\hline$+10^{\circ}$ & 7,5 & 5,191 & 5,159 & $5,175 \mathrm{a}$ & $-0,63$ \\
\hline$+5^{\circ}$ & 7,5 & 4,995 & 4,891 & $4,943 \mathrm{a}$ & $-2,13$ \\
\hline Médias & & $5,199 \mathrm{a}$ & $4,969 \mathrm{~b}$ & & 4,34 \\
\hline $\begin{array}{l}\text { Fatores seguidos } \\
\text { teste de Tukey. } \\
\text { DMS }=0,1376 \mathrm{p} \\
\text { inclinaçóes na ab } \\
\text { DMS =0,0918 p } \\
\text { DMS }=0,1697 \mathrm{pa}\end{array}$ & rymomon & tra, dentro do $\mathrm{m}$ & o fator de varia & & $\begin{array}{l}\text {, ao nível de } 5 \% \text { pelo } \\
\text { DMS }=0,2544 \text { para } \\
\text { ida na abertura } 7,0 \mathrm{e}\end{array}$ \\
\hline
\end{tabular}

Os resultados das análises estatísticas mostraram que as médias dos valores medidas pela balança e monitor para as diversas inclinações do elevador não diferiram entre si ao nível de 5\% pelo teste Tukey, com exceção para a média na inclinação $+5^{\circ}$ à direita, com a abertura da comporta de seção ajustável no ponto de escala 6,0, que diferiu das demais. Estas proximidades entre os dados nas diferentes posições transversais do elevador indicam que 0 clinômetro ou o algoritmo que considera a inclinação é eficiente para compensar as inclinações da máquina. Isto foi possível, devido ao tanque alimentador fornecer para cada abertura da comporta de seção ajustável, uma taxa de fluxo constante. As médias de sistemas de medida variaram 
significativamente, pelo teste de Tukey, para as três aberturas da comporta de seção ajustável, mostrando que houve erro de leitura das taxas de fluxo do monitor em relação àbalança.

Observa-se para as aberturas 7,0 e 7,5 que o monitor sempre subestimou os fluxos em relação à balança. Apenas na abertura 6,0, com menor taxa de fluxo, houve uma superestimativa, por parte do sensor. Por outro lado, o fato de ser significativas as diferenças entre as leituras da balança e do monitor para diferentes fluxos, ora com defasagens para mais, ora para menos, indica que uma adequada faixa de calibração é importante para que não haja desvios significativos. Se o monitor for corretamente calibrado, o erro de totalização tende a ser pequeno.

As análises com as três aberturas de comporta de seção ajustável, nas escalas de 6,0, 7,0 e 7,5 apresentaram coeficientes de variação de 2,96, 4,08 e $3,25 \%$, respectivamente. Coeficientes de variação desta ordem para leitura de fluxo do monitor de produtividade em relação à balança indica que o equipamento é preciso em suas leitura.

Os erros médios relativos, em módulo, para os ensaios realizados com as três aberturas da comporta, foram muito semelhantes, conforme apresentado na Tabela 19, com erro médio, em módulo, de 4,41\%, para as três aberturas.

Procuroutse também verificar se havia uma relação que fosse significativa entre os dados medidos pela balança e o monitor de produtividade, através de equações de regressão, para cada uma das três aberturas de comporta $(6,0$ 7,0 e 7,5), nas três inclinações transversais, apresentadas na Figura 33. 
Abertura 6,0

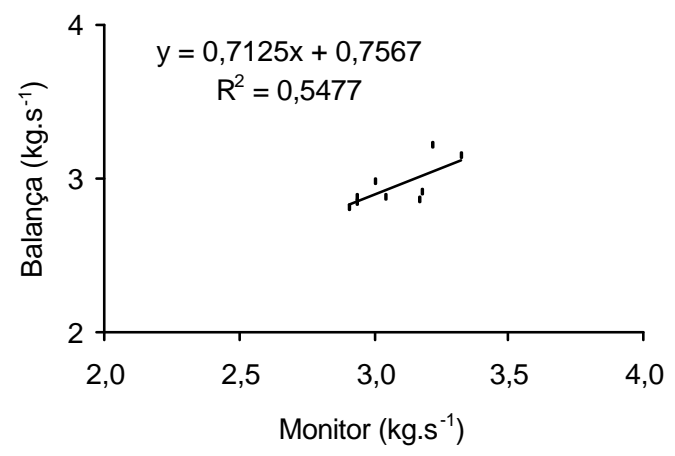

(a)
Abertura 7,0

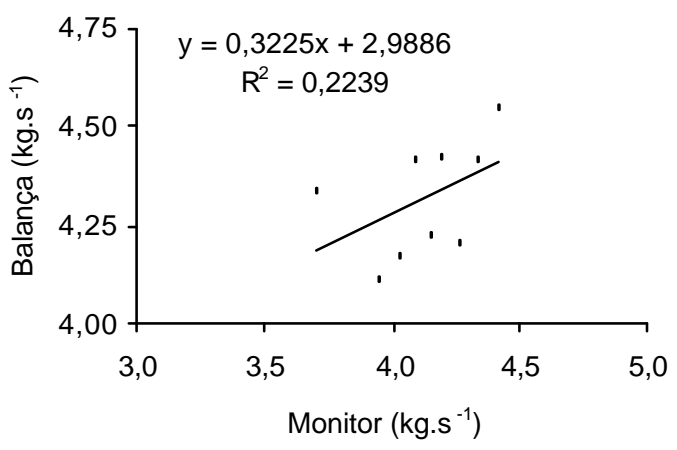

(b)

Abertura 7,5

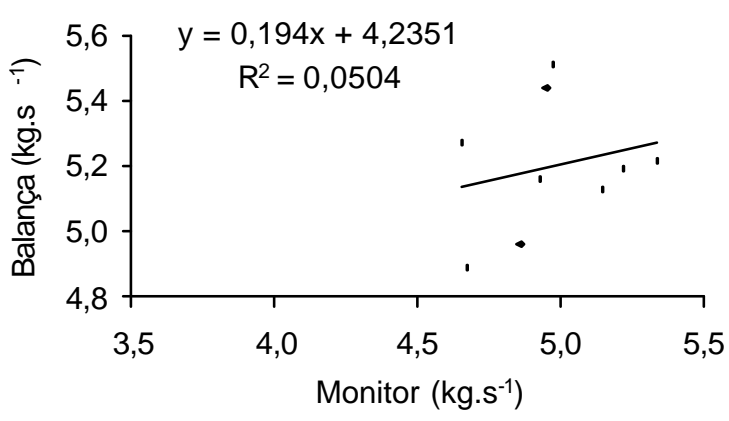

(c)

Figura 33 - Gráficos de regressão de fluxos de grãos para abertura da comporta de seção ajustável nos pontos de regulagem de escala (a) 6,0 (b) 7,0 e (c) 7,5, com dados do monitor nas 3 inclinações transversais confrontados com os dados da balança.

Os resultados da análise de regressão mostraram uma fraca relação, apresentando coeficiente de determinação $\left(R^{2}\right)$ da ordem de 0,548, 0,224 e 0,0504, para as aberturas 6,0, 7,0 e 7,5, respectivamente, mostrando não haver uma relação linear entre as leituras, não sendo possível estimar a leitura do sensor, com relação àbalança, para uma certa entrada de fluxo, quando se tem diferentes inclinações transversais do elevador. 


\subsubsection{Comparação entre as leituras da balança e do sensor de fluxo de volume para taxas de fluxo constantes em diversas aberturas da comporta.}

Outra análise, com os dados da Tabela 15, foi desenvolvida no esquema fatorial $7 \times 2$, com 3 repetições, para 7 taxas de fluxo, correspondentes æ̀ aberturas da comporta nos pontos de escala 5,50, 6,00, $6,50,6,75,7,00,7,50$ e 8,00 e dois sistemas de medidas de fluxo (balança e monitor de produtividade), com o elevador transversalmente em nível. O resultado da análise de variância mostrou que a abertura da comporta é altamente significativa. O sistema de medida para esta análise não foi significativo e a interação entre abertura da comporta e sistema de medida foi altamente significativa. A síntese desta análise é apresentada na Tabela 20.

Tabela 20. Resumo da análise estatística para as médias de taxas de fluxo $\left(\mathrm{kg} . \mathrm{s}^{-1}\right)$ obtidas para diversas aberturas da comporta e sistemas de medida, com o elevador em nível.

\begin{tabular}{ccccrr}
\hline Aberturas da comporta & Balança & Monitor & Médias & \multicolumn{2}{c}{ Teste F } \\
\hline 5,50 & $2,247 \mathrm{~A} \mathrm{a}$ & $2,602 \mathrm{~B} \mathrm{a}$ & $2,424 \mathrm{a}$ & 10,941 & \\
6,00 & $2,888 \mathrm{~A} \mathrm{~b}$ & $3,131 \mathrm{~B} \mathrm{~b}$ & $3,009 \mathrm{~b}$ & 5,086 & \\
6,50 & $3,621 \mathrm{~A} \mathrm{c}$ & $3,786 \mathrm{~A} \mathrm{c}$ & $3,704 \mathrm{c}$ & 2,372 & n.s. \\
6,75 & $3,938 \mathrm{~A} \mathrm{c}$ & $4,109 \mathrm{~A} \mathrm{~cd}$ & $4,024 \mathrm{~d}$ & 2,546 & n.s. \\
7,00 & $4,393 \mathrm{~A} \mathrm{~d}$ & $4,290 \mathrm{~A} \mathrm{~d}$ & $4,342 \mathrm{e}$ & 0,911 & n.s. \\
7,50 & $5,410 \mathrm{~B} \mathrm{e}$ & $4,857 \mathrm{~A} \mathrm{e}$ & $5,134 \mathrm{f}$ & 26,519 & $* *$ \\
8,00 & $6,535 \mathrm{~B} \mathrm{f}$ & $6,235 \mathrm{~A} \mathrm{f}$ & $6,385 \mathrm{~g}$ & 7,807 & $*$ \\
Médias & $4,147 \mathrm{~A}$ & $4,145 \mathrm{~A}$ & & & \\
Teste $\mathrm{F}$ & $371,768{ }^{* *}$ & $243,553{ }^{* *}$ & & & \\
\hline
\end{tabular}

Letras maiúscula lê-se na horizontal, letras minúsculas lê-se na vertical.

Fatores seguidos por uma mesma letra, dentro do mesmo fator de variação, não diferem entre-si, ao nível de $5 \%$ pelo teste de Tukey.

DMS $=0,2408$ para médias de abertura comporta.

DMS $=0,0832$ para médias de sistema de medida.

Para a análise das médias foi aplicado o teste de Tukey. Observa-se pela comparação das médias gerais para a balança e o monitor, que elas não diferem entre si significativamente. Na média, o monitor subestimou a leitura feita pela balança. 
Quando se comparam as médias dos sistemas de medidas, balança e monitor de produtividade, dentro de cada taxa de fluxo, correspondente æ̀े aberturas da comporta de seção ajustável em cada ponto da escala, houve diferenças significativas de $5 \%$ pelo teste de Tukey entre as taxas de fluxo medidas por ambos os sistemas para as aberturas correspondentes aos pontos na escala $5,50,6,00,7,50$ e 8,00, não havendo diferença significativa nos pontos de escala 6,50,6,75 e 7,00, que são os valores centrais utilizados na calibração do monitor de produtividade, mostrando que a calibração realizada foi ideal e que os fluxos constantes nesta região tendem a menores erros. $O$ monitor de produtividade superestimou as leituras em relação àbalança para a abertura da comporta de seção ajustável no ponto de escala 6,75, e menores. Para o ponto de escala 7,00 , e maiores, subestimou as leituras efetuadas pela balança. Novamente, neste ensaio, obteve-se um coeficiente de variação da ordem de 3,17\%, podendo-se inferir que o sensor é preciso nas leituras de fluxo de volume de grãos.

Essa mesma tendência, é observada quando se analisa o gráfico de regressão apresentado na Figura 34. O coeficiente de determinação de 0,9723, mostra existir uma relação linear direta entre as medidas de fluxo da balança e as do sensor de fluxo de volume. O coeficiente angular $(1,212)$, indica que em média, as leituras de taxa de fluxo feitas pelo monitor subestimam as leituras feitas com a balança, para as condições onde se manteve o elevador em nível. Porém, com a adição do coeficiente de intersecção na equação pode-se dizer que até a taxa de fluxo de $4,13 \mathrm{~kg} \cdot \mathrm{s}^{-1}$, o monitor de produtividade superestima os valores medidos pela balança, invertendo a partir deste ponto. Esta taxa de fluxo é propiciada pela abertura da comporta de seção ajustável próximo do ponto de escala média $(6,75)$ dentre as aberturas utilizadas na calibração do monitor de produtividade. Este valor de inversão é praticamente o valor médio das taxas de fluxo dos ensaios com o elevador transversalmente nivelado, de $4,15 \mathrm{~kg} \cdot \mathrm{s}^{-1}$, encontrado na Tabela 20. Isto demonstra o equilíbrio existente entre as leituras do monitor a partir do ponto da taxa de fluxo média de calibração, 
visto que foram realizadas na mesma proporção leituras acima e abaixo da abertura média.

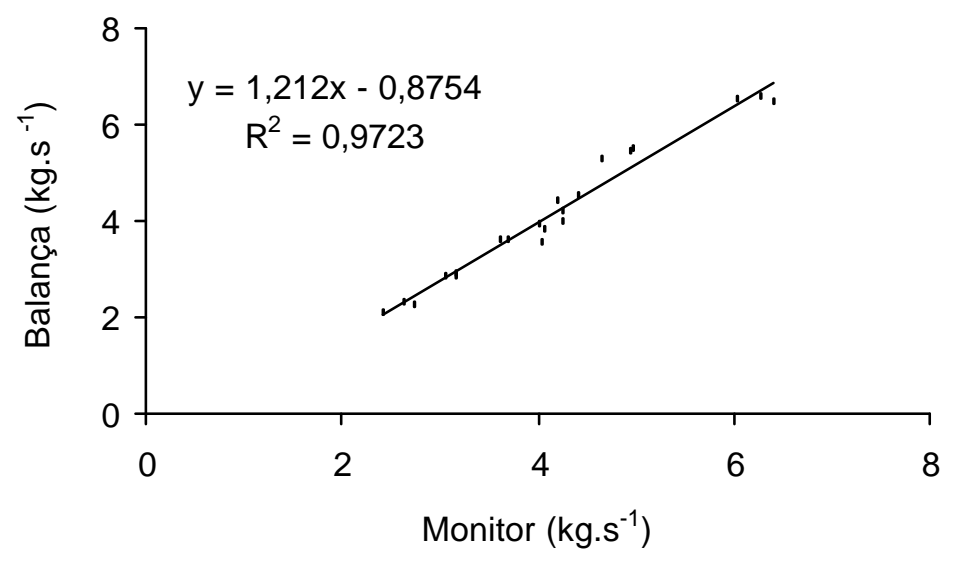

Figura 34 - Relação entre as taxas de fluxo lida pela balança e pelo sensor de produtividade, para as diversas aberturas da comporta de seção ajustável, com o elevador transversalmente em nível.

Para as posições do elevador inclinado a $+10^{\circ}$ e $+5^{\circ}$ foram desenvolvidos gráficos de regressão correlacionando as taxas de fluxo lidas pela balança e monitor de produtividade, individualmente, dentro de cada fator de inclinação. Foram consideradas em cada uma delas, as três taxas de fluxo ensaiadas, referente às aberturas da comporta de seção ajustável de 6,0, 7,0 e 7,5, cujos resultados são apresentados na Figura 35.

Os coeficientes de determinação $\left(R^{2}\right)$ para essas curvas foram $0,9443 \mathrm{e}$ 0,9727, mostrando que, as medidas do monitor de produtividade correlacionamse linearmente com as da balança. Estas curvas servem para estimativa dos dados de balança a partir dos dados de monitor quando varia o fluxo de alimentação. 
Inclinação $+5^{\circ}$

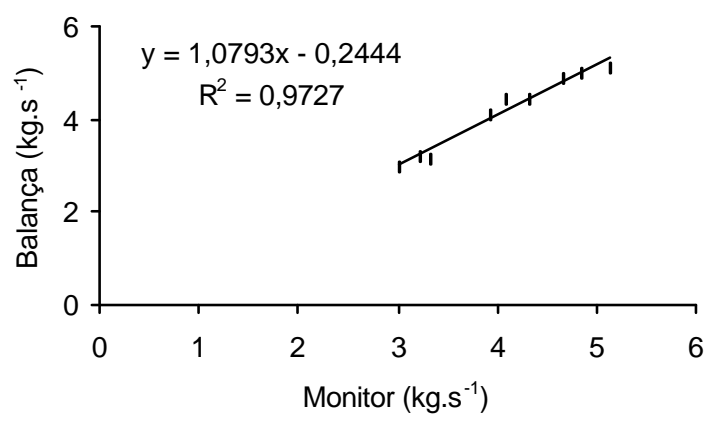

(a)
Inclinação $+10^{\circ}$

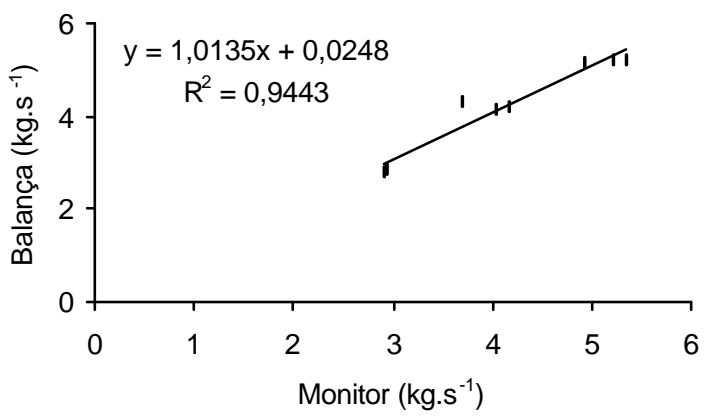

(b)

Figura 35 - Gráficos de regressão entre leituras do monitor e da balança nas diferentes taxas de fluxo aplicadas, referentes æ̀ aberturas da comporta no ponto de escala 6,0, 7,0 e 7,5, para as inclinações transversais do elevador de $+5^{\circ} \quad$ (a) $\mathrm{e}+10^{\circ}$ (b).

Nas inclinações de $+10^{\circ}$ e $+5^{\circ}$, tanto os coeficientes angulares se aproximaram da unidade, como os coeficientes de intersecção aproximaram-se de zero, indicando que o monitor possui medidas parecidas com as feitas pela balança, como pode ser observado na Figura 35. O menor coeficiente de determinação encontrado na regressão da inclinação $+5^{\circ}$ à direita foi devido a uma das repetições referente a abertura da comporta de seção ajustável no ponto de escala 7,0 ter se distanciado das demais.

A média dos erros relativos do monitor de produtividade para fluxos constantes, quando este se encontrava transversalmente em nível, foi em módulo 7,18\%. Para o elevador inclinado transversalmente $a+10^{\circ}$ e $+5^{\circ}$, o erro médio em módulo foi bem menor, sendo de 3,34\% e 2,91\%, respectivamente. A média geral dos erros em módulo, relativo a cada repetição dos tratamentos realizados, para todos os ensaios com fluxos constantes, nas três inclinações ensaiadas, foi de $5,31 \%$. Estes dados de médias gerais de totalização são compatíveis com os encontrados por Kormann et al. (1998), Arslan e Colvin (1998) e Burks et al. (2001) em ensaios de bancada com diferentes monitores de mercado. $O$ erro que deve ser levado em consideração é o erro em módulo, 
pois o que importa é quantificar a grandeza dos erros pontuais gerados pelas leituras do monitor e não o erro totalizado que não informa o quanto os valores se dispersaram. Com dados do monitor subestimando e superestimando os valores da balança, aparentemente, há uma compensação do erro médio nas leituras do monitor de produtividade se for calculado o erro de totalização, levando em consideração os sinais. Isto ocorre em situações de campo quando são calculados os erros por médias do tanque da colhedora.

De forma geral, o monitor de produtividade teve erros pontuais menores que $6 \%$ em $70 \%$ dos ensaios a fluxos constantes, com o elevador transversalmente em nível e inclinado.

\subsubsection{Ensaio com taxa de fluxo variável}

Os ensaios com fluxos variados foram desenvolvidos variando três taxas de fluxo de grãos durante o período de cada ensaio (descarregamento total dos grãos de milho do tanque alimentador) para as três inclinações transversais do elevador estudadas de $+0^{\circ},+10^{\circ}$ e $+5^{\circ}$. Os resultados dos ensaios podem ser observados nos gráficos apresentados nas Figuras 36 a 38 . 


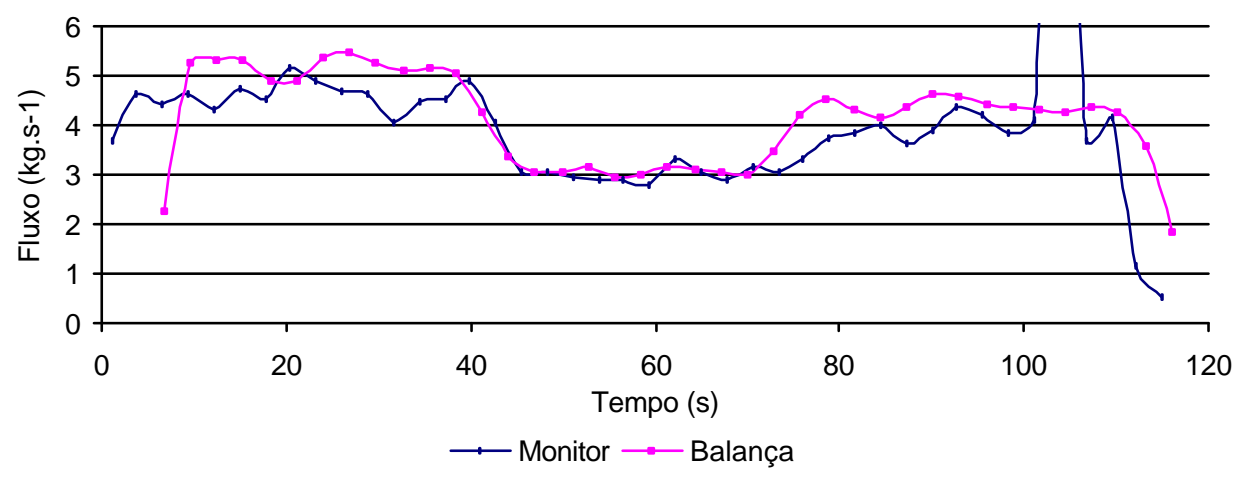

(a)

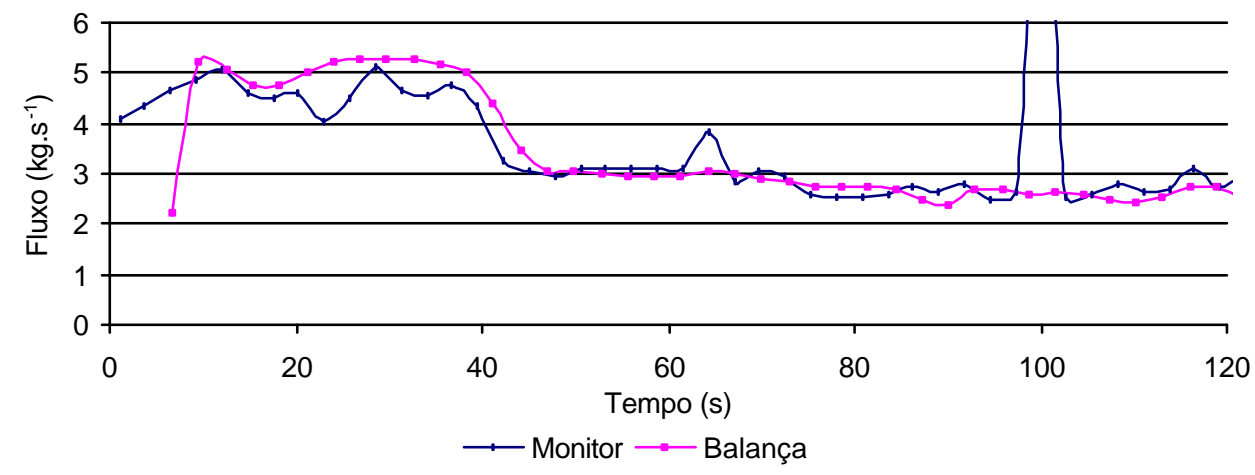

(b)

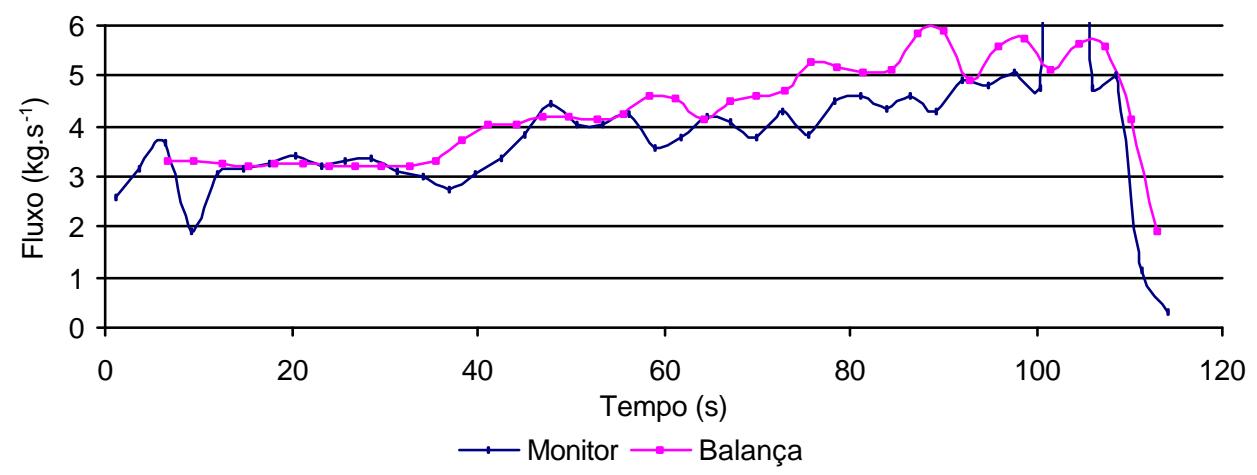

(c)

Figura 36 - Taxas variáveis de fluxos para o elevador em nível, com aberturas da comporta de seção ajustável referentes aos pontos na escala, $7,5, \quad 6,0, \quad 7,0$ (a), 7,5, 6,0, 5,5 (b) e 6,0, 7,0, 7,5 (c), respectivamente. 


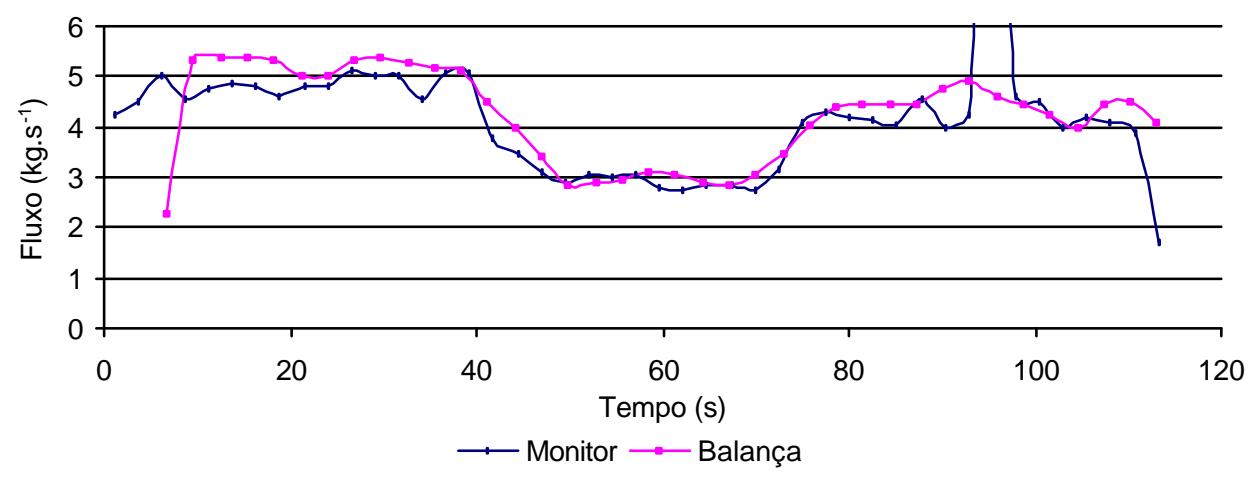

(a)

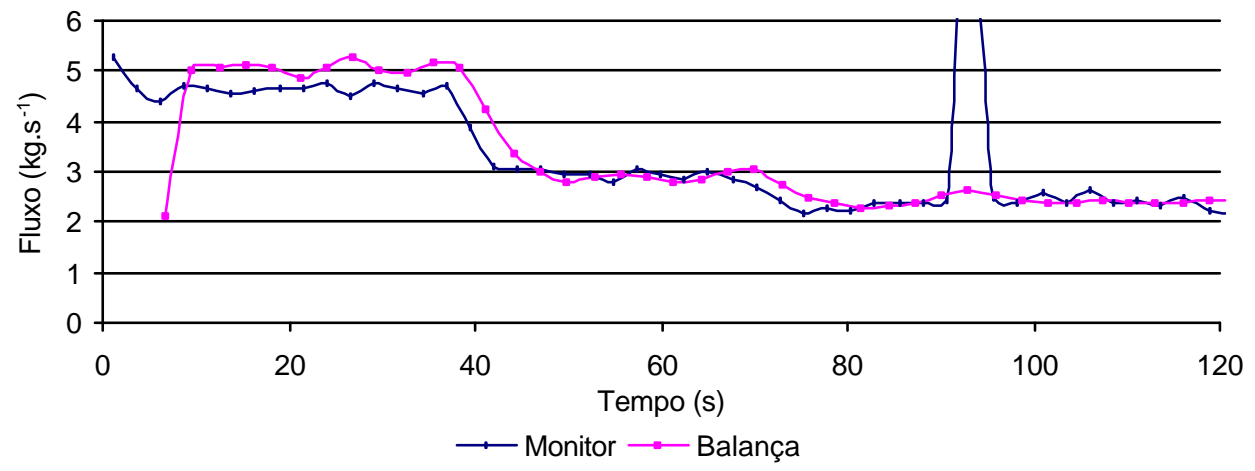

(b)

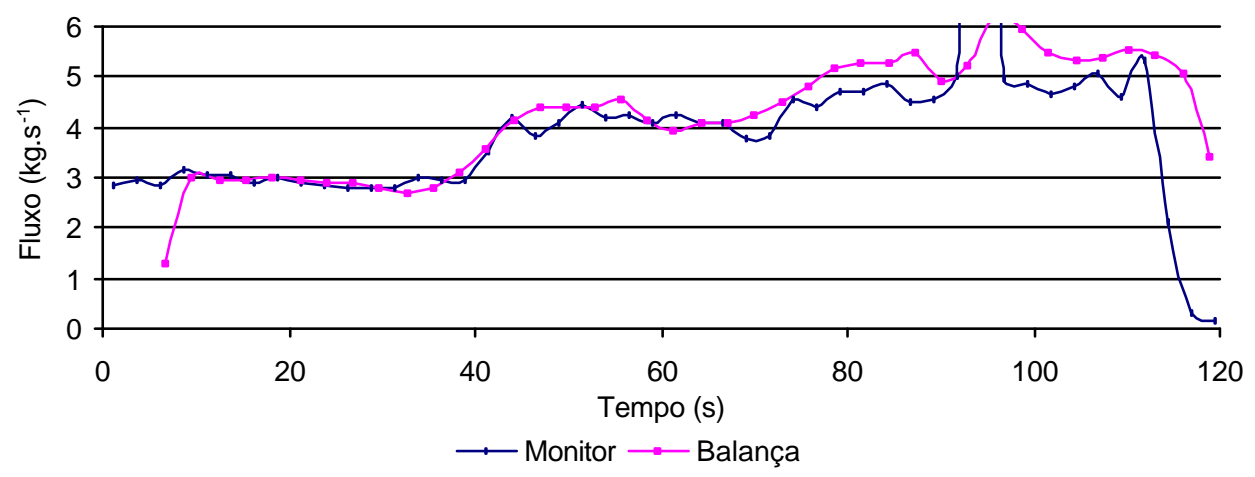

(c)

Figura 37 - Taxas variáveis de fluxos para o elevador com inclinação de $+5^{\circ}$ à direita, com aberturas da comporta de seção ajustável referentes aos pontos na escala, 7,5, 6,0, 7,0 (a), 7,5, 6,0, 5,5 (b) e 6,0, 7,0, 7,5 (c), respectivamente. 


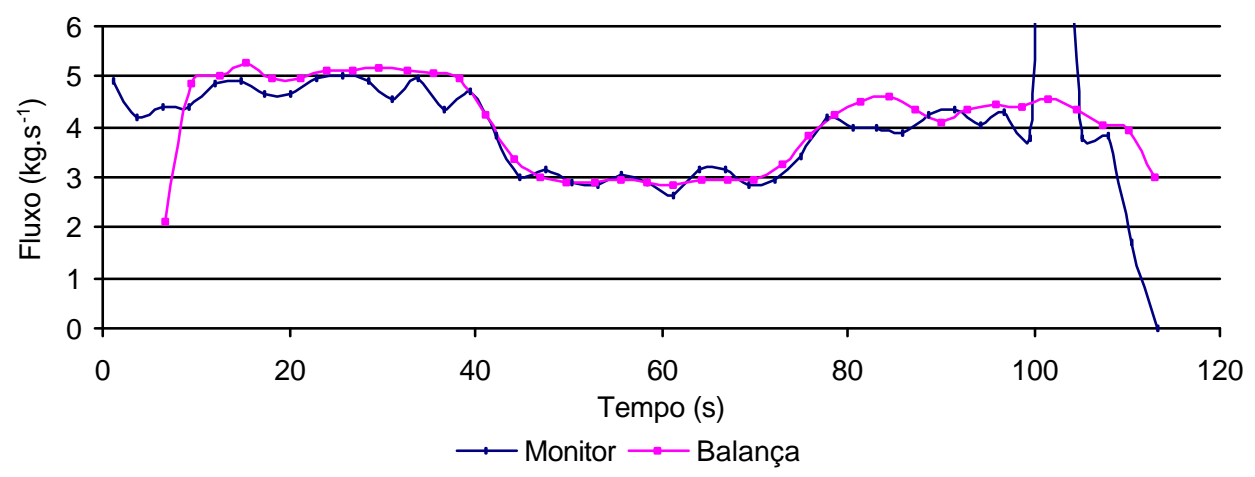

(a)

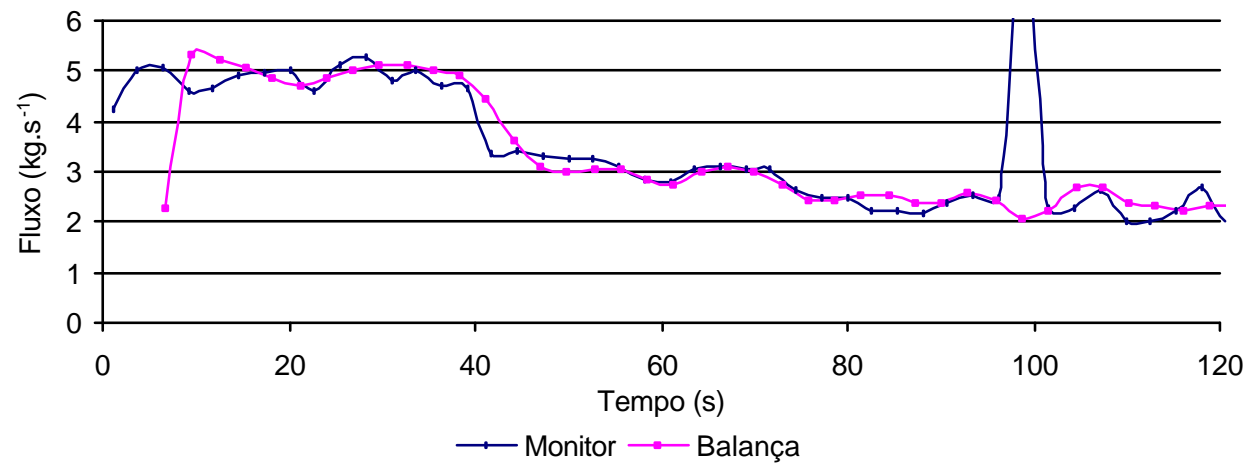

(b)

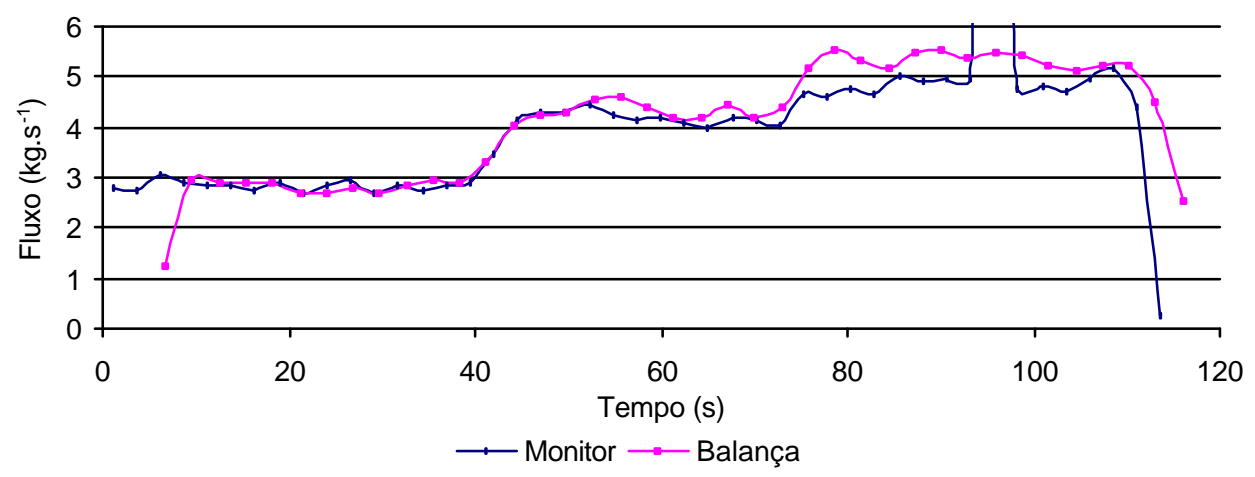

(c)

Figura 38 - Taxas variáveis de fluxos para o elevador com inclinação de $+10^{\circ}$ à direita, com aberturas da comporta de seção ajustável referentes aos pontos na escala, 7,5, 6,0, 7,0 (a), 7,5, 6,0, 5,5 (b) e 6,0, 7,0, 7,5 (c), respectivamente. 
Observando os gráficos pode-se inferir que há uma tendência do monitor de produtividade responder imediatamente às variações de taxas de fluxo de grãos de milho passando pelo sensor para as mudanças ocorridas entre as três taxas de fluxo estudadas. Isso permite avaliar que os erros de tempo de atraso dos grãos ocorridos em campo são unicamente função do processamento da colhedora e características da cultura, uma vez que o monitor responde de imediato ao fluxo, sendo que propicia erros de quantidade de massa lida, mas não de tempo de leitura. Observa-se também que em todos arquivos gerados pelo monitor de produtividade produziu-se um pico de leitura ao redor de 100s, não sendo um padrão imposto no ensaio e sim um erro ou um ajuste intrínseco do equipamento.

Os erros gerados pelos gráficos dos ensaios com taxas de fluxo variadas foram calculados em cada trecho com fluxo constante no gráfico. Os erros em módulo calculados são apresentados na tabela 21.

Tabela 21. Erros médios calculados para cada trecho com taxas de fluxo constante dos gráficos de taxas variadas.

\begin{tabular}{|c|c|c|c|c|c|c|}
\hline \multirow{2}{*}{$\begin{array}{l}\text { Ângulos de } \\
\text { Inclinação }\end{array}$} & \multirow{2}{*}{$\begin{array}{c}\text { Variações da } \\
\text { abertura }\end{array}$} & \multicolumn{4}{|c|}{ Pontos na escala da comporta } & \multirow{2}{*}{$\begin{array}{l}\text { Médias por } \\
\text { ensaio } \\
(\%)\end{array}$} \\
\hline & & $\begin{array}{l}7,5 \\
-\end{array}$ & 7,0 & $\begin{array}{l}6,0 \\
\%)---\end{array}$ & $\begin{array}{l}5,5 \\
--\end{array}$ & \\
\hline$+0^{\circ}$ & $7,5 \quad 6,0 \quad 7,0$ & $-11,49$ & $-9,08$ & $-1,94$ & & 7,50 \\
\hline$+0^{\circ}$ & $\begin{array}{lll}7,5 & 6,0 & 5,5\end{array}$ & $-8,43$ & & 2,76 & $-0,28$ & 3,82 \\
\hline$+0^{\circ}$ & $6,0 \quad 7,0 \quad 7,5$ & $-13,07$ & $-5,62$ & 0,45 & & 6,38 \\
\hline Médias & & 11,00 & 7,35 & 1,72 & 0,28 & 5,90 \\
\hline$+5^{\circ}$ & $\begin{array}{llll}7,5 & 6,0 & 7,0\end{array}$ & $-6,96$ & $-8,95$ & $-1,75$ & & 5,89 \\
\hline$+5^{\circ}$ & $\begin{array}{lll}7,5 & 6,0 & 5,5\end{array}$ & $-8,58$ & & 1,34 & $-0,58$ & 3,50 \\
\hline$+5^{\circ}$ & $6,0 \quad 7,0 \quad 7,5$ & $-9,43$ & $-2,49$ & 0,91 & & 4,28 \\
\hline Médias & & 8,32 & 5,72 & 1,34 & 0,58 & 4,56 \\
\hline$+10^{\circ}$ & $\begin{array}{llll}7,5 & 6,0 & 7,0\end{array}$ & $-5,83$ & $-7,39$ & 1,33 & & 4,85 \\
\hline$+10^{\circ}$ & $\begin{array}{lll}7,5 & 6,0 & 5,5\end{array}$ & $-1,54$ & & 2,87 & $-4,01$ & 2,80 \\
\hline$+10^{\circ}$ & $6,0 \quad 7,0 \quad 7,5$ & $-9,38$ & $-4,01$ & $-0,26$ & & 4,55 \\
\hline Médias & & 5,58 & 5,70 & 1,49 & 4,01 & 4,07 \\
\hline Médias gerais & & 8,30 & 6,25 & 1,51 & 1,62 & 4,84 \\
\hline
\end{tabular}


Analisando os dados da Tabela 21 e das Figuras 34 a 36, pode-se observar que, de modo geral, as leituras do monitor em relação æ̀̀ da balança dentro de cada trecho analisado, onde abertura da comporta de seção ajustável era mantida numa mesma posição, comportaram-se de maneira parecida de quando foram feitos os ensaios para vazões constantes, superestimando a taxa de fluxo na abertura da comporta no ponto de escala 6,0 e subestimando para os pontos de escala 7,0 e 7,5. De forma geral a ordem em que determinada taxa de fluxo foi processada no ensaio não interferiu na leitura do sensor. Os ensaios com o elevador transversalmente inclinado obtiveram menores erros que os ensaios com o elevador em posição transversal nivelada, indicando que o algoritmo que considera a inclinação é eficiente para compensar as inclinações da máquina, mesmo com variações das taxas de fluxo.

Pode-se observar pela Tabela 21 que o erro relativo das médias de cada trecho do gráfico variaram de $-11,49 \%$ a $2,87 \%$. As maiores taxas de fluxo, referentes à aberturas da comporta de seção ajustável nos pontos de escala 7,5 e 7,0, tiveram os maiores erros relativos, de $8,30 \%$ e $6,25 \%$, respectivamente, de uma média de todos ensaios com taxas de fluxo variadas. Para os pontos de escala 6,0 e 5,5 os erros foram sempre menores, com a média dos erros em módulo para o ponto de escala 6,0 de 1,51\% e 1,62\% para o ponto de escala 5,5. O erro médio geral dos ensaios com taxas de fluxo variadas, calculado a partir do erro médio em módulo de cada ensaio foi de $4,84 \%$.

Quando são comparados os dados de massa de totalização gerados no monitor com massa total registrada pela balança, incluindo os tempos de enchimento e esvaziamento do elevador de grãos, o erro médio para ensaios com taxas de fluxo variadas foi menor em módulo do que o erro médio dos ensaios de taxas de fluxo constantes. A média dos erros em módulo, dos ensaios realizados nas inclinações transversais de $+0^{\circ},+5^{\circ} \mathrm{e}+10^{\circ}$, incluindo os tempos de enchimento e esvaziamento do elevador de grãos, foi de $1,81 \%$ e $6,66 \%$, respectivamente. 
Os erros médios dos ensaios para as taxas de fluxo variadas foram apresentados na Tabela 21, em módulo, onde os três ensaios com taxas de fluxo variadas com o elevador na posição transversal em nível $\left(+0^{\circ}\right)$ apresentou um erro relativo de $5,90 \%$. Para o elevador inclinado a $+5^{\circ}$ e $+10^{\circ}$ o erro foi de $4,56 \%$ e $4,07 \%$, respectivamente.

Para cálculo do erro médio global, referente ao erro médio em módulo, de todos os ensaios realizados neste experimento, foram tomados os valores médios de erros das três repetições de cada taxa de fluxo constante ensaiada (cada tratamento) para as três condições de inclinações transversais do elevador estudadas, de $+0^{\circ},+5^{\circ}$ e $+10^{\circ}$ e mais os valores médios de erros de cada ensaio realizado com taxas de fluxo variadas. $O$ valor encontrado do erro médio global foi de $5,12 \%$.

Pelos dados relatados neste experimento observa-se que as variações (erros) foram menores quando se trabalhou ao redor do fluxo médio dentro da amplitude de fluxos testados, aumentando o erro quanto mais extremas eram as taxas de fluxo. Na literatura encontram-se informações em que o monitor de produtividade apresenta, em média, erro de 2 a 4\%, quando trabalhando no campo (Baerdemaeker et al., 1985; Kormann et al., 1998; Arslan e Colvin, 1999, Wilcox, 1999a; Burks et al., 2001). Se isto acontece, pode indicar que as áreas de cultura, aparentemente, possuem dados que ora são superestimados, ora são subestimados de tal forma que haja um equilíbrio entre os erros pontuais, resultando em erro de totalização pequeno. Os erros médios encontrados para o monitor estudado, foram superiores aos encontrados em experimento de campo por Molin et al. (2000), com o mesmo equipamento, com erro menor que $3 \%$, pois em campo o erro é calculado por totalização de cada tanque graneleiro da colhedora, não apontando os desvios ocorridos ponto a ponto.

Quando se realizou os ensaios com o elevador transversalmente inclinado, optourse por utilizar três taxas de fluxo dentro dos limites de calibração, buscando unicamente valores representativos de campo dentre os levantados nos ensaios do tanque alimentador, não havendo preocupação em 
escolher dados de acordo com a taxa de fluxo média de calibração. Pelo que se observou neste trabalho, propõe-se que em futuros ensaios de monitor de produtividade, a calibração do monitor seja realizada de forma que o valor da taxa de fluxo média de grãos na calibração seja a mesma do valor médio estudado a taxas de fluxo constantes, analisando-se as tendências dos desvios acima e abaixo da média, também para as inclinações transversais. Outra importante modificação é colocar um visor de acrílico na janela do elevador para observar a distribuição da carga das taliscas do elevador. Com isso, é possível desligar o elevador e verificar a distribuição dos grãos nas taliscas com elas ainda em estágio final de movimento, sem que os grãos tenham escorrido da talisca.

O presente estudo procurou avaliar algumas situações topográficas ocorridas em campo, estudando três posições transversais fixas do elevador, em nível e a $+5^{\circ}$ e $+10^{\circ}$ inclinado, a diferentes taxas de fluxo. Sabe-se entretanto, que várias situações não foram aqui estudadas, como em campo, sob condições dinâmicas onde há variações contínua das inclinações transversais e longitudinais, variações da velocidade de avanço da colhedora, diferentes calibrações do sistema, tempo de processamento dos grãos na colhedora, entre outros, ficando inúmeras situações sem resposta quanto ao comportamento do monitor de produtividade, necessitando serem realizadas mais pesquisas nesta área.

\subsubsection{Grau de umidade dos grãos de milho}

Os resultados de grau de umidade de grãos de milho medida pelo método da estufa e aqueles registrados pelo monitor de produtividade, com amostras colhidas durante o tempo em que foram desenvolvidos os ensaios, são apresentados na Tabela 22, assim como o erro relativo entre ambas para cada data de medida. 
Tabela 22. Grau de umidade dos grãos de milho utilizados no ensaio determinada pelo método da estufa e aqueles registrados pelo monitor de produtividade e o erro relativo entre ambos.

\begin{tabular}{cccc}
\hline \multirow{2}{*}{ Amostras } & $\begin{array}{c}\text { Teores de água Estufa } \\
\%\end{array}$ & $\begin{array}{r}\text { Teores de água Monitor } \\
\%\end{array}$ & $\begin{array}{c}\text { Erros } \\
\%\end{array}$ \\
\hline 1 & 13,47 & 16,46 & 22,22 \\
2 & 13,32 & 16,22 & 21,78 \\
3 & 12,34 & 16,51 & 33,72 \\
4 & 12,58 & 12,45 & $-1,02$ \\
5 & 12,27 & 12,33 & 0,45 \\
6 & 13,09 & 13,40 & 2,33 \\
7 & 12,48 & 13,81 & 10,63 \\
8 & 11,48 & 12,80 & 11,51 \\
9 & 11,99 & 12,48 & 4,13 \\
\hline
\end{tabular}

Cada amostra da Tabela 22 é uma média de quatro sub-amostras colhidas para verificar o teor de águo dos grãos durante o dia trabalhado. Até a data da terceira amostra não havia sido inserido um fator de correção do grau de umidade no monitor de produtividade, ocasionando erros médios de leituras até esta data de $25,91 \%$. A partir da quarta amostra foi inserido no monitor um fator de correção do grau de umidade de $-2,5 \%$, o que propiciou uma correção da leitura. Não se buscou ajustar novamente o fator de correção do grau de umidade do monitor, estudando qual seu comportamento até o final dos ensaios. Nesta condição o monitor passou a apresentar um erro médio em módulo de 5,01\%.

Todos os valores de taxas de fluxo utilizados no trabalho sem haver correção do grau de umidade no monitor, foram posteriormente devidamente calculados e ajustados para o mesmo fator de correção de $-2,5 \%$.

\subsection{SUGESTÕES PARA TRABALHOS FUtUROS}

Como propostas para trabalhos futuros, sugere-se:

$\equiv$ que a bancada de ensaio sofra algumas mudanças estruturais em relação à apresentada neste trabalho, para maior eficiência e facilidade de manuseio, ou seja: apoiar o tanque de pesagem sobre quatro pontos, com uma célula 
de carga em cada um deles e não suspenso por um ponto, por uma única célula de carga; posicionar o elevador em balanço, colocando os dois pés de sustentação de um mesmo lado, eliminando a barra de fixação da estrutura que limita o posicionamento dos tanques ou então, inverter o elevador na estrutura da bancada, dando-lhe um tombo de $90^{\circ}$, fazendo com que 0 condutor helicoidal fique perpendicular àbarra de fixação;

$\equiv$ ensaio para verificar se há simetria, neste trabalho sugerida, entre as posições transversais do elevador àdireita e àesquerda;

き maior número de posições transversais do elevador;

$\boxminus$ trabalhos com o elevador inclinado longitudinalmente e interações entre inclinações longitudinais e transversais; 


\section{CONCLUSÕES}

A bancada de ensaio mostrourse adequada para avaliação de sistemas de mensuração da produtividade de grãos. A geometria quadrada da seção de abertura da comporta, na base do tanque de alimentação, foi eficiente para fornecer vazões uniformes com o tempo. A balança foi capaz de registrar dados acuradamente, com variação de massa na calibração dinâmica de 0,05\% e na calibração estática, desvio padrão do sinal de saída de $0,61 \mathrm{~kg}$.

A análise do sensor de fluxo de volume e suas interações com outros sensores e densidade do produto, mostrou que pode ser utilizado em coleta de dados para confecção de mapas de produtividade, sendo que nas situações experimentadas, em $70 \%$ dos ensaios com taxas de fluxo constantes, apresentou erros pontuais de leitura menores que 6,00\%. O monitor de produtividade superestimou valores menores do que o da taxa de fluxo média de calibração e subestimou para taxas de fluxo maiores. O monitor não é confiável para trabalhar com leituras de taxas de fluxo de grãos fora dos limites de calibração. O sensor de fluxo de volume respondeu imediatamente às variações de taxas de fluxo de grãos de milho passando pelo sensor quando foi embutida propositadamente variação de taxas de fluxo no sistema. O algoritmo que considera a inclinação é eficiente para compensar as inclinações transversais da máquina. Nos ensaios com taxas de fluxo de grãos constantes, o monitor foi preciso e teve erro médio geral de todos os ensaios a taxas de fluxo constantes de $5,31 \%$ em módulo. Para taxas de fluxo variadas, o erro médio geral, em módulo, dos ensaios foi de $4,84 \%$, enquanto que o erro médio 
global do monitor de produtividade para as leituras com taxas de fluxo constantes e variadas, foi de $5,12 \%$.

O sensor de velocidade do monitor de produtividade é acurado. A averiguação das leituras realizadas pelo sensor de grau de umidade para as situações estudadas, apresentou erro médio em módulo de 5,01\%. 
ANEXOS 


\section{ANEXO A}

No anexo A, é apresentado o certificado de calibração da célula de carga do equipamento de tração e compressão Instron 4466, utilizado para a calibração da célula de carga usado nos ensaios realizados no trabalho. 


\title{
Calibration Certificate
}

\author{
Loadcell Type: $2525-804$ \\ Capacity: $10 \mathrm{KN}$ \\ Serial Number: UK406
}

Instron Ltd. certifies that this loadcell has been tested for accuracy and repeatability on calibration apparatus traceable to Intemational Standards with an uncertainty of measurement not exeeding one third of the permissible error of the loadcell. The accuracy of the loadcell has been found to be equal to or better than $0.025 \%$ of cell rated output or $0.25 \%$ of the indicated load, whichever is the greater
Tested By:
$26 \mathrm{CB}$
Date: $27-05-1997$

\section{Test Results}

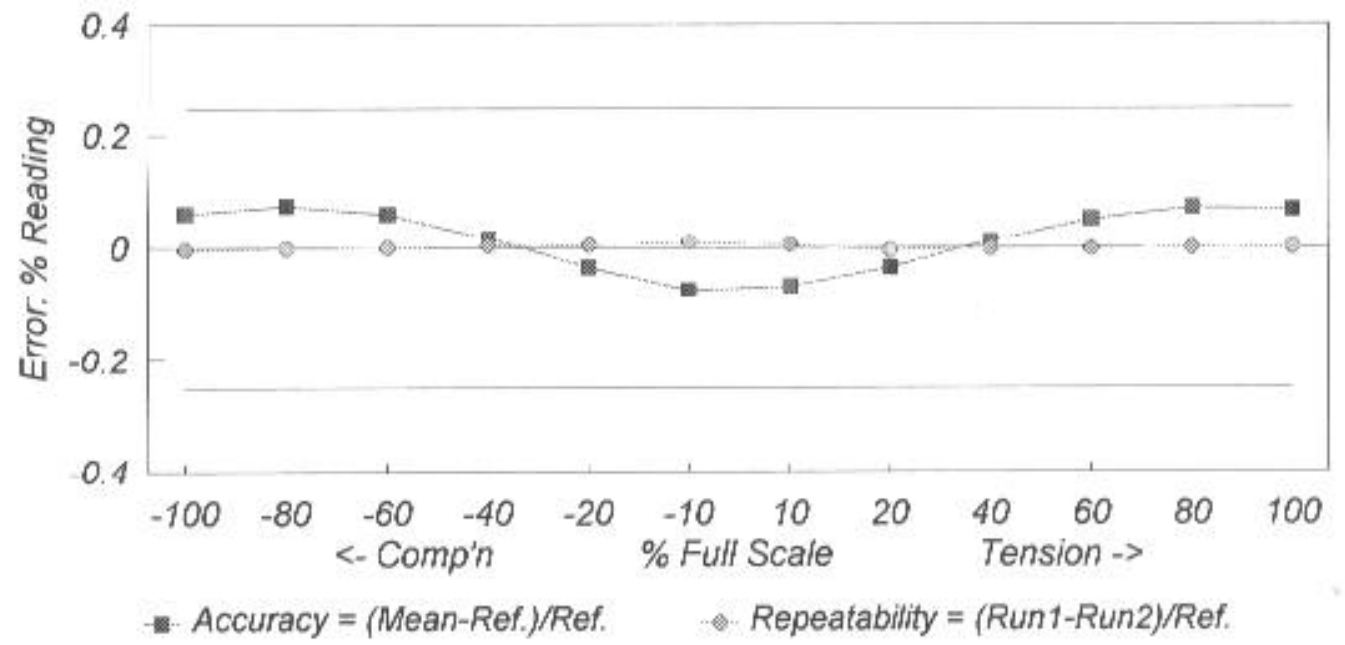

For System Cafibration to National and intemational Standards contact your local instron Branch office, or: instron Ltd Coronation Rnard, High Wycnmbe, Aucks, HP12 3SY, UK. Phone (01494) 464646

Instron Corp: 100 Royal Street, Canton, Mass, MA02021, USA Phone (617) 8282500

The Difference is Measurable

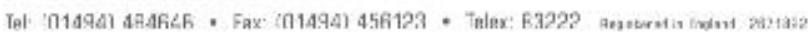

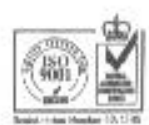




\section{ANEXO B}

No anexo B, é apresentada a tabela de saída do programa original do arquivo do monitor de produtividade. 


\section{Exemplo de tipo do arquivo gerado pelo Ceres 2, (arquivo 55).}

DH000055@00001200@00002200@00003100@00004080@00005060

VH000055@ RDS Technology Ltd@ Ceres 2 Y ield Meter@ NG406-540@20001221@152125

DN000055@00101073@00102073@00103073@00104073@00105073@00106073

VN000055@0000000@0000000@0000000@0000000@0000000@0000000

DN000055@00107073@00108073@00109073@00110073@00111073@00112073

VN000055@0000000@0000000@0000000@0000000@0000000@0000000

DN000055@00006042@00016062@00012052@00017065@00201096@00202106@00204051@00203010@00301020

VN000055@0000@999999@00000@000022@000000000@0000000000@00000@0@00

VN000055@0000@999999@00000@000913@000000000@0000000000@00000@0@00

VN000055@0400@002466@01600@001185@000000000@0000000000@00000@0@00

VN000055@0400@000638@01650@001293@000000000@0000000000@00000@0@00

VN000055@0400@000610@01650@001120@000000000@0000000000@00000@0@00

VN000055@0400@000686@01650@001214@000000000@0000000000@00000@0@00

VN000055@0400@000657@01650@000788@000000000@0000000000@00000@0@00 VN000055@0400@000623@01650@001016@000000000@0000000000@00000@0@00 VN000055@0400@000645@01650@000998@000000000@0000000000@00000@0@00 VN000055@0400@000666@01650@001117@000000000@0000000000@00000@0@00 VN000055@0400@000658@01650@001052@000000000@0000000000@00000@0@00 VN000055@0400@000733@01650@001111@000000000@0000000000@00000@0@00 VN000055@0400@000652@01650@001003@000000000@0000000000@00000@0@00 VN000055@0400@000634@01600@001133@000000000@0000000000@00000@0@00 VN000055@0400@000601@01600@001071@000000000@0000000000@00000@0@00 VN000055@0400@000564@01600@001060@000000000@0000000000@00000@0@00 VN000055@0400@000590@01600@001011@000000000@0000000000@00000@0@00 VN000055@0400@000592@01600@001202@000000000@0000000000@00000@0@00 VN000055@0400@000668@01600@001141@000000000@0000000000@00000@0@00 VN000055@0400@000662@01600@001032@000000000@0000000000@00000@0@00 VN000055@0400@000650@01600@001071@000000000@0000000000@00000@0@00 VN000055@0400@000625@01600@001017@000000000@0000000000@00000@0@00 VN000055@0400@000659@01650@001131@000000000@0000000000@00000@0@00 VN000055@0400@000668@01650@001050@000000000@0000000000@00000@0@00 VN000055@0400@000678@01650@001109@000000000@0000000000@00000@0@00 VN000055@0400@000693@01650@001060@000000000@0000000000@00000@0@00 VN000055@0400@000643@01650@001041@000000000@0000000000@00000@0@00 VN000055@0400@000611@01600@001152@000000000@0000000000@00000@0@00 VN000055@0400@000647@01600@001093@000000000@0000000000@00000@0@00 VN000055@0400@000598@01600@001113@000000000@0000000000@00000@0@00 VN000055@0400@000621@01600@001112@000000000@0000000000@00000@0@00 VN000055@0400@000598@01600@001089@000000000@0000000000@00000@0@00 VN000055@0400@000597@01600@001048@000000000@0000000000@00000@0@00 VN000055@0400@000658@01600@001115@000000000@0000000000@00000@0@00 VN000055@0400@000676@01600@001028@000000000@0000000000@00000@0@00 VN000055@0400@000613@01650@001041@000000000@0000000000@00000@0@00 VN000055@0400@000679@01650@001088@000000000@0000000000@00000@0@00 VN000055@0400@000655@01650@000988@000000000@0000000000@00000@0@00 VN000055@0400@000314@01700@001950@000000000@0000000000@00000@0@00 VN000055@0000@000017@00000@000028@000000000@0000000000@00000@0@00 VN000055@0000@999999@00000@000011@000000000@0000000000@00000@0@00 VN000055@0000@999999@00000@000004@000000000@0000000000@00000@0@00 VN000055@0000@999999@00000@000017@000000000@0000000000@00000@0@00 VN000055@0000@999999@00000@000059@000000000@0000000000@00000@0@00 VN000055@0000@999999@00000@000055@000000000@0000000000@00000@0@00 DN000055@00007062@00008072@00009072

VN000055@000026@0000007@0000042

DN000055@00011073@00012052@00015010@00014071

VN000055@0076000@01628@7@0000111

EN

ZN 


\section{ANEXO C}

A Figura C1 e Figura C2, mostram os formulários de saída de dados dos programas PDmon-1.0 e Pdbal-1.0, respectivamente. 


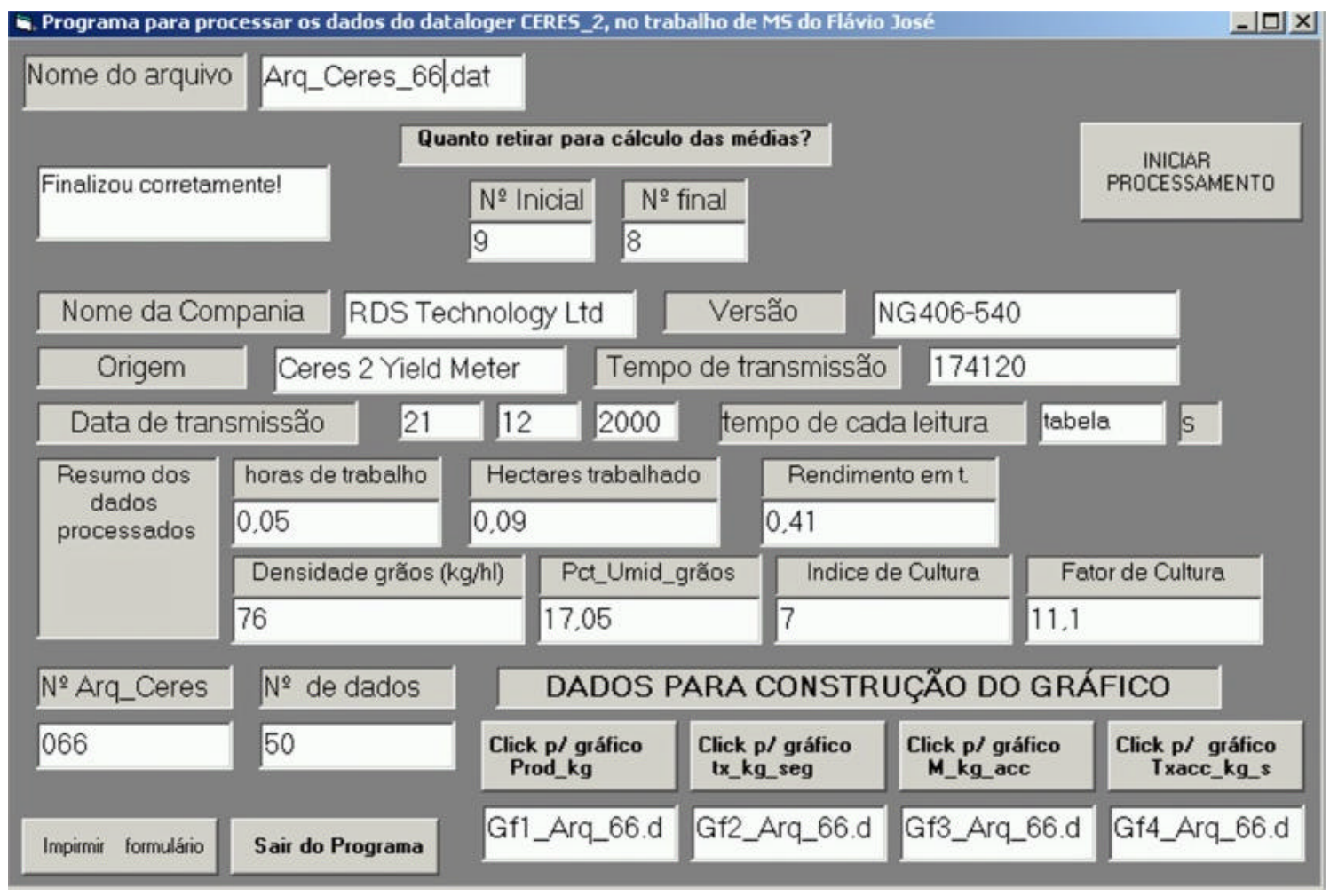

Figura C1 - Formulário do programa PDmon-1.0, tendo processado o arquivo no 66 , mostrando o resumo dos dados. 


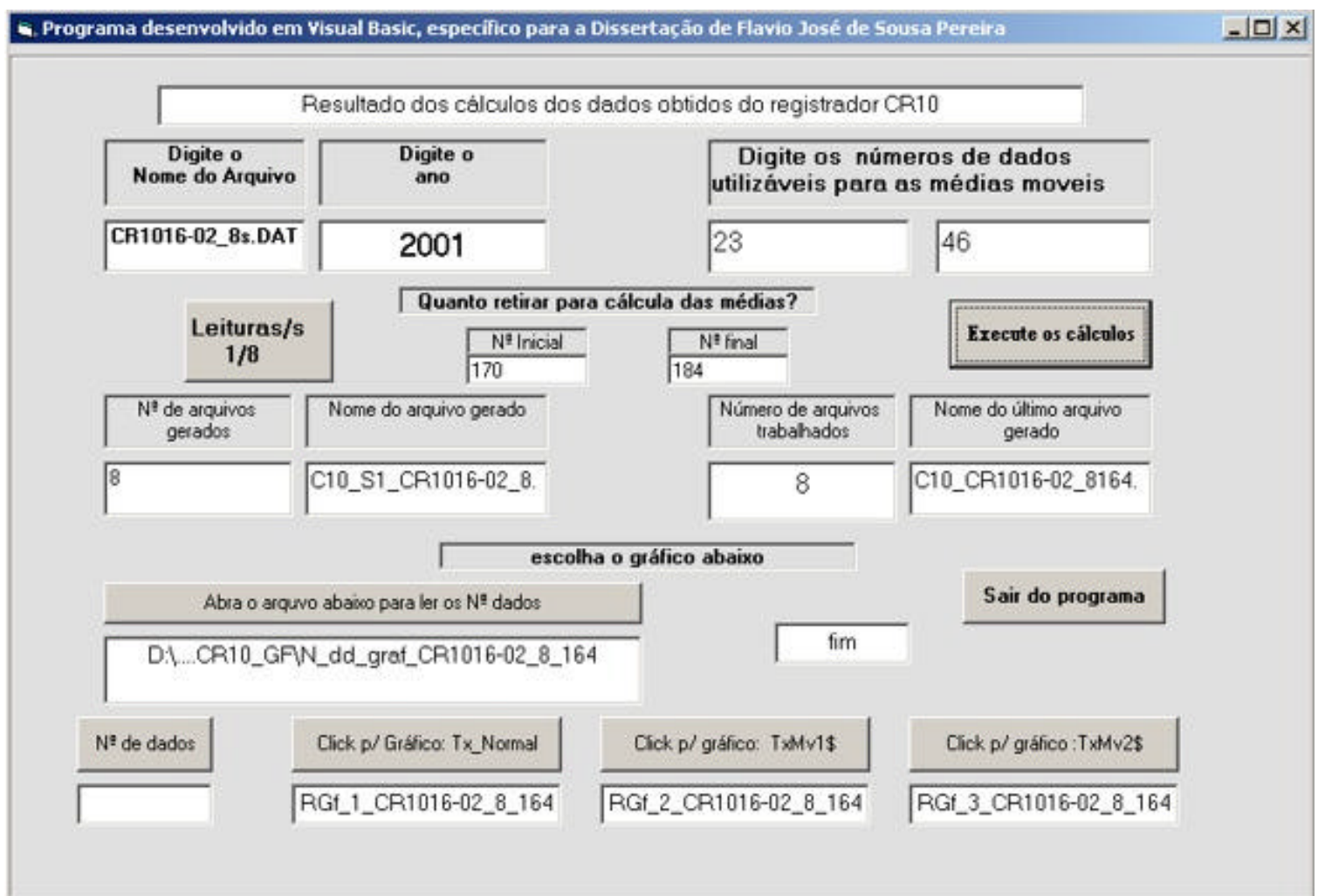

Figura C2 - Formulário do programa PDbal-1.0, tendo processado os arquivos gerados no dia 16/02, indicando o diretório e nome dos arquivos de dados e gráficos gerados 


\section{ANEXO D}

A Tabela D1, apresenta os valores levantados na calibração do tanque alimentador, indicando a vazão de grãos de milho em função da área de abertura da comporta de seção ajustável do tanque. 
Tabela D1. Vazão de grãos de milho em função da área de abertura da comporta.

\begin{tabular}{cccc}
\hline & Áreas & \multicolumn{2}{c}{ Vazões de milho } \\
\hline $\begin{array}{c}\text { Escalas } \\
\text { Unidades }\end{array}$ & $\begin{array}{c}\text { Medidas } \\
\mathrm{m}^{2}\end{array}$ & $\begin{array}{c}\text { Nível 1 } \\
\mathrm{kg} \cdot \mathrm{s}^{-1}\end{array}$ & $\begin{array}{c}\text { Nível } 2 \\
\mathrm{~kg} . \mathrm{s}^{-1}\end{array}$ \\
\hline 2 & 0,000958 & 0,151 & 0,147 \\
2 & 0,000958 & 0,150 & 0,144 \\
2 & 0,000958 & 0,151 & 0,144 \\
2 & 0,000958 & 0,097 & 0,114 \\
& & & 0,967 \\
4 & 0,003447 & 0,936 & 0,978 \\
4 & 0,003447 & 0,867 & 0,971 \\
4 & 0,003447 & 0,867 & 0,978 \\
4 & 0,003447 & 0,855 & 2,845 \\
6 & & & 2,868 \\
6 & 0,007595 & 3,031 & 2,868 \\
6 & 0,007595 & 3,009 & 2,892 \\
6 & 0,007595 & 2,933 & \\
& 0,007595 & 2,927 & 6,576 \\
8 & & & 6,333 \\
8 & 0,013346 & 6,590 & 6,415 \\
8 & 0,013346 & 6,683 & 6,351 \\
8 & 0,013346 & 6,509 & 10,383 \\
10 & 0,013346 & 6,179 & $10,150,685$ \\
10 & 0,018927 & 10,727 & \\
10 & 0,018927 & 10,651 & 10,536 \\
\hline
\end{tabular}




\section{REFERÊNCIAS BIBLIOGRÁFICAS}

ARSLAN, S.; COLVIN, T.S. Laboratory test stand for combine grain yield monitors. Applied Engineering in Agriculture, v.14, n.4, p.369-371. 1998.

ARSLAN, S.; COLVIN, T.S. Laboratory performance of a yield monitor. Applied Engineering in Agriculture, v.15, n.3, p.189-195. 1999.

BAERDEMAEKER, J.DE; DELCROIX, R.; LINDEMANS, P. Monitoring the grain flow on combines. In: AGRHMARIATION 1., Chicago, 1985. Proceedings. Chicago: S.E., 1985. p.329-338.

BALASTREIRE, L.A.; ELIAS, A.I.; AMARAL, J.R. do Agricultura de precisão: mapeamento da produtividade da cultura do milho. Engenharia Rural, v.8, n.1, p.97-111, 1997.

BALASTREIRE, L.A.; AMARAL, J.A. Concepção e construção de um sistema para o desenvolvimento e a calibração de sensores de fluxo de grãos. In: BALASTREIRE, L.A. (Ed.). 0 estado-da-arte da agricultura de precisão no Brasil. Piracicaba: L.A. Balastreire, 2000. p.201-205.

BLACKMORE, B.S.; MARSHALL, C.J. Yield mapping; errors and algorithms. Precision Agriculture, v.4, n.3, p.403-415, 1996.

BORGELT, S.C. Sensing and measuring technologies for site specific management. Madison: ASA, CSSA, SSSA, 1993. 15p.

BURKS, T.F.; FULTON, J.P; SHEARER, S.A.; SOBOLIK, C.J. Influence of dynamically varying inflow rates on clean grain elevator yield monitor accuracy. St. Joseph: ASAE, 2001. 14p. (Paper, 01-1182). 
CASSMAN, K.G.; PLANT, R.E. A model to predict crop response to applied fertiliser nutrients in heterogeneous fields. Fertilizer Research, v.31, p.51163, 1992.

DALLY, J.W.; RILEY, W.F.; McCONNELL, K.G. Instrumentation for engineering measurements. New York: John Wiley, 1993, 584p.

DOEBELIN, E.O. Measurement systems aplication and design. Washington: Mac Graw Hill Book, 1966, 439p.

ELIASON, M.; HEANEY, D.; GODDARD, T.; GREEN, M.; MCKENZIE, C.; PENNY, D.; GEHUE, H.; LACHAPELLE, G.; CANNON, M.E. Yield Measurement and field mapping with an integrated GPS system. In: CONFERENCE ON SITE-SPECIFIC MANAGEMENT FOR AGRICULTURAL SYSTEMS, Bloomington, 1994. Proceedings. 1994. 11p.

GODWIN, R. J.; WHEELER, P. N. Yield mapping by mass accumulation rate. St. Joseph: ASAE, 1997. 10p. (Paper, 97-1061).

KLEMME, K.A.; FROEHLICH, D.P.; SCHUMACHER, J.A. Spatially Variable Technology For Crop Yield. St. Joseph: ASAE, 1992. (Paper, 92-1543).

KORMANN, G.; DEMMEL M.; AUERNHAMMER, H. Testing stand for yield measurement systems in combine harvesters. St. Joseph: ASAE, 1998. 9p. (Paper, 98-3102).

LOWENBERG-DEBOER, J.; SWINTON, S.M. Economics of site-specific management in agronomic crops. W. Lafayette: Purdue University, 1995. 29p. (Staff, Paper 95-14).

MCBRATNEY, A.B.; PRINGLE, M.J. Spatial variability in soil - implications for precision agriculture In: PRECISION AGRICULTURE 1997, Warwick, 1997. Proceedings. Oxford: BIOS Scientific, 1997, v.1, p.3-31.

MCBRATNEY, A.B.; WLEHAN, B.M. The potencial for site-specific management of cotton farming systems. Co-operative Research Centre for Sustainable Cotton Production, 1995. 25p. (Discussion Paper, 1)

MOLIN, J.P. Agricultura de precisão. Parte I: o que é e estado da arte em sensoriamento. Engenharia Agrícola, v.17, n.2, p.97-107, 1997. 
MOLIN, J.P. Geração e interpretação de mapas de produtividade para agricultura de precisão. In: BORÉM, A.; GIÚDICE, M.P. del; QUEIROZ, D.M. de. (Ed.) Agricultura de precisão. Viçosa. Universidade Federal de Viçosa, 2000. p.237-257.

MOLIN, J.P.; CREMONINI, L.C.M.; MENEGATTI, L.A.; GIMENEZ, L.M. Acurácia de um monitor de produtividade com sensor de fluxo volumétrico (compact disc). In: CONGRESSO BRASILEIRO DE ENGENHARIA AGRíCOLA, 29., Ceará, 2000. CONBEA 200 - construindo a engenharia agrícola do futuro: trabalhos. Ceará: SBEA, 2000.

NIELSEN, D.R.; BOUMA, J. Soil spatial variability. IN: WORKSHOP INTERNATIONAL SOCIETY SOIL SCIENCE AND SOIL SCIENCE SOCIETY AMERICAN, Wageningen, 1984. Proceedings. Wageningen: Netherlands Pudoc, 1984. p.25-33

PEREIRA, V.P.; FREIRE, J.T. Solo - propriedades. apostila do curso de solos. Jaboticabal: UNESP, FCAV, 1971. 22p.

REITZ, P.; KUTZBACH, H.D. Data acquisition for yield mapping with combine harvesters. In: INTERNATIONAL CONFERENCE OF COMPUTERS IN AGRICULTURE, 5, Orlando, 1994. Proceedings. Orlando, St. Joseph: ASAE, 1994. p.42-47.

SABIR, M.S.; STUCHLY, S.S.; HAMID, A. A mass flowmeter for grain. Transactions of the ASAE, v.19, n.6, p.1138-1142, 1976.

SANAEI, A.; YULE, I.J. Yield measurement reliability on combine harvesters. St. Joseph: ASAE, 1996. 14p. (Paper, 96-1020).

SANTOS, A.O.; MAZIERO, J.V.G.; CAVALLI, A.C.; VALERIANO, M.M.; OLIVEIRA, H.; MORAES, J.F.L.; YANAI, K. Monitoramento localizado da produtividade de milho cultivado sob irrigação. Revista Brasileira de Engenharia Agrícola e Ambiental, v.5, n.1, p.88-95, 2001.

SCHROCK, M.D.; KUHLMAN, D.K.; HINNEN, R.T.; OARD, L.D.; PRINGLE, J.L. Sensing grain yield with a triangular elevator. Madison: ASA, CSSA, SSSA, 1995, 14p. 
SCHUELLER, J.K. A review and integrating analysis of Spatially-Variable Control of crop production. Fertilizer Research, v.33, p.1-34, 1992.

SCHUELLER, J.K. Technology for precision agriculture. In: PRECISION AGRICULTURE 1997, Warwick, 1997. Proceedings. Oxford: BIOS, Scientific, 1997. v.1, p.33-43.

SEARCY, S.W. Agricultura de precisão: um desafio para a extensão e educação continuada. In: BALASTREIRE, L.A. (Ed). O estado-da-arte da agricultura de precisão no Brasil. Piracicaba: L.A. Balastreire, 2000. p.1724.

WILCOX, J. Tech check: variations in yield maps may be the results of your precision farming tools, not changes in yor fields. Successful Farming. v.97, n.2, p.41-43, 1999a.

WILCOX, J. Right on almost: yield monitors are useful, but they shouldn't be the only source of information. Successful Farming. v.97, n.3, p.30-32, 1999b. 